\title{
Nanotechnology-based drug delivery systems for control of microbial biofilms: a review
}

This article was published in the following Dove Press journal:

International Journal of Nanomedicine

\author{
Matheus Aparecido Dos \\ Santos Ramos' \\ Patrícia Bento Da Silva ${ }^{2}$ \\ Larissa Spósito' \\ Luciani Gaspar De Toledo' \\ Bruna Vidal Bonifácio' \\ Camila Fernanda Rodero ${ }^{2}$ \\ Karen Cristina Dos Santos ${ }^{2}$ \\ Marlus Chorilli \\ Taís Maria Bauab'
}

'São Paulo State University (UNESP), School of Pharmaceutical Sciences, Campus Araraquara, Department of Biological Sciences, Araraquara, SP, Brazil; ' 2 ão Paulo State University (UNESP), School of Pharmaceutical Sciences, Campus Araraquara, Department of Drugs and Medicines. Araraquara, SP, Brazil

Correspondence: Taís Maria Bauab São Paulo State University (UNESP), School of Pharmaceutical Sciences, Campus Araraquara, Department of Biological Sciences, Rodovia Araraquara Jaú, Km 0 I - s/n Campos Ville,

Araraquara, SP, Brazil

Tel +55 I6 330l 6955

$\mathrm{Fax}+551633220073$

Email bauabtm@fcfar.unesp.br

\begin{abstract}
Since the dawn of civilization, it has been understood that pathogenic microorganisms cause infectious conditions in humans, which at times, may prove fatal. Among the different virulent properties of microorganisms is their ability to form biofilms, which has been directly related to the development of chronic infections with increased disease severity. A problem in the elimination of such complex structures (biofilms) is resistance to the drugs that are currently used in clinical practice, and therefore, it becomes imperative to search for new compounds that have anti-biofilm activity. In this context, nanotechnology provides secure platforms for targeted delivery of drugs to treat numerous microbial infections that are caused by biofilms. Among the many applications of such nanotechnology-based drug delivery systems is their ability to enhance the bioactive potential of therapeutic agents. The present study reports the use of important nanoparticles, such as liposomes, microemulsions, cyclodextrins, solid lipid nanoparticles, polymeric nanoparticles, and metallic nanoparticles, in controlling microbial biofilms by targeted drug delivery. Such utilization of these nanosystems has led to a better understanding of their applications and their role in combating biofilms.
\end{abstract}

Keywords: nanotechnology systems, microbial biofilms, anti-biofilm activity

\section{Introduction}

The incidence of infectious diseases continues to grow at an exponential rate each year and has a direct association with high rates of morbidity and mortality. ${ }^{1}$ The complex dynamics of infectious diseases has caught the attention of several scientists to investigate the possible causes that lead to the persistence and spread of acute and chronic infections. ${ }^{2}$ Acute infections are triggered by microbial cells that are in their planktonic forms; however, over time such microbes develop strategies to ensure their survival and adaptation to the stressful environments. This leads to the formation of a cohesive and strong community of cells that possess intercellular communication, known as biofilm..$^{3,4}$

Microbial biofilms may be defined as heterogeneous communities (representing species diversity, for instance, a symbiotic association of bacteria and fungi) of aggregated, organized, and functional microbial cells, that remain embedded into the matrix of extracellular polymeric substances (EPS), which allows their irreversible adhesion to biotic or abiotic surfaces. ${ }^{5,6}$

The EPS matrix is primarily produced by the biofilm constituting microorganisms themselves; the former is especially composed of nucleic acids, extracellular proteins, phospholipids, teichoic acid, and exopolysaccharides. Mineral crystals, silt, milk residues, and blood components or dirt may also be present in EPS matrix, depending upon the conditions and locations in which biofilms are formed. ${ }^{7}$ Molecular interactions 
between EPS matrix and its various components and the constituents' contribution toward the integrity of the matrix are not clearly understood yet. However, several EPS functions have been determined that have proved advantageous for biofilms. ${ }^{8}$

The formation of biofilms, usually with the thickness of milli- or even micrometer order, naturally occurs around solid surfaces that are in contact with water, such as living tissues, medical devices, and water bodies/systems. ${ }^{9}$ In the environment and even on the abiotic surfaces, it is very common to find microbial biofilms with other commensal species, which are, therefore, called biofilm multispecies. ${ }^{10}$ Bacteria and fungi are both capable of forming biofilms on surfaces, but certain factors involved during the course of their formation differ from each other.

Studies conducted by Almeida and França ${ }^{11}$ and Percival et $\mathrm{al}^{12}$ demonstrated that biofilms are heterogeneous structures, and these consist of discontinuous phases on the support surface; that is, there may be an area with high density of cells along with areas where there may be no colonization. Furthermore, a great diversity in the morphology of these cells has been recorded; microbes may possess different shapes, such as filamentous, spiral, or rod, or they may exist as cocci or bacilli. ${ }^{11,12}$

At present, the major concern of the medical research scientists working in this field is the adhesion and proliferation of the biofilm-forming microorganisms, inhibition of which may be a successful strategy to combat biofilm formation. Therefore, it is recommended to use stainless steel for manufacturing surgical devices, as this material is resistant to corrosion and fracture. All these measures are imperative owing to the capacity of biofilms to proliferate and get fixed on porous and rough surfaces. ${ }^{13}$

In general, the development of a biofilm over a biotic or abiotic surface is a dynamic process that involves various steps, viz., adhesion, growth, and production of EPS matrix. ${ }^{4}$ A cycle indicating the five sequential stages involved in the formation of biofilm is depicted in Figure 1.

The five sequential stages are described below:

Stage 1: In this step, the deposition of free planktonic cells occurs by the arrival of microbes to the adhesion site. The presence of macromolecules, which form the constraint film as a substrate for the microbial cells, initiates biofilm formation. ${ }^{14}$

Stage 2: This stage, known as the reversible adhesion phase, marks the beginning of adhesion of microbial cells and the communication process among them that is responsible for the subsequent steps. Although in

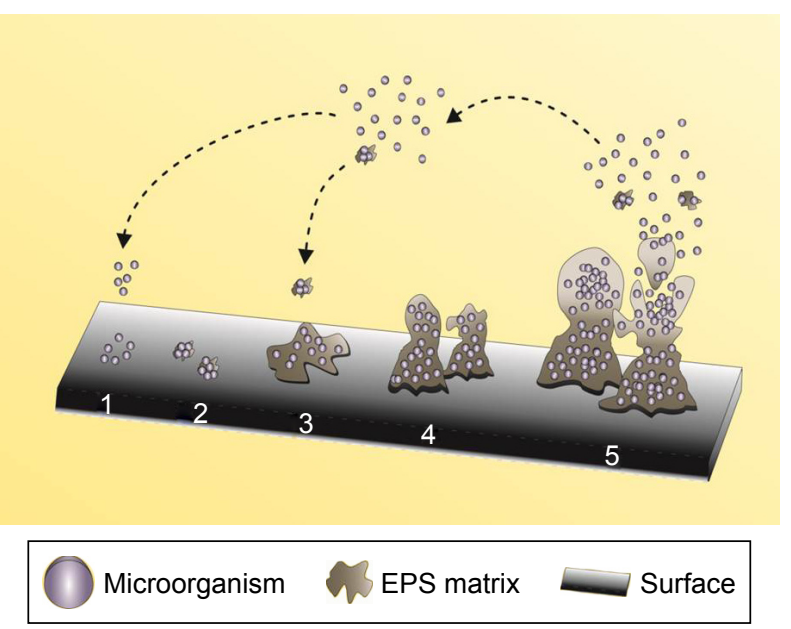

Figure I Stages of microbial biofilm formation over a surface.

Notes: The stages include: adherence of microbial cells (I), reversible adhesion (2), irreversible adhesion (3), maturation (4), and detachment of cells (5). The arrows explain the migration of single cells and pieces of biofilm in EPS matrix that are released after the detachment stage, and the capacity to restart the formation process. Abbreviation: EPS, extracellular polymeric substances.

small quantities, the EPS matrix can be observed in this stage. $^{15}$

Stage 3: Post initial adhesion to the surface, the cells that still have weak bonds with the surface consolidate the adhesion process by high EPS production that leads to an increase in their reproduction rate. The matrix also acts as a recycling center, as it is known to keep all the available lysed cell components including the DNA; thus, it may be considered as a genetic material reservoir to enable horizontal gene transfer and a source of nutrients, and provides protection against adverse conditions, such as drying, oxidation, exposure to biocides, antibiotics, certain metallic cations, and ultraviolet radiations, and immune responses. The production of the matrix represents the successful formation of biofilm communities, and propagation and survival of the cells in their local environment. ${ }^{16,17}$

Stage 4: The maturation step or biofilm maintenance represents the dynamics between the microbial cells and the biofilm architecture. In this step, replication of the microorganisms occurs resulting in the generation of intense communication via signaling molecules (quorum sensing, QS). Such a mechanism enables individual cells to communicate and coordinate their actions by the production and detection of extracellular signaling molecules that are called the auto-inducers, which are responsible for the uptake of the substrate into the biofilm. Further, in this step, other microorganisms may also get adhered to form a multispecies biofilm. ${ }^{18}$ 
Stage 5: In this stage, the detachment of the inside of the biofilm cells occurs. The high population density causes the release of the packed cells in an array to the external environment. Planktonic cells are released back into the surroundings, and these cells will start the cycle again. ${ }^{17}$

The actual mechanism behind the biofilm formation is still unknown and will remain a hot topic of scientific research for many years. Nevertheless, it is known that the biofilm composition and the mechanisms involved are related to the resistance and virulence of the microbes.

According to the complexity of diseases associated with microbial biofilms, in this work we propose a structured review about the impact of microbial biofilms in the infectious diseases and present the main drug delivery systems based on nanotechnology as a strategy for the control and treatment of biofilms focusing in a treatment prospection.

\section{Bacterial biofilms: general aspects}

In the last 20 years, bacterial infections have posed a considerable threat to human health. The infections may appear as an isolated disease or systemic and primarily occur in hospital environments. ${ }^{19}$

Among all the microorganisms, the bacterial species are the major biofilm producers, provided that the conditions are favorable, although some may have a greater ability than others. Most of the species demonstrate elevated growth rate, great adaptability, and competence for the production of substances and extracellular structures that protect the microbes in their habitat, and as per the characteristics, make these capable of perfectly colonizing any type of surface, even in adverse conditions. ${ }^{20}$

Bacteria show two survival states, namely the planktonic form (individual/free cells) and the population aggregates (biofilms). The bacterial development in the planktonic form is an important phenomenon for the propagation of biofilms. Nevertheless, the survival of a biofilm as a defense mechanism is related to its sustenance, which is dependent upon its continued life cycle, if the biofilm offers safety against adverse environmental extrinsic factors. ${ }^{21,22}$

There are certain advantages of bacterial biofilms, for example, the ecological participation in symbiotic relationships. The examples of this phenomenon are abundant in nature, and those exhibiting such relationships include diazotrophic prokaryotic bacteria that colonize vegetable roots and several other bacteria found in the digestive tract of the ruminants, where they promote the degradation and recycling of insoluble materials. ${ }^{21}$
During the entire process of bacterial biofilm formation, there are complex factors involved, which have been poorly understood and have inspired the scientific community to analyze the whole dynamics of the complex microbial architecture. The contact of bacteria with biotic and abiotic surfaces is the first stage of biofilm formation, which is considered an important and complex process. ${ }^{23}$

Considering only the abiotic surfaces, the initial attraction of planktonic bacterial cells to the surface seems to occur randomly by Brownian movement and gravitational force or in a guided way via chemotaxis and motility. ${ }^{24}$

Motility is one of the extremely important characteristics since studies have shown that flagellated bacteria or the bacteria that have greater locomotion capacity form more complex and structured biofilms. Besides, the facility to migrate to other places gets increased. ${ }^{25}$

Bacteria promote a variety of adhesion strategies to remain in contact with the fixation surface; after that, the microbes promote the release of EPS mixture, which increases their affinity for different types of surfaces, for example, porous, rough, and chemically heterogeneous surfaces. ${ }^{8}$

The reversible adhesion occurs by nonspecific physicochemical interactions between the bacteria and the material, including the hydrodynamic forces, electrostatic interactions, van der Waals forces, and hydrophobic interactions. ${ }^{21,26}$ In addition, the bacteria make use of some of their proteinaceous structures, for example, pilli and fimbriae, in order to enhance the adhesion on surfaces. Besides, bacteria also have mechanisms to overcome the repulsive forces between the cell membrane and abiotic surfaces, especially in the presence of a conditioning film, which can easily be found in biomedical devices. , $^{87,28}$

The composition of a conditioning film or an organic film is variable and depends upon the site of biofilm formation. Nevertheless, its basic constitution includes proteins, such as albumin, immunoglobulin, fibrinogen, and fibronectin. ${ }^{29}$ Therefore, the film acts as a substrate for initial establishment of the biofilm. When adequate proximity and other predisposing factors are reached for appropriate elongation of biofilm formation, the bacterial cells promote enhanced production, release, and detection of self-inducing signaling molecules that regulate the biofilm formation..$^{30,31}$

As the adhesion process progresses, the accumulation of such signaling molecules results in the induction and transcription of specific genes, which regulate various bacterial functions, such as motility, virulence, and production of the matrix containing EPS, and consequently, exacerbate the development of biofilm (formation of stronger structures 
with dynamic complexity). The generation of EPS matrix facilitates colonization by other species as well. It is presumed that within a multispecies biofilm, the EPS increase the stability of the other species by mediating interactions between the polymers of different species. ${ }^{32}$

After the completion of reversible adhesion step, the irreversible adhesion phase occurs, which is due to the bacteria that still have weak interactions with the surface but manage to stick to the substratum due to the high production of EPS and cell signaling-based communication. ${ }^{33}$

The cell-to-cell communication process, referred to as QS, is found in several pathogenic bacteria which offers benefits such as the ability of sporulation, expression of virulence genes, DNA transfer, biofilm formation, and even antibiotic production. The molecular events in bacteria are partially controlled by QS via chemical signals, and such a mechanism of intracellular communication is dependent upon the population density within a biofilm. ${ }^{34}$

In bacterial biofilms, QS is a common phenomenon that favors the access to nutrients or more favorable environmental sites, thus allowing bacteria to induce defense responses against eukaryotic hosts while optimizing their ability to differentiate into most appropriate forms for their sustenance and survival in harsh environments.

The chronic bacterial infections are mainly related to the total biofilm formation cycle. Some of the major bacterial species, which are capable of triggering an infection in internal human organs, are Pseudomonas aeruginosa, the main causal agent of pneumonia and cystic fibrosis $(\mathrm{CF}),{ }^{35}$ Escherichia coli, the causative microbe of the urinary tract infections (UTIs), ${ }^{36}$ and Mycobacterium tuberculosis, which causes human tuberculosis. ${ }^{37}$

In dental infections caused by Streptococcus mutans (dental caries), the bacteria overcome the mechanical cleaning and antimicrobial treatments ${ }^{38}$ by forming biofilms. Since the amount of colonized bacteria in the oral cavity is high and the renewal of biofilm mass is easily achieved, S. mutans, very peacefully, acquires resistance against the drugs.

The implantation of medical devices, such as intravenous catheters, prosthetic heart valves, joint prosthetics, peritoneal dialysis catheters, heart pacemakers, and endotracheal tubes, is a viable alternative that ensures the maintenance of a patient's life. However, the presence of bacterial biofilms on such medical devices has been identified as the foremost cause of clinical infections. The reason is the ease of formation of biofilms due to the inflammatory responses generated by the host, which further allow bacteria to adhere to the surfaces of the devices. ${ }^{23,39}$ The Gram-positive species, such as Staphylococcus epidermidis and Staphylococcus aureus, colonize and form biofilms on medical devices, followed by Gram-negative species, like $P$. aeruginosa. ${ }^{40}$

The presence of biofilms on the cardiovascular electronic devices (CEDs) is very commonly witnessed in medical routine, which poses considerable risk to host's health leading to a compromised immune system. ${ }^{41}$ The main bacterial species found in biofilms that are adhered to the CED surface belong to the genus Staphylococcus, for example, $S$. epidermidis and $S$. aureus, and these correspond to about $70 \%$ of the total infections. ${ }^{41}$

Although $S$. aureus is the major Gram-positive bacteria that forms biofilms on $\mathrm{CED},{ }^{42}$ the other species with same characteristics may also be related to the infections. A study by Madhavan et $\mathrm{al}^{43}$ evaluated the presence of Gram-positive cocci with a coagulase-negative profile in the blood samples of 74 patients, who were having CED implants and sequentially developed bacteremia. The results demonstrated a high prevalence of Gram-positive cocci, S. aureus, among the infectious cases.

Infectious endocarditis (IE) is classified as a major disease that originates from the incidence of biofilms, primarily formed by $S$. aureus and $P$. aeruginosa. The establishment of such infection is directly related to the ability of the microorganisms to colonize in normal or abnormal valves or altered endothelial surfaces in the heart due to contamination of bloodstream of the host. ${ }^{44}$

As per the published reports, the episodes of IE caused due to the contamination by $P$. aeruginosa are rare in comparison to those caused by Staphylococcus spp., although to a lesser extent. However, the IE caused by the former tends to be more aggressive and is associated with a higher mortality rate than the latter. ${ }^{45}$ In contrast, the presence of biofilms formed by $P$. aeruginosa is widely observed in cases of CF. ${ }^{46}$

Even though lifelong drug therapy is continued for patients, a high proportion of CF cases shows respiratory failure due to the chronic bacterial infection caused by the biofilm-induced inflammation of lungs. ${ }^{40,47}$

Chronic wounds (CWs) that behave as biofilm reservoirs are of major concern due to the risk of development of systemic infections. A CW is often colonized by a wide range of bacterial species that includes $S$. aureus, $P$. aeruginosa, Enterococcus faecalis, coagulase-negative Staphylococci, Proteus spp., and anaerobic bacteria. ${ }^{48} S$. aureus has been considered to be the main agent of biofilm formation in CWs; however, there are reports that define the role of other bacteria, such as $P$. aeruginosa, as well in $\mathrm{CW}$. The infection 
caused by the latter reportedly reaches even the deeper layers of cells, thus aggravating the infection. ${ }^{49}$

The bacterial infections of female reproductive systems, such as bacterial vaginosis, are characterized by the disturbance of the vaginal microbiota. Lactobacilli that are normally commensal inhabitants of vagina are replaced due to significant increase in the concentration of a diverse set of bacteria, like Gardnerella vaginalis, Chlamydia trachomatis, and the bacterial species belonging to the genus Mobiluncus ${ }^{50}$ which are capable of developing biofilms in the female genital tract, thereby triggering chronic infections for which effective therapies are not available. ${ }^{51}$

Biofilms have also been reported in the auditory tracts causing infections, such as otitis media, which is characterized as a middle-ear infection and occurs especially in children. However, in certain cases of biofilms, particularly those formed by S. aureus, the infection may persist or reemerge frequently, and so such infections have been characterized as chronic otitis media (COM). Furthermore, in otolaryngology, the presence of biofilms in the ear canal has been associated with chronic sinusitis and COM with effusion. ${ }^{52}$

Gastric infections are still of great concern in gastroenterology, and particularly, oncology, owing to the association of Gram-negative bacteria Helicobacter pylori. This bacterium forms biofilm in order to ensure its integrity and survival ${ }^{53}$ and is frequently involved in chronic gastritis, functional dyspepsia, peptic or duodenal ulcer, and gastric cancer or lymphomas. Further, H. pylori also displays a survival profile in acidic environments; it remains intact in the stomach environment and promotes the destruction of the gastric mucosa making the organ sensitive and vulnerable to ulcerative lesions. In addition, it also blocks the sterilization process of food, thus interfering in the digestion process. ${ }^{54}$ The currently available therapy to eradicate this bacterium is complex and costly and presents severe side effects for the patients. ${ }^{55}$

Bacterial prostatitis is a UTI that affects males of all ages. A wide spectrum of bacterial species is involved in this disease; the acute phase exhibits the presence of E. coli (67\%), P. aeruginosa (13\%), Klebsiella spp. (6\%), Gram-positive species $(5 \%)$, and others $(9 \%) .{ }^{56}$ In the chronic phase, the major aggravating factor is the presence of biofilms mainly of Gram-negative species, such as E. coli, ${ }^{57}$ which is responsible for most cases of chronic UTIs (E. coli uropathogenic), thus causing about $40 \%$ of the total hospital infections. Moreover, E. coli has been directly related to biofilm formation in urinary catheters, since direct contact of the bacterial cells with the urine can carry infection to internal organs which, in turn, may trigger local and even systemic infections. ${ }^{58}$
Thus, to devise novel therapeutic strategies, the scientific community has shifted focus to nanotechnology ${ }^{59-61}$ for the effective prevention of biofilm formation. ${ }^{62}$ In view of this, the present review draws the attention of the readers to the factors involved in adhesion of bacterial cells leading up to the establishment of biofilms. ${ }^{18,63}$

\section{Fungal biofilms: general aspects}

Fungal infections are a major issue for clinicians because of their high rate of incidence, especially in the immunocompromised patients. The risk factors that determine acquisition and high prevalence of fungal infections are host immunity, prolonged use of broad-spectrum antibiotics, long-term use of intravascular and urethral catheters, hemodialysis, treatment with corticosteroids, parenteral nutrition, the use of immunosuppressive anticancer drugs, and transplants among others. ${ }^{64,65}$

Fungi can dwell as biofilms in different body niches and subsequently induce infections. The site of infection depends on several factors, such as the amount and type of the available nutrients, host immune response, flow conditions and $\mathrm{pH}$ at the infection site, and substrate for cell adhesion and growth of the biofilm. ${ }^{66}$

The substrate for adhesion may be considered as a major factor for the formation of fungal biofilms. The materials that prevent adhesion of microorganisms with satisfactory in vitro results are used to manufacture medical devices. However, in the case of in vivo application of such models, several precautions, for example, a sepsis, need to be taken by the medical team, as contact of the device with the host body fluids, such as urine, saliva, and blood nutrients, provides favorable conditions for the formation of biofilms. ${ }^{67,68}$

The flow conditions may also play an important role in the development of fungal biofilms; for instance, the majority of the Candida spp. form biofilms at different flow rates of body fluids, which can be low (salivary flow: prosthetic stomatitis), intermittent (urinary catheters and vascular circulation), and rapid (bloodstream: fungal endocarditis). ${ }^{69,70}$ Furthermore, the flow is directly related to the transport of oxygen and nutrients that are essential for the development of biofilms.

The nutritional composition of different body niches varies; thus, some species develop better at some places compared to others; for example, blood is rich in nutrients, sugars, and proteins, so the biofilm development is high, which is further facilitated by high vascularization. ${ }^{66}$

The yeast species Candida albicans is known to frequently form biofilms and has been extensively studied by medical researchers, as it is the third most common cause 
of intravascular infections (catheters) among the other types. ${ }^{68,71}$ However, in recent years, several other biofilmforming species of the genus Candida, Candida tropicalis, Candida krusei, Candida glabrata, and Candida parapsilosis, that affect human body have been identified. ${ }^{72,73}$ Further, some other types of fungi, such as Malassezia spp. ${ }^{74}$ Pneumocystis spp.,${ }^{75}$ Histoplasma capsulatum, ${ }^{76}$ Cryptococcus neoformans, ${ }^{77}$ and Cryptococcus gatti, ${ }^{78}$ may also be associated with the infections in humans.

Yeast and the cells of filamentous fungi may naturally occur as two different phenotypes, that is, the planktonic form (free cells) or the sessile form (biofilms). According to Ramage et al, ${ }^{79}$ the sessile phenotype involves the development of a group of strains on a polymeric matrix that is rich in water and allows passage of nutrients and oxygen. In addition, the polymeric matrix confers protection against the host immune response and prevents diffusion of antimicrobial drugs. Moreover, since fungi are eukaryotes and more complex than bacteria, the infections caused due to fungal biofilms remain difficult to diagnose and treat. The detailed analysis of such fungal biofilms has been done during the last years..$^{80,81}$

Since long, the sequences of fungal biofilm formation were thought to be same as in the case of bacteria. However, some studies conducted on the dynamics of genetics and the interactions of fungi, host, and environment have changed this scenario. Even though the overall process is the same, that is, primary adhesion, irreversible adhesion, maturation, and dispersion, depending on the characteristics of fungi, the dynamics involved is different.

The genus Candida has hyphae or pseudohyphae that are associated with the proliferation and development of the biofilms. ${ }^{65}$ The hyphal formation is critical for tissue invasion, as it is more resistant to phagocytosis in comparison to yeast. The virulence of $C$. albicans has been closely linked to the hyphae-forming ability. ${ }^{82}$ The hyphae of $C$. tropicalis are similar in morphology to $C$. albicans and are related to the invasion of oral epithelium. However, the ability of C. parapsilosis to invade oral epithelium is not related to the production of pseudohyphae. ${ }^{83}$ The hyphae promote the ability of the fungus to evade the host defense responses and thus serve as an essential factor for pathogenicity to form biofilms. ${ }^{84}$

The models for the formation of fungal biofilms have been described by Douglas ${ }^{69}$ and Harding et $\mathrm{al}^{85}$ that can be studied to understand the characteristics of fungal biofilms as well. The authors, in both the studies, used C. albicans as the model organism and reported that although the biofilm formed by the fungal species has several similarities with the bacterial biofilm, the presence of hyphae and pseudohyphae is the primary difference between the two. The proposed model includes five steps: (i) adsorption of yeast cells on a surface (biotic or abiotic), (ii) adhesion to the surface, (iii) formation of microcolonies (this step occurs after the initial growth and development of hyphae followed by the formation of microcolonies in the upper layer that predominantly comprises hyphae and production of EPS matrix), (iv) maturation of biofilm, and (v) dispersion of the mature biofilm cells and restart of the cycle.

A preliminary model for the sequential development of filamentous fungi has been proposed and consists of six steps: (i) adsorption of fungal propagules, such as spores, conidia, or hyphae, on solid surfaces (the authors compare this step with reversible adhesion stage of the bacterial biofilms); (ii) promotion of adherence and attachment by release of adhesive substances by germinating spores; (iii) stage 1 of formation of microcolonies (involves apical elongation and branching of hyphae during early growth and colonization of the surface with concomitantly increased production of EPS, which enables colony growth and adhesion to the substrate); (iv) stage 2 of formation of microcolonies or beginning of maturation, which involves the formation of compact hyphal network or mycelia and the formation of water channels that enable the passage of nutrients; (v) maturation phase, which is characterized by high production of fruiting bodies, spores, and other survival structures (this is an extremely important stage since aerial growth is a predisposing factor that allows the dispersion of yeast for new colonization); and (vi) dispersion or planktonic phase, which is similar to the dispersion step in the case of bacterial biofilms, the only difference being the release of spores and fungal filaments that act as propagules to initiate the next cycle.

During the formation of fungal biofilms, QS plays a significant role in the communication between the fungal cells. QS allows the development of the cooperative relationship between the cells that leads to the coordination of different cell behaviors and secretion of signaling molecules. ${ }^{86}$

However, there are certain signaling molecules involved in QS of fungal biofilms that need a special reference. A pioneering study by Hornby et $a 1^{87}$ demonstrated farnesol as the QS molecule that is responsible for inhibition of hyphae formation of $C$. albicans in the stationary phase. The study was important to understand the dynamics of C. albicans biofilms and inspired other researchers for further analysis. ${ }^{88-97}$ 
Chen et $\mathrm{al}^{93}$ identified tyrosol to be a molecule that is involved in QS of C. albicans; thus, these two molecules (farnesol and tyrosol) became well-known regulators of QS in the fungal species. ${ }^{98}$

The control of fungal biofilms has been studied in the context of various fields, such as biotechnology, mycology, and medical research. The infection is complex and results in a poor response to a therapy. The knowledge of the mechanisms that are related to the dynamics involved in the architecture of biofilms is still insufficient.

Routinely, in hospitals, it is common to observe the development of fungal biofilms on the surfaces of medical devices, such as artificial valves, pacemakers, defibrillators, endotracheal tubes, dialysis devices, prosthetic joints, catheters, urinary/intrauterine devices, and contact lenses, which is classified as extreme risk to the patient's health. ${ }^{94}$

Since long, C. albicans and Aspergillus fumigatus have been considered as prevalent fungi in infectious cases. However, in recent years, other fungal species have also been observed to cause infection in clinical practice. ${ }^{64}$ Candida spp. are often found in normal human biota which facilitates their interaction with the implanted biomaterials and surfaces of the host. The treatment of infections that are caused by the fungal biofilms can be inefficient, as the infection often recurs when the therapy ends, and thus, to overcome it, the removal of the device becomes necessary. ${ }^{95}$

Invasive candidiasis (IC), especially candidemias (blood infection caused by Candida spp.), is directly related to the presence of biofilms in body niches and abiotic surfaces of medical devices. ${ }^{96}$ Nowadays, candidemias have been reported as the fourth most common blood infections affecting more than 0.25 million people each year and are responsible for about 50,000 deaths. According to population-based studies, candidemias occupy the seventh position in the ranking of ten most prevalent infections of the human blood that may be fatal. ${ }^{97}$

The prevalence of IC in hospitals is still a major concern, and the presence of biofilms makes this infection yet more complicated. A recent observational survey conducted over 16 years by Caggiano et $\mathrm{a}^{99}$ demonstrated that the infection by Candida spp. was responsible for triggering heart failure in the patients of different age groups, who visited the Southern Hospital in Italy. The authors concluded that C. albicans infection was the most prevalent among all the hospital departments. Moreover, the researchers identified that the incidence of IC caused by C. albicans has exponentially elevated over the years and the non-albicans cases have increased by $75 \%$.
Although C. albicans is the prevalent species among the cases of candidemias, the presence of other species has been observed in clinical settings causing concern, as certain species, such as C. krusei, show high levels of resistance, which poses difficulty in the effectiveness of treatment. ${ }^{83}$ Candidemias are very common in neonates. Recently, Rongpharpi et al ${ }^{100}$ reported seven episodes of IC that were caused by $C$. krusei in neonates, and extreme measures were taken to prevent the subsequent nosocomial infections.

In a recent case, $\mathrm{D}$ 'Acunto et a ${ }^{10}$ identified C. parapsilosis to be responsible for generalized IC in two neonates. The authors reported the use of drugs, fluconazole and amphotericin $\mathrm{B}$, for control of the infection, but with no success. Therefore, voriconazole was used to treat the patients. However, voriconazole is classified as a drug of choice in the cases of systemic fungal infections that are caused by the species of the genus Aspergillus. ${ }^{101}$ Furthermore, the drug exhibits several side effects, such as fever, gastrointestinal symptoms, reversible visual disorders, hepatitis, jaundice, and skin reactions.

The ability of Candida spp. to develop and consequently form biofilms on mucous membranes of the human body is associated with various types of diseases, for example, vulvovaginal candidiasis (VVC). This disease is the most common cause of yeast infection in women with $80 \%$ of the cases caused by C. albicans. ${ }^{102}$ However, in $20 \%$ of the cases, other non-albicans species may be involved in the infectious processes ${ }^{83}$ Moreover, the episodes of recurrent VVC are the most common cause of morbidity in women and predispose the development of cervical cancer. ${ }^{102,103}$ A major problem with fungal dissemination through VVC is the use of intrauterine contraceptive devices as the yeast can adhere to their abiotic surface by increasing the density of biofilms. ${ }^{104}$

The respiratory tract is a perfect habitat for the formation of fungal biofilms. Respiratory fungal infections are chiefly caused by filamentous fungi. Invasive pulmonary aspergillosis (IPA) caused by airborne opportunistic fungi belonging to the Aspergillus spp. (especially A. fumigatus) is one example. IPA is characterized as severe pneumonia leading to the lifethreatening invasion of the lung parenchyma and involving erosion in the vasculature leading to necrosis. ${ }^{105}$

Intensive care unit (ICU) patients, especially those with chronic obstructive pulmonary disease, are at a risk of developing nosocomial IPA. Other species of Aspergillus, viz., Aspergillus flavus, Aspergillus niger, Aspergillus terreus, and Aspergillus nidulans, are also known to trigger respiratory tract diseases in humans. ${ }^{106}$ A. fumigatus may also be 
associated with the cases of $\mathrm{CF}$, although at a less frequency as compared to $P$. aeruginosa cases. ${ }^{107}$

Another fungal respiratory disease, which is acquired by inhalation and has a high level of morbidity, is the histoplasmosis. It is one such respiratory fungal infection that accounts for about half a million cases per year only in the US. ${ }^{108}$ The ability of $H$. capsulatum to form biofilms remained unknown for a long time until identified by Suárez-Alvarez et al. ${ }^{109}$ The researchers showed that $H$. capsulatum yeasts could adhere to the cryosections of different organs and further provided evidence for an important mechanism of colonization and spread of the yeasts, which involves adhesion of the microorganisms to the host tissues, including the cell surface and extracellular components. Two years later, Pitangui et al ${ }^{110}$ demonstrated the in vitro ability of $H$. capsulatum to form biofilms and evaluated its invasion potential in cell lines.

The species of the genus Pneumocystis have been known as the major cause of infections in immunocompromised individuals, especially those who have HIV infection, as it is the major cause of lethal pneumonia in such cases. ${ }^{111}$ The main species associated with the development of pneumonia in humans are Pneumocystis jirovecii and Pneumocystis carinii, ${ }^{112}$ and the diseases caused by these generally involve the formation of biofilms in host's lungs as the latter are suitable for reproduction provided the immunodeficient state of the patient.

Cryptococcosis is an opportunistic fungal disease that affects individuals from different age groups and is induced by Cryptococcus, especially C. neoformans and C. gatti. ${ }^{113}$ Both the species are responsible for triggering infectious processes, such as pneumonia, meningitis, and meningoencephalitis, which often cause the death of the affected patients, especially the transplant recipients and the immunocompromised ones. ${ }^{114}$ The progress of infection by these species involves the formation of biofilms in organs, such as the lungs and brain, that further complicates the therapy. The fungus possesses a polysaccharide capsule that completely surrounds it for the protection against phagocytosis by the cells of the immune system and has a direct relationship with the formation of biofilms. ${ }^{77}$ Fungal infections that are caused by Trichosporon spp. are also considered as a serious threat to humans as their diagnosis and therapy are also complex. ${ }^{115}$ Since long, the species of this genus have been detected in the cases of skin surface mycoses, such as "piedra", which is white, and hypersensitivity pneumonitis. However, in recent decades, the medical field has associated the presence of Trichosporon spp. with the cases of systemic infections, especially in immunocompromised patients, such as those who are neutropenic and those who use central venous catheters. ${ }^{116}$

The potential of certain uncommon Trichosporon spp. to form biofilms, mainly on intravenous catheters, is an issue that needs to be addressed soon. A study performed by de Pavia Fagundes Júnior et al $^{117}$ demonstrated emerging cases of systemic infections that were triggered by Trichosporon asahii in ICU patients with heart failure. The species belonging to Trichosporon genus have a significant adaptation as recently reported by Mattede et al ${ }^{118}$ who confirmed the presence of these species in urinary catheters causing UTIs in ICU patients.

\section{Major factors leading to the development of antimicrobial resistance to biofilms}

Due to the genetic and structural dynamics of microbial biofilms, the treatment and eradication of the same seem to be complex. Certain resistance mechanisms that have been attributed to the sessile cells provide favorable conditions for survival and reproduction of microbes, making them less susceptible to elimination in contrast to the planktonic forms of the same microorganisms. ${ }^{79}$ The incidence of infections caused by microbial biofilms is a problem for the entire health care system and our society. Thus, efforts need to be continued in the pharmaceutical industry to develop novel products for the treatment of drug-resistant infections as there are only limited number of agents that are effective against biofilms. ${ }^{119}$

Besides, the planktonic-form microbes employ mechanisms of resistance, such as the transfer of resistance genes by QS processes, the production of specific enzymes, and the evolution of natural mutations, and certain other processes explain the increased resistance by biofilms against the antimicrobial agents presently used in clinical practice. ${ }^{120}$

The sessile state of microorganisms is crucial for the formation of biofilms. The success of an antibiotic treatment against an infection depends on the drug concentration at the site of infection which must be high enough to inhibit the proliferation of pathogenic microorganisms. Thus, the antibiotics must reach their target sites, in their active forms, in order to promote efficient binding to the target and finally interfere with the target function. In bacterial biofilms, the bacteria involved in the biofilm have high resistance to the antimicrobial agents that are effective against cells of the same species in planktonic form. The minimum inhibitory concentration (MIC) for the bacteria that are in biofilms may be $10-1,000$ times greater than that for their planktonic form. ${ }^{121}$ 
The main and most studied component of biofilms is the EPS, which has been classified as a physical and chemical barrier for the prevention of the action of antibiotics and protection against attack from the host immune response. In addition, EPS matrix provides resistance to thermal stress and mechanical strength, and limits the spread of sanitizers. ${ }^{8}$ The EPS matrix can react with sanitizers and promote inactivation as it is already known that certain chemical sanitizers (sodium hypochlorite) may have their action reduced or even eliminated in the presence of organic compounds, such as proteins, polysaccharides, and lipids. ${ }^{122}$

The microorganisms that exist as biofilms, particularly those dwelling in the inner layers, have low rates of metabolism and growth, and the EPS matrix acts as an adsorber that reduces the amount of drug available for the interaction with the biofilm microbes. In other words, the EPS matrix is capable of reducing the physical penetration of the antimicrobial agents. ${ }^{123}$ It can be understood in this way that the EPS matrix has pores that are very small and do not allow the larger drug molecules to pass through. Moreover, antibiotics may be adsorbed on the matrix itself owing to its hydrophilic and anionic nature, and an adequate amount of the antimicrobial drug does not reach the host tissues, which renders the therapy ineffective. ${ }^{124,125}$

Another aspect to consider is that the cells in the inner part of a biofilm often lack oxygen and nutrients, which forces the microbes to enter the stationary (or dormant) phase of growth. Thus, the microorganisms in the inner layers of biofilms become less susceptible to the action of chemotherapeutic agents since these agents require active growth of microbes. ${ }^{126}$ In this regard, it has been noted that within a biofilm, there are two microbial subpopulations with different phenotypes, one being active and the other inactive, metabolically. The former is on the surface and in contact with the external environment, and thus susceptible to antibiotics, while the latter is submerged in the EPS matrix within the biofilm with a slow rate of cell division, and thus remains resistant to the drugs. ${ }^{127,128}$

According to Mah, ${ }^{129}$ a biofilm can acquire antibiotic resistance by natural mutation or acquisition of resistance genes (for conjugation, transformation, or transduction) as well. These genes may alter the expression of antibioticmodifying enzymes leading to the production of modified proteins that may be the targets of antibiotics. Another phenomenon that may lead to the development of resistance to antibiotics and allow sustenance of cells even during the exposure to chemotherapeutic agents is the induction of reversible phenotypic state, primarily, due to the action of the efflux pumps. The expression of efflux pumps is mainly based on the expulsion of antimicrobial agents from the cells, which has been associated with increased resistance by microbial cells in biofilms, especially the Gram-negative bacteria. ${ }^{130}$ The system AcrAB-TolC, belonging to the family RND, is well characterized in E. coli and confers resistance to antibiotics, such as chloramphenicol, tetracyclines, and quinolones. However, these positively regulated genes are observed in the biofilm-forming cells; additionally, this mechanism may also be found in the strains of Salmonella typhimurium. ${ }^{131}$ In $P$. aeruginosa, the pumps, MexAB-OprM and MexCDOprJ, appear to be involved in the resistance to macrolides and are directly related to the formation of biofilms. ${ }^{132,133}$

The efflux pump mechanism is also observed in yeasts, such as $C$. albicans. The species has two types of efflux pumps: the first one is known as the ATP-binding cassette ${ }^{134}$ and the second type is the multidrug resistant (MDR). ${ }^{133}$ The genes that encode the pumps are upregulated during the formation and maturation of biofilms. Thus, it has been recorded that during the development of biofilms of this fungus, the tolerance to fluconazole is quickly acquired and is mainly attributed to the expression of genes CDR1, CDR2, and MDR1. ${ }^{135}$

Since biofilms represent the mixture of different types of microorganisms living as one community, it is likely that the resistance to multiple drugs may also occur. Not only the planktonic cells but the sessile microbes in biofilms also display specific resistance to antimicrobial agents. However, it is speculated that the classical individual mechanisms provide additional resistance to plaques, thus contributing to the overall resistance. ${ }^{129}$

The currently available drugs have limitations, such as the inability to reach the biofilm microbes and even inefficiency in the cases of strains with a resistance profile. Novel alternatives have been applied for the control and eradication of biofilms. Thus, the present article intends to highlight the use of nanotechnology in drug delivery systems, which aims to enhance the pharmacological action of the bioactive compounds.

\section{Nanotechnology}

The term nanotechnology is related to the development and use of the systems and materials at the nanoscale size $(1-1,000 \mathrm{~nm})$ and the application of the concepts of manipulating materials at atomic, molecular, and macromolecular levels. The advantages of nanotechnology are mainly due to the unique characteristics of the materials at the nanoscale, which usually differ from the macrolevel characteristics of 
the materials. The change in the properties of materials is primarily due to the high surface area-to-volume ratio causing them to be highly reactive, affecting their mechanical and electrical properties. Thus, at the nanoscale, quantum effects dominate the behavior of the materials leading to interesting changes in their electromagnetic and optical properties. ${ }^{136}$

Nanotechnology has played important roles in various fields of science and contributed to the progress in physics, chemistry, engineering, medicine, and pharmaceutical industries. Owing to the ability to control mechanical, magnetic, optical, and catalytic properties of materials, nanotechnology has provided numerous benefits to all areas of science. Nanotechnology has substantially contributed to various fields, such as chemical synthesis, energy supply, food production, data storage, and biotechnology, to name a few. In medicine, nanotechnology gained importance due to its applications in the prevention, diagnostics, and treatment of various diseases. ${ }^{137}$

If one thinks of the disadvantages, the problem that is mostly encountered in the area of nanotechnology is the limited size of these materials, as these can penetrate any living system. Besides, enough investigations have not yet been conducted to allow commenting on the duration for which these materials may remain in the environment or the long-term consequences, which may entail accumulation of such materials in the ecological and living systems. Therefore, short-, medium-, and long-term effects of these nanomaterials are yet to be understood completely. ${ }^{138}$

Ranging from the combination of materials or devices with drugs and biomolecules, adding benefits like slow and controlled drug release, promoting greater efficiency of tissue penetration to greater protection against drug degradation, nanotechnology can be used to prevent, monitor, control, and cure diseases in several ways. ${ }^{137}$ At present, the main types of nanosystems used for the delivery of bioactive substances are liposomes (LIPs), microemulsions (MEs), nanoemulsions, cyclodextrins (CDs), solid lipid nanoparticles (SLNs), polymeric nanoparticles (PNs), and metallic nanoparticles (MNPs). The nanostructured systems have become promising tools for the treatment of infectious diseases, which are resistant to conventional treatments or persistent, improving the quality and expectancy of life of patients who suffer from such diseases. ${ }^{139}$

Due to the resistance mechanisms and biofilm formation, which these microorganisms eventually develop, the effectiveness of conventional antimicrobial agents is gradually declining. A promising strategy to overcome bacterial resistance is nanotechnology, which makes use of nanocarriers for delivery of drugs and biomolecules for the prevention and treatment of bacterial biofilms. ${ }^{140}$

The applicability of these systems in the treatment of biofilms is variable; however, nanotechnology-based drug delivery systems can facilitate drugs to directly interact with the complex structure of biofilms and exert action during the different stages of the biofilm formation.

Among the main abilities of these systems, two are predominantly studied by researchers, the direct interaction with planktonic cells (single cells) and the interaction with or denaturation of the EPS matrix. Figure 2 schematizes the interaction of a drug delivery system containing nanoparticles for drug release and their interaction in the biofilm formation stages. ${ }^{141}$

The direct interaction of nanoparticles with individual cells (Figure 2B) that are involved in the initial event of the process of biofilm formation (primary adhesion) may prevent the continuous process of formation, since the direct interaction between the nanoparticles and membranes of the microorganisms (eg, lipid nanoparticles, LIPs, and others) facilitates entry of the drug into the intracellular medium. This type of interaction can also be attributed during the final event (dispersion), where individual cells are detached from the polymer matrix making them able to restart the formation cycle.

The interaction of nanostructured systems such as nanomulsions LIPs, SLNs, lipoproteins and micelles, and others can also exert direct action on the biofilm polymer matrix (Figure $2 \mathrm{C}$ ), promoting the fusion of the nanoparticles and

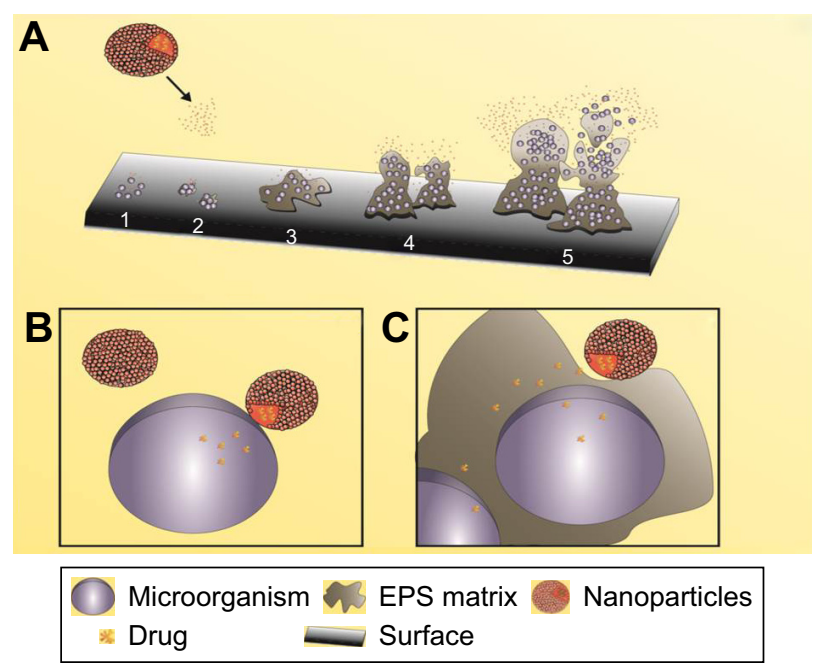

Figure 2 Interactions of nanoparticles based in drug delivery system on biofilm formation process.

Notes: Interaction of nanoparticles based in drug delivery systems in different stages of biofilm formation (A): adherence of microbial cells (I), reversible adhesion (2), irreversible adhesion (3), maturation (4), and detachment of cells (5). Nanoparticles interaction with single cells (B) and EPS matrix (C).

Abbreviation: EPS, extracellular polymeric substances. 
provoking the denaturation of the proteins and the fusion of the lipid bilayers, facilitating the entry of the nanoparticles inside the biofilm to promote contact with the microbial cells. ${ }^{142,143}$

\section{Liposomes}

Since the delivery of aqueous drugs through biological membranes is considered a challenge, it was devised to develop a system of similar nature to deliver such drugs. Some delivery systems, such as LIPs, were analyzed first to solve this problem. ${ }^{144}$ LIPs may be described as small spherical vesicles composed of a phospholipid bilayer or sphingolipids in the membrane that are used to deliver desired drugs at the target sites in the body. Figure 3 presents the structure of LIPs and the difference in comparison with a micelle.

These bilayer molecules can be made from cholesterol (CHOL) or other nontoxic phospholipids, and depending upon their composition, the properties, such as rigidity or fluidity and the charge of the bilayer, can be regulated. ${ }^{145}$

According to Al-Jamal et al, ${ }^{144}$ LIPs are established nanometric systems that can be used to deliver antifungals, cytotoxic drugs, vaccines, and imaging agents. In addition, LIPs offer other advantages, such as biodegradability and biocompatibility, lower toxicity and doses, and the capacity of loading lipophilic and hydrophilic drugs, all of which make them more efficient than the other nanosystems. On the contrary, LIPs also exhibit certain limitations such as poor solubility, short half-life, and the possibility of oxidation and hydrolysis of phospholipids, besides their high costs. ${ }^{145}$

Ahmed et al ${ }^{146}$ investigated the use of PEGylated LIPs to improve the interaction of drug with the bacterial biofilms. The authors prepared LIPs that comprised lipid mixtures by vesicle extrusion method and evaluated if their adsorption

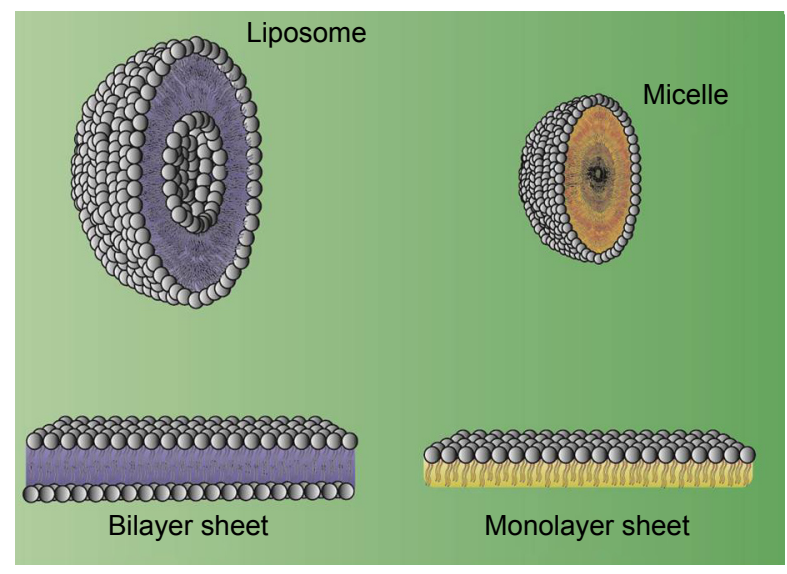

Figure 3 Structure of liposomes. to the biofilms of $S$. aureus would improve after changing the concentrations of lipid and phospholipid-grafted poly(ethylene)glycol (PEG). The results demonstrated the "stealth" property of PEGylated LIPs that also applies to bacterial biofilms, which showed a considerable reduction.

Robinson et $\mathrm{al}^{147}$ investigated the difference between cationic and anionic LIPs, which were developed by the extrusion method, in order to deliver hydrophobic bactericide triclosan (TCS) to bacterial biofilms. Cationic LIPs with varying concentrations of dimyristoylphosphatidylcholine (DMPC), CHOL, and dimethyldioctadecylammonium bromide (DDAB) were tested against various bacteria, viz., Streptococcus oralis, Streptococcus sanguis C104, Streptococcus gordonii, Streptococcus salivarius DBD, and S. salivarius 8618. Among all, the best cationic LIP absorption was displayed by $S$. salivaris DBD, and the least absorption was displayed by $S$. sanguis $\mathrm{C} 104$. For the anionic LIPs, which were composed of DMPC and phosphatidylinositol (PI), the best results were observed against $S$. sanguis C104, while the strategy did not work against $S$. salivarius biofilm. The findings demonstrated the significance of electrostatic interaction for delivery of TCS, as the use of LIP formulations had a substantial effect on the mixed species of the biofilms.

Catuogno and Jones ${ }^{148}$ studied the antibacterial property of the solid-supported LIPs that were produced by zinc citrate particles against the biofilms formed by the most common oral bacterium, S. oralis. The authors tested the capacity of anionic (PI and 1,2-dipalmitoyl-sn-glycero-3-phosphocholine [DPPC], 4-19 mol\% PI) and cationic (DDAB, DPPC, and CHOL, 4-19 mol\% DDAB) LIPs that would be able to work as carriers for drugs, such as TCS, a lipid-soluble agent, and the aqueous-soluble penicillin-G. The results showed that the adsorption of LIPs to the bacterial biofilms was dependent on the concentrations of PI and DDAB used; however, an improvement in the antimicrobial efficacy was observed, as demonstrated by the better stability of the drug-loaded LIPs. The balance between attractive hydroxyl interactions and repulsive electrostatic forces that are associated with hydrogen bonding could explain the anionic LIP-biofilm interactions, while the cationic ones may be attributed to the electrostatic forces of attraction, and hence the content of positively charged phospholipids.

Drulis-Kawa et al ${ }^{149}$ developed anionic and cationic LIPs that encapsulated meropenem (MER) and compared the differences of interaction to $P$. aeruginosa biofilms. The authors revealed that the cationic LIPs, especially the ones that were composed of phosphatidylcholine (PC), 1,2dioleoyloxy-3-trimethylammonium-propane (DOTAP), 
and CHOL (at $5: 2: 3 \mathrm{~mol} / \mathrm{mol} / \mathrm{mol}$ ratio) or PC, 1,2dioleoyl-sn-glycero-3-phosphoethanolamine (DOPE), and stearylamine (SA) (at 4:4:2 $\mathrm{mol} / \mathrm{mol} / \mathrm{mol} \mathrm{ratio}$ ), had higher efficacy than the anionic ones, which may probably be explained by their ionic interactions with the bacterial cell envelope. It is also important, here, to highlight that these formulations showed MIC values that were less than the usual ones, besides demonstrating improved stability and diminished drug leakage. In order to investigate more deeply the reason why cationic LIPs presented a better interaction, further studies were conducted using 23 ATCC and clinical strains of $P$. aeruginosa that displayed varying susceptibility to certain antibiotics. The results demonstrated a high interaction of nanoparticles with the bacterial cells, specifically of the cationic LIPs that can be explained by the negatively charged external membrane of the microbes with the positively charged LIPs. In addition, some hydrophobic areas in the membrane may also contribute toward the enhanced interaction of the LIPs with the bacterial cell membranes.

Gubernator et al ${ }^{150}$ studied in vitro antimicrobial activity of cationic LIPs (the compositions studied were PC/CHOL/ DOTAP 3:4:3 and PC/DOPE/DOTAP 3:4:3) that harbored ciprofloxacin (cipro), MER, or gentamicin (GEN) against the Gram-negative clinical bacterial strains of P. aeruginosa, Klebsiella pneumoniae, and E. coli. Promising results were observed when cipro and MER were delivered using LIPs. The formulations presented the same or reduced MIC values in comparison to the free drugs. However, the liposomal GEN showed higher MIC values than the free drug against all the microorganisms, especially $P$. aeruginosa. The authors concluded that these differences could be due to the characteristics of the different drugs used, highlighting that the success of an antimicrobial treatment depends upon the complete formulation and not just on the delivery system employed for a drug.

Omri et $\mathrm{al}^{151}$ investigated the effect of free and LIPencapsulated polymyxin B (POLY B) against the ability of $P$. aeruginosa to produce pulmonary biofilms. LIPs were composed of DPPC and CHOL (2:1), and P. aeruginosa samples were obtained from the sputum of patients with $\mathrm{CF}$. In general, the LIP formulations of the drug showed improved antibacterial activity, presenting reduced MIC values than the ones recorded for the free drug. ${ }^{152-154}$

Alhajlan et al ${ }^{155}$ performed an in vivo experiment on rats that had lung infections of $P$. aeruginosa. The study was conducted in four treatment groups, and all administrations were done via pulmonary route: (i) group 1, treated with saline; (ii) group 2, treated with free POLY B; (iii) group 3 , treated with empty LIPs; and (iv) group 4, treated with
POLY B loaded into the LIP composed of DPPC:CHOL in 2:1 molar ratio. The results showed that the animals that were treated with liposomal POLY B presented significantly reduced bacterial count in the lung tissues $(3.7 \pm 0.4 \log 10$ colony-forming unit [CFU]/pair of lungs), while the animals that received POLY B alone presented 5.1 $\pm 0.2 \log 10 \mathrm{CFU} /$ pair of lungs. In addition, the group 4 rats showed better accumulation of the drug in their lungs, around five times higher than the group 2 .

Alipour et al ${ }^{156}$ studied the effect of liposomal POLY B against $P$. aeruginosa and also against several other Gramnegative bacteria, such as Bordetella bronchiseptica, E. coli, K. pneumoniae, Acinetobacter lwoffii, and Acinetobacter baumannii. The findings by the research group highlighted that all the microorganisms showed a higher sensitivity profile when the drug was used in combination with LIPs in comparison to the free drug, especially the resistant strain, P. aeruginosa (PAM13641-1).

Alipour et $\mathrm{al}^{157}$ also performed an in vivo experiment in rats with pulmonary $P$. aeruginosa infection. After the generation of the liposomal bismuth-ethanedithiol-loaded tobramycin, the authors administered it via intratracheal route into the infected rats and compared those rats to the ones which were treated with the free drug. The results indicated lung bacterial counts of 3 and $4.7 \log _{10} \mathrm{CFU} /$ lung in the rats treated with liposomal tobramycin and free tobramycin, respectively. Since the drug did not accumulate in kidneys of the LIP-encapsulated drug recipients, the authors suggested that LIPs ensured targeted delivery of the drug, which was not the case for the administration of the free drug.

Alhajlan et al ${ }^{155}$ evaluated the efficacy and safety of liposomal clarithromycin (CAM) and its effect on virulence of $P$. aeruginosa. The LIPs were synthesized by the dehydration-rehydration technique with different compositions: positively charged liposomal formulation was composed of DDAB, DPPC, and CHOL in a ratio of $4: 2: 1$; the negatively charged liposomal formulation was composed of dicetyl phosphate, DPPC, and CHOL in a ratio of 4:2:1; and the uncharged liposomal formulation was composed of DPPC and CHOL in a ratio of $6: 1$. The strains were obtained from the lungs of patients who suffered from $\mathrm{CF}$. The results revealed that LIP-encapsulated delivery of CAM led to reduced MIC of $8 \mathrm{mg} / \mathrm{L}$ in contrast to $256 \mathrm{mg} / \mathrm{L} \mathrm{MIC} \mathrm{in} \mathrm{the}$ case of naked drug delivery. Further, the use of LIPs also aided in the inhibition of the bacterial growth (as observed in biofilm assay) and cytotoxicity of A549 cells by 3-4 logs.

Table 1 summarizes the results of several studies related to the application of LIPs most used for control of microbial biofilms. 
Table I LIPs used for control of microbial biofilms

\begin{tabular}{|c|c|c|c|c|c|}
\hline Formulation & $\begin{array}{l}\text { Active } \\
\text { ingredients }\end{array}$ & $\begin{array}{l}\text { Applications of nanostructured } \\
\text { formulations }\end{array}$ & Composition (w/w) & Pathogen & Ref \\
\hline LIP+ & NA & $\begin{array}{l}\text { Improve the interaction of drug to the } \\
\text { bacterial biofilms }\end{array}$ & $\begin{array}{l}\text { DPPC, DDAB, CHOL, DPPE, } \\
\text { and PEG-2000 (83:74:9:8:0-9) }\end{array}$ & Staphylococcus aureus & 146 \\
\hline LIP+ & NA & $\begin{array}{l}\text { Improve the interaction of drug to the } \\
\text { bacterial biofilms }\end{array}$ & $\begin{array}{l}\text { DPPC, DDAB, CHOL, } \\
\text { DPPE, and PEG-2000 } \\
(87.5: 78.5: 4.5: 8: 0-9)\end{array}$ & S. aureus & 146 \\
\hline LIP- & NA & $\begin{array}{l}\text { Improve the interaction of drug to the } \\
\text { bacterial biofilms }\end{array}$ & $\begin{array}{l}\text { DPPC, PI, DPPE, and PEG-2000 } \\
(91: 82: 9: 0-9)\end{array}$ & S. aureus & 146 \\
\hline LIP- & NA & $\begin{array}{l}\text { Improve the interaction of drug to the } \\
\text { bacterial biofilms }\end{array}$ & $\begin{array}{l}\text { DPPC, PI, DPPE, and PEG-2000 } \\
(95.5: 86.5: 4.5: 0-9)\end{array}$ & S. aureus & 146 \\
\hline TCS-LIP & Triclosan & $\begin{array}{l}\text { Inhibition of growth of the mixed } \\
\text { biofilms of the oral bacteria }\end{array}$ & $\begin{array}{l}\text { DMPC, CHOL, and DDAB } \\
(64: 23: 13)\end{array}$ & $\begin{array}{l}\text { Streptococcus oralis, } \\
\text { Streptococcus sanguis } \\
\text { CI04, Streptococcus } \\
\text { gordonii, Streptococcus } \\
\text { salivarius DBD, and } \\
\text { S. salivarius } 8618\end{array}$ & 147 \\
\hline Zn-TCS-LIP+ & Triclosan & $\begin{array}{l}\text { Antibacterial effect of LIPs adsorbed } \\
\text { on solid particulate zinc citrate }\end{array}$ & $\begin{array}{l}\text { DDAB }(4 \%-19 \%) \text {, DPPC, } \\
\text { and } \mathrm{CHOL}\end{array}$ & S. oralis & 148 \\
\hline Zn-TCS-LIP- & Triclosan & $\begin{array}{l}\text { Antibacterial effect of LIPs adsorbed } \\
\text { on solid particulate zinc citrate }\end{array}$ & $\mathrm{PI}(4 \%-19 \%)$ and DPPC & S. oralis & 148 \\
\hline MER-LIP+ & Meropenem & $\begin{array}{l}\text { Kinds of bacterial structure or } \\
\text { envelope properties have a major } \\
\text { influence on the fusion process }\end{array}$ & PC, DOTAP, and CHOL (5:2:3) & Pseudomonas aeruginosa & 149 \\
\hline MER-LIP- & Meropenem & $\begin{array}{l}\text { Kinds of bacterial structure or } \\
\text { envelope properties have a major } \\
\text { influence on the fusion process }\end{array}$ & PC, DOPE, and SA (4:4:2) & P. aeruginosa & 149 \\
\hline Cipro-LIP & Ciprofloxacin & Improve in vitro bacterial activity & PC, CHOL, and DOTAP (3:4:3) & $\begin{array}{l}\text { P. aeruginosa, Klebsiella } \\
\text { pneumoniae, and } \\
\text { Escherichia coli }\end{array}$ & 150 \\
\hline MER-LIP & Meropenem & Improve in vitro bacterial activity & PC, CHOL, and DOTAP (3:4:3) & $\begin{array}{l}\text { P. aeruginosa, } \\
\text { K. pneumoniae, and } E \text {. coli }\end{array}$ & 150 \\
\hline GEN-LIP & Gentamicin & Improve in vitro bacterial activity & PC, CHOL, and DOTAP (3:4:3) & $\begin{array}{l}\text { P. aeruginosa, } \\
\text { K. pneumoniae, and } E \text {. coli }\end{array}$ & 150 \\
\hline Cipro-LIP(2) & Ciprofloxacin & Improve in vitro bacterial activity & PC, DOPE, and DOTAP (3:4:3) & $\begin{array}{l}\text { P. aeruginosa, } \\
\text { K. pneumoniae, and E. coli }\end{array}$ & 150 \\
\hline MER-LIP(2) & Meropenem & Improve in vitro bacterial activity & PC, DOPE, and DOTAP (3:4:3) & $\begin{array}{l}\text { P. aeruginosa, } \\
\text { K. pneumoniae, and } E \text {. coli }\end{array}$ & 150 \\
\hline GEN-LIP(2) & Gentamicin & Improve in vitro bacterial activity & PC, DOPE, and DOTAP (3:4:3) & $\begin{array}{l}\text { P. aeruginosa, } \\
\text { K. pneumoniae, and } E \text {. coli }\end{array}$ & 150 \\
\hline POLY B-LIP & Polymyxin B & $\begin{array}{l}\text { Therapeutic effectiveness of the } \\
\text { liposomal polymyxin B formulation } \\
\text { administered intratracheally in a rat } \\
\text { model of chronic lung infection }\end{array}$ & DPPC and $\mathrm{CHOL}(2: 1)$ & P. aeruginosa & $|5|$ \\
\hline CAM-LIP+ & Clarithromycin & $\begin{array}{l}\text { Formulations' ability to prevent biofilm } \\
\text { formation, virulence factor production, } \\
\text { and motility of clarithromycin-resistant } \\
\text { strains of } P \text {. aeruginosa }\end{array}$ & $\begin{array}{l}\text { DDAB, DPPC, and CHOL } \\
(4: 2: 1)\end{array}$ & P. aeruginosa & 155 \\
\hline CAM-LIP- & Clarithromycin & $\begin{array}{l}\text { Formulations' ability to prevent biofilm } \\
\text { formation, virulence factor production, } \\
\text { and motility of clarithromycin-resistant } \\
\text { strains of } P \text {. aeruginosa }\end{array}$ & DCP, DPPC, and CHOL (4:2:1) & $P$. aeruginosa & 155 \\
\hline CAM-LIP & Clarithromycin & $\begin{array}{l}\text { Formulations' ability to prevent biofilm } \\
\text { formation, virulence factor production, } \\
\text { and motility of clarithromycin-resistant } \\
\text { strains of } P \text {. aeruginosa }\end{array}$ & DPPC and $\mathrm{CHOL}(6: 1)$ & $P$. aeruginosa & 155 \\
\hline
\end{tabular}

Abbreviations: LIP, liposome; DPPC, I,2-dipalmitoyl-sn-glycero-3-phosphocholine; DDAB, dimethyldioctadecylammonium bromide; CHOL, cholesterol; DPPE, I,2bis(diphenylphosphino)ethane; PEG, poly(ethylene)glycol; PI, phosphatidylinositol; TCS, triclosan; DMPC, dimyristoylphosphatidylcholine; MER, meropenem; PC, phosphatidylcholine; DOTAP, I,2-dioleoyloxy-3-trimethylammonium-propane; DOPE, I,2-dioleoyl-sn-glycero-3-phosphoethanolamine; SA, stearylamine; Cipro, ciprofloxacin; GEN, gentamicin; POLY B, polymyxin B; CAM, clarithromycin; DCP, dicetyl phosphate; Ref, reference; NA, not applicable. 


\section{MEs and nanoemulsions}

MEs, as a drug delivery system, have become a highlight in the pharmaceutical research and industry. This is attributed to their potential to load a wide variety of molecules with different properties and deliver them efficiently to various parts of the body. MEs can be defined as transparent emulsions or phase-transition systems with either oil microdroplets dispersed in water or water microdroplets dispersed in oil. These are surrounded by an amphiphilic compound known as surfactant or amphiphile that is frequently associated with a suitable co-surfactant, thereby producing a thermodynamically stable system consisting of nanometric droplets in an internal phase. ${ }^{158,159}$ MEs are considered as reservoir systems; once the active constituent is isolated from the dissolution medium through a membrane or interface, it must be transposed for release. One of the characteristic features of MEs is their ability to separate from a dimensionally restricted environment and associate with different molecular compounds. Their versatile nature, such as low surface tension, in turn, improves the properties of the associated molecules, for example, solubility, stability, and bioavailability profile, consequently resulting in their increased absorption and permeation. When a surfactant is incapable of achieving nanometric droplets, it becomes indispensable to use a co-surfactant to enhance the surface area of droplets, thereby reducing the size of the particle and providing a better therapeutic effect. ${ }^{160}$

MEs can be spontaneously generated, which makes them more advantageous than other delivery systems. In addition, MEs demonstrate an excellent thermodynamic stability, adequate appearance, and increased capacity to load drugs, which in turn result in their easy penetration through biological membranes, improved bioavailability, and reduced toxicity. ${ }^{161}$ Moreover, these systems serve as potent antimicrobial agents due to the inability of microbes to survive in pure fat or oil. In addition, some studies show that the structure of MEs contributes significantly to their antimicrobial activity by especially targeting the bacterial cytoplasmic membrane. ${ }^{162}$

There are many advantages that make MEs to be considered as the first choice of nanotechnology-based systems. First, they can be prepared without any kind of energy once they are considered thermodynamically stable systems that can be spontaneously formed. Also, they are able to load both hydrophilic and lipophilic drugs, improving the efficiency and thus reducing total dose and side effects. Regarding their limitations, MEs are not a good choice when high-melting substances need to be solubilized. In addition, a high amount of surfactant is needed to stabilize droplets formed during the formation, and there are some problems related to their stability, which depends on $\mathrm{pH}$ and temperature levels. ${ }^{163,164}$

Similar to MEs, nanoemulsions can be defined as heterogeneous systems in which one liquid (the inner phase) is dispersed in another (the outer phase) in the form of droplets in the presence of an emulsifying agent. The physicochemical properties of nanoemulsions are influenced by both their qualitative and quantitative compositions, and hence, they should be synthesized under strictly controlled conditions. ${ }^{165}$ Certain inconsistencies exist in the literature with respect to the concept of nanoemulsions in relation to MEs. Although both systems have similar structural and visual characteristics, they differ in their thermodynamic stability. Contrary to the nanoemulsions, MEs constitute thermodynamically more stable systems. Further, ironically, the droplet size of MEs is generally smaller than the nanoemulsions (as opposed to the nomenclature). ${ }^{166}$ Nevertheless, despite low thermodynamic stability, nanoemulsions are kinetically stable systems and exhibit several potentialities, such as drug delivery systems, especially for hydrophobic molecules with reduced water solubility. ${ }^{167}$ Figure 4 schematizes the organization of a micro- and nanoemulsion (oil-in-water and water-in-oil).

Numerous studies have been conducted by various groups on MEs and nanoemulsions. Ramalingam et $\mathrm{l}^{168}$ performed studies to analyze the efficacy of an oil-in-water nanoemulsion containing cetylpyridinium chloride (CPC) on dental unit waterline biofilms. The nanoemulsion was synthesized using soybean oil (25 vol\%), deionized water (65 vol\%), Triton X-100 (10 vol\%), and CPC (1 wt $\%)$. The bacterial count was observed after exposing the formulation for 1, 6 , $12,24,48$, and $72 \mathrm{~h}$ to the biofilm formed by microorganisms, including Staphylococcus spp. All experiments resulted in a tremendous reduction in the number of microbial colonies, especially after 12 and $24 \mathrm{~h}(67 \mathrm{CFU} / \mathrm{mL})$. However, the authors obtained even better results after 48 and $72 \mathrm{~h}$ of exposures when no visible colonies could be observed.

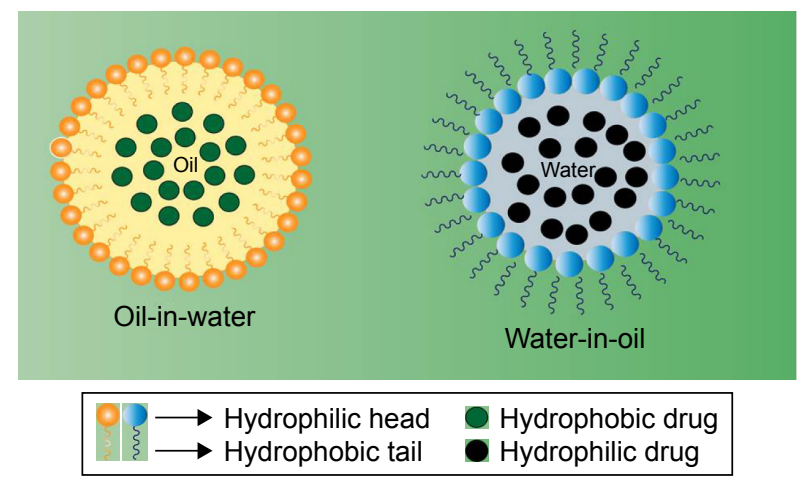

Figure 4 Micro- and nanoemulsion structure: oil-in-water and water-in-oil. 
In 2011, Ramalingam et al ${ }^{169}$ tested the antimicrobial activity of a nanoemulsion on cariogenic $S$. mutans to control biofilm formation. The results displayed an inhibition of $S$. mutans grown in the concentrations ranging from 1:100 to $1: 10,000$. In addition, mature biofilms of the microorganism were significantly reduced after the treatment with the formulation.

In 2012, Ramalingam et al ${ }^{168}$ evaluated the activity of CPC loaded onto a nanoemulsion against planktonic $S$. mutans, Lactobacillus casei, Actinomyces viscosus, C. albicans, and a mixed culture using microdilution technique and biofilm assay. The results demonstrated that compared to the components alone, the application of the formulation exhibited a better and enhanced activity against microorganisms, both individually and in mixed culture. Teixeira et al ${ }^{170}$ studied the ability of MEs and nanoemulsions to inhibit the synthesis of biofilms by $S$. aureus NCTC 1803, S. typhimurium PSB 367, Listeria monocytogenes, P. aeruginosa, and E. coli O157:H7. Although both systems were capable of removing biofilms of E. coli, S. aureus, and S. typhimurium, ME was also effective against $P$. aeruginosa, a nosocomial agent with very high resistance to antimicrobial agents. However, L. monocytogenes was found to be resistant to both the systems.

Liu and Huang ${ }^{171}$ developed curcumin (CUR)-loaded myristic acid-based MEs to study their antibacterial activity against skin infections caused by $S$. epidermidis BCRC11030 (ATCC 12228). During formulation, myristic acid, a middle-chain fatty acid, was mixed dropwise with isopropanol (1:2) to improve the solubility followed by the preparation of surfactants, namely Tween ${ }^{\circledR} 80$ and F127. The components were mixed for $10 \mathrm{~min}$ leading to the formation of transparent MEs. Myristic acid was chosen as one of the constituents because it demonstrated the best antibacterial activity compared with other fatty acids. Its antibacterial activity was found to be even higher than azelaic acid, commonly used to treat acne vulgaris. The results showed that before being loaded into the ME, CUR was 12 times less effective against the bacterium, but showed an $\mathrm{MIC}_{50}$ of $0.86 \mu \mathrm{g} / \mathrm{mL}$ after being loaded into the ME. In addition, when CUR was loaded together with myristic acid into the ME, it produced a synergistic inhibitory effect against $S$. epidermidis, implying that myristic acid may serve as an efficient vehicle for $\mathrm{ME}$ to load CUR.

Instead of encapsulating antimicrobial agents into an $\mathrm{ME}$, some studies have demonstrated the use of MEs that are directly composed of components exhibiting antimicrobial properties so as to augment their effectiveness against microbial biofilms. Al-Adham et al ${ }^{172}$ evaluated the effect of MEs as anti-biofilm agents after validating their effects against planktons. They formulated an ME containing 15\% Tween $80,6 \%$ pentanol, and 3\% ethyl oleate in water and checked its efficiency against established $P$. aeruginosa biofilm. The results exhibited three log-cycle reductions in viabilities when biofilms were treated with an ME as compared to the control treatment that resulted in only one log-cycle reduction.

Table 2 summarizes the results of several studies related to the application of MEs and nanoemulsions most used for control of microbial biofilms.

Table 2 MEs and nanoemulsions used for control of microbial biofilms

\begin{tabular}{|c|c|c|c|c|c|}
\hline Formulation & $\begin{array}{l}\text { Active } \\
\text { ingredients }\end{array}$ & $\begin{array}{l}\text { Applications of nanostructured } \\
\text { formulations }\end{array}$ & Composition & Pathogen & Ref \\
\hline CPC-Na & $\begin{array}{l}\text { Cetylpyridinium } \\
\text { chloride }\end{array}$ & $\begin{array}{l}\text { Improved efficacy against } \\
\text { microorganisms involved in the caries } \\
\text { process in excess of the efficacy of } \\
\text { the unemulsified components }\end{array}$ & $\begin{array}{l}\text { Soybean oil ( } 25 \text { vol\%), } \\
\text { deionized water ( } 65 \text { vol\%), } \\
\text { Triton X-100 (10 vol\%), and } \\
\text { CPC (I wt\%) }\end{array}$ & $\begin{array}{l}\text { Streptococcus mutans, } \\
\text { Lactobacillus casei, Actinomyces } \\
\text { viscosus, and Candida albicans }\end{array}$ & 168,169 \\
\hline Nano & NA & $\begin{array}{l}\text { Capacity to destroy biofilms formed } \\
\text { by different pathogens }\end{array}$ & $\begin{array}{l}\text { Soybean oil (I6\%), tri-n-butyl } \\
\text { phosphate }(2 \%) \text {, Triton X-100 } \\
(2 \%) \text {, and water }\end{array}$ & $\begin{array}{l}\text { Staphylococcus aureus NCTC } \\
\text { I803, Salmonella typhimurium } \\
\text { PSB 367, Listeria monocytogenes, } \\
\text { Pseudomonas aeruginosa, and } \\
\text { Escherichia coli OI57:H7 }\end{array}$ & 170 \\
\hline Micro & NA & $\begin{array}{l}\text { Capacity to destroy biofilms formed } \\
\text { by different pathogens }\end{array}$ & $\begin{array}{l}\text { Ethyl oleate ( } 3 \%) \text {, } \\
\text { n-pentanol }(6 \%) \text {, Tween }{ }^{\circledR} 80 \\
\text { (I5\%), and water }\end{array}$ & $\begin{array}{l}\text { S. aureus NCTC I803, } \\
\text { S. typhimurium PSB } 367 \text {, } \\
\text { L. monocytogenes, P. aeruginosa, } \\
\text { and E. coli OI57:H7 }\end{array}$ & 170 \\
\hline CUR-ME & Curcumin & $\begin{array}{l}\text { Inhibit the pathogen Staphylococcus } \\
\text { epidermidis on the skin }\end{array}$ & $\begin{array}{l}\text { Myristic acid and isopropanol } \\
\text { (I:2), surfactants (Tween } 80 \\
\text { and FI27), and water }\end{array}$ & S. epidermidis & 171 \\
\hline ME & NA & $\begin{array}{l}\text { Anti-biofilm effects of pharmaceutical } \\
\text { microemulsions }\end{array}$ & $\begin{array}{l}\text { I } 5 \% \text { Tween } 80 \text { (15\%), } \\
\text { pentanol }(6 \%) \text {, and ethyl } \\
\text { oleate }(3 \%) \text { in water }\end{array}$ & P. aeruginosa PAOI & 172 \\
\hline
\end{tabular}

Abbreviations: ME, microemulsion; CPC, cetylpyridinium chloride; CUR, curcumin; Ref, reference; NA, not applicable. 


\section{Cyclodextrins}

CDs are a family of cyclic oligosaccharides that are obtained from starch-containing materials by enzymatic means. CDs were discovered in 1891 by the French researcher, Villiers, who noticed the ability of these molecules to form crystals. ${ }^{173}$ Natural CDs are formed by the treatment of starch with amylase from Bacillus macerans, producing at least six glucose units. Among them, $\alpha$-cyclodextrin ( $\alpha-C D$, six units), $\beta$-cyclodextrin ( $\beta-C D$, seven units), and $\gamma$-cyclodextrin $(\gamma-\mathrm{CD}$, eight units) are the most common members (Figure 5). ${ }^{174,175}$ The external surface of the $\mathrm{CD}$ that offers protons $(\mathrm{H} 1, \mathrm{H} 2, \mathrm{H} 4, \mathrm{H} 6)$ provides it a hydrophilic nature, whereas its cavity displays hydrophobic characteristics due to the presence of rings of $\mathrm{C}-\mathrm{H}$ groups (H3 and H5) together with a ring of oxygen atoms forming glycosidic linkages. ${ }^{176-178}$ Therefore, CDs are truncated cone-shaped molecules with a relatively hydrophobic cavity and an external hydrophilic surface that can form supramolecular structures (inclusion complexes, ICs) with various molecules, mainly small molecules. The interactions, such as van der Waals, hydrophobic, and hydrogen bonding, contribute to the driving forces of IC formation, which can modify the biological, physical, and chemical properties of guest molecules..$^{179,180}$

Due to their ability to form ICs, CDs are considered as efficient drug-carrying and drug-delivering systems. Besides, CDs are excellent solubilizers and physical and chemical stabilizers, and provide protection to the guest molecules from degradation in the gastrointestinal tract, thereby enhancing drug bioavailability. ${ }^{181} \mathrm{CDs}$ have been used as a pharmaceutical excipient, mainly to solubilize drugs with poor solubility in an aqueous environment through the synthesis of drug-CD complexes. ${ }^{182,183}$ The naturally occurring CDs have been used at a large scale in the evaluation and development of pharmaceutical formulations. However, their applications suffer from certain limitations; for example, $\beta-C D$ exhibits a restricted solubility in water. Thus, new approaches to improve the action of CDs as drug carriers, such as the use of several chemically modified $\mathrm{CDs},{ }^{183}$ are required. $\mathrm{CD}$ derivatives are classified into three groups: hydrophilic, hydrophobic, and ionizable derivatives. Each group performs a specific action. For example, in the hydrophilic group, 2,6-dimethyl- $\beta-C D, 2,3,6$,-trimethyl- $\beta-C D$, 2-hydroxypropyl- $\beta$-CD (HP- $\beta-C D$ ), and maltosyl- $\beta-C D$ can enhance the water solubility of poorly water-soluble substances. Similarly, molecules within the hydrophobic group, such as 2,6-diethyl- $\beta-\mathrm{CD}$, are capable of delaying the dissolution rate of poorly water-soluble drugs. Besides, the ionizable derivatives, such as O-carboxymethyl- $\beta-C D$ (CM- $\beta$-CD), O-carboxymethyl-O-ethyl- $\beta-C D, \beta-C D$ sulfate, and sulfobutyl ether $\beta-C D$, can improve the inclusion ability and decrease the localized irritation caused by drugs. ${ }^{184,185}$

The properties exhibited by CDs are relevant for pharmaceutical area given the fact that they can improve the

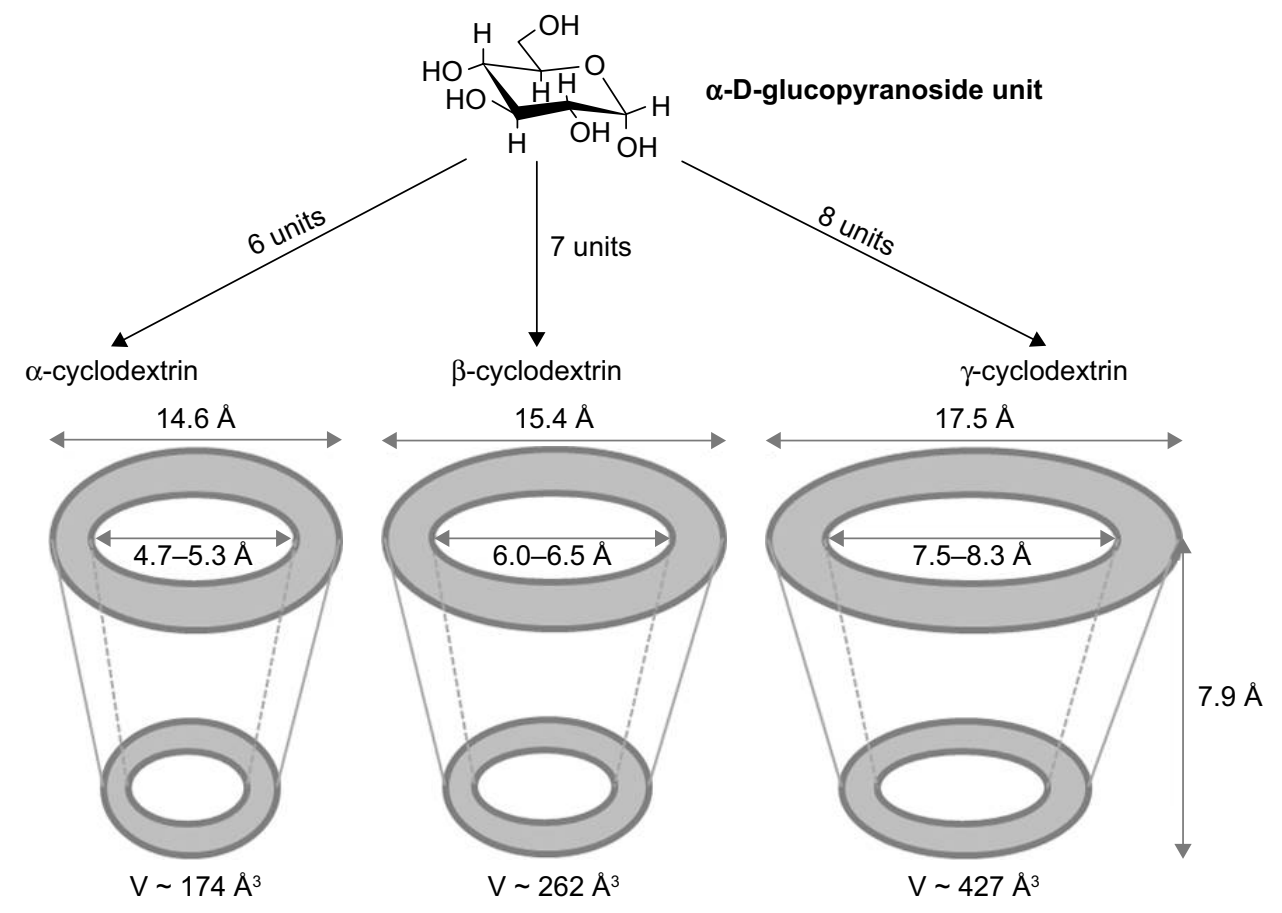

Figure 5 Structure and properties of $\alpha-, \beta$-, and $\gamma$-cyclodextrin. 
solubility of water-soluble drugs, augment the chemical and physical stability, and provide protection to the guest molecules from the action of molecules and enzymes present in the gastrointestinal tract. ${ }^{186,187}$ However, there are limitations for parenteral formulation with $\mathrm{CD}$, based on the type of $\mathrm{CD}$ used. For example, only $\alpha-\mathrm{CD}$ can be used in parenteral formulation; $\beta-\mathrm{CD}$ affects the urinary volume and kidney and liver enzymes ${ }^{188}$ and $\gamma$-CD exhibits nephrotoxicity, and hence, both these CDs are unsuitable for parenteral use. ${ }^{189}$ Besides, the type and concentration of CD-drug complex also affect the encapsulation efficiency ${ }^{190}$ and the bioavailability of the drugs. ${ }^{191}$ The other limitation with the native CD is the difficulty in the incorporation of large and hydrophilic substances. Thus, many chemical modifications have been performed to solve this disadvantage. ${ }^{192}$

In the past years, several alternatives have been implemented and utilized to control and treat various microbial biofilms. ${ }^{187,193-195}$ The characteristics exhibited by CDs, including lower toxicity, increased solubility of drugs, and an ability to act as stabilizers, make them eligible agents as drug carriers. These above-mentioned properties have attracted interest in the utilization of CDs to boost the action of drugs against bacterial and fungal biofilms. ${ }^{196-198}$

Brackman et al ${ }^{199}$ developed gauzes functionalized with HP- $\beta$-CD to load vancomycin (VAN), hamamelitannin (HAM) (a natural product isolated from Hamamelis virginiana), and a quorum sensing inhibitor (QSI) of $S$. aureus. The authors evaluated the anti-biofilm activity of HP- $\beta-C D$ complex against $S$. aureus and $P$. aeruginosa in vitro in a $\mathrm{CW}$ model. The functionalized HP- $\beta$-CD gauzes inhibited QS and the formation of biofilms when compared with nonfunctionalized gauzes. The results demonstrated the utilization of HP- $\beta$-CD-functionalized gauzes containing a combination of VAN and HAM to be a promising approach against both single-species and mixed-species biofilms. Hence, HP- $\beta$ $\mathrm{CD}$-functionalized gauzes may serve as an alternative to the treatment and prevention of wound infections caused by bacteria.

In a study performed by Garcia-Fernandez et al, ${ }^{197}$ HP- $\beta$-CD was utilized for the loading and release of benzalkonium chloride (BzCl), for inhibiting $S$. aureus biofilm. The authors assessed the utilization of CDs to endow hydrogels and gauzes to increase and maintain the antimicrobial and delivery capacity for several hours. In this study, the CDs displayed an efficient delivery of $\mathrm{BzCl}$, which in turn could successfully inhibit biofilm formation in the initial stage. They also decreased the number of living microbial cells in preformed biofilms in an in vitro $\mathrm{CW}$ biofilm model. Based on the results, the researchers concluded that $\mathrm{BzCl}$-loaded functionalized HP- $\beta-C D$ gauzes may be employed for the prevention and treatment of infectious wounds, although in vivo assays are necessary to confirm the findings.

Fidaleo et $\mathrm{al}^{200}$ evaluated the anti-biofilm activity of TCS complexed with HP- $\beta-C D$ and CM- $\beta-C D$. The two complexes (TCS-CD) were observed to exhibit anti-QS activity by interfering with cell-to-cell communication mechanisms in Chromobacterium violaceum model system. Thus, the authors suggested the use of TCS-CD complexes for producing antimicrobial hydrogels or hydrophilic coatings for medical devices to inhibit biofilm formation on the devices and promote the release of antimicrobial agents.

A recent study demonstrated the potential of HP- $\beta-C D$ to clean reverse osmosis membranes contaminated and fouled by $P$. aeruginosa. The $\mathrm{CD}, \mathrm{HP}-\beta-\mathrm{CD}$, removed the biofilm forming complex with the EPS of bacteria. Although the mechanism of removal of the biofilm by HP- $\beta$-CD was unknown, the authors attributed it to the structural distribution of HP- $\beta-C D$ on the surface of the biofilm. In addition, the authors believed that there could be a destabilization of the biofilm due to the generation of free energy, making the detachment an energetically propitious process. ${ }^{201}$

Iordache et a ${ }^{198}$ developed a thin film consisting of $\beta-C D$ complexed with usnic acid, a dibenzofuran with pharmacological properties, to improve the release of a drug into the bacterial cells. The thin film was observed to be successful in preventing the adhesion of cells and development of S. aureus biofilm at all stages. Besides, the film demonstrated good biocompatibility, an attribute that may lead it to serve as an alternative for promoting medical surfaces capable of preventing microbial colonization.

Shanmuga Priya et $\mathrm{al}^{202}$ formulated a solid complex with $\beta-C D$ and drug rifabutin (RFB) to increase the solubility and antimicrobial activity of the drug. The conjugation to the solid complex enhanced the effectiveness of the drug in reducing the biofilm formation by E. faecalis, S. aureus, Proteus vulgaris, and $P$. aeruginosa, when compared to the control. The study related the in vitro anti-biofilm action of pure RFB and its $\beta$-CD complex against both Gram-positive and Gram-negative microorganisms.

$\beta$-CDs have been used for the stable delivery of silver nanoparticles (AgNPs) due to their physicochemical properties, such as hydrophilicity, high molecular weight, the presence of a large number of hydrogen donors and acceptors, and inclusion capacities. ${ }^{203,204} \mathrm{~A}$ recent study involving AgNPs- $\beta$-CD complex demonstrated an excellent antibacterial activity of the complex, which inhibited the formation of 
biofilm by $S$. epidermidis, the common bacteria isolated from medical devices, such as catheters, prosthetic implants, and intrauterine devices. In addition, the AgNPs- $\beta-C D$ complex was more effective than AgNPs. The authors used different concentrations of silver (Ag, 8 and $16 \mathrm{ppm}$ ) on biofilm of S. epidermidis; the AgNPs- $\beta$-CD complex inhibited biofilm formation to more than 90\%, whereas AgNPs could inhibit only $10 \%-15 \% .^{204}$

In a recent work performed by Oprea et al, ${ }^{205}$ the antibiofilm activity of zinc oxide- $\beta$-CD-cefepime ( $\mathrm{ZnO}-\mathrm{CD}-\mathrm{Cfp}$ ) complex against $E$. coli was assessed. The complex was selected and evaluated owing to its enzymatic resistance to $\beta$-lactam antibiotics. $\mathrm{ZnO}$ nanoparticles are used as antibacterial agents; however, the primary problem with them is their poor solubility in water. Thus, the use of CDs can enhance the solubility and bioavailability of these nanoparticles. Besides, the authors demonstrated that $\mathrm{ZnO} / \mathrm{CD}$ complex displays an efficient release of Cfp, consequently leading to an improvement in the anti-biofilm activity. The results also demonstrated that the obtained coatings can prevent the biofilm formation and adhesion after 24-48 h, and the complex also demonstrated inhibitory effect against mature biofilm on the coated surfaces.

The last few years have witnessed studies involving CDs to improve the delivery of drugs to control fungal biofilms. Nava-Ortiz et $\mathrm{al}^{206}$ used medical devices designed from polyethylene and polypropylene functionalized with HP- $\beta-C D$ and $\beta-\mathrm{CD}$ to incorporate miconazole (MICO). Since the drug $\mathrm{MICO}$ is insoluble in water, CDs serve as an efficient option to assist the solubilization, thereby providing adequate bioavailability. Besides, the surface functionalization involved the grafting of glycidyl methacrylate after pre-irradiation with oxidative $\gamma$-rays. These complexes demonstrated positives results, including a reduction in microbial adhesion and prevention of the development of Candida biofilm.

In another work, a topical formulation of amphotericin B (AmB) solubilized in $\gamma$-CD (AmB-CD complex) inhibited the biofilm formation by Candida spp., C. albicans, Candida dubliniensis, C. glabrata, Candida guilliermondii, and C. parapsilosis, except for C. krusei, which was resistant to AmB-CD. The other yeasts, such as Saccharomyces and Trichosporon, were found to be sensitive to the complex. The AmB-CD, compared to AmB dissolved in dimethylsulfoxide, exhibited a high penetration through these biofilms. Despite the suggestion by the authors that the AmB-CD could be employed in catheters and prosthesis to prevent fungal infections of bloodstream, a requirement for further toxicological and clinical studies is warranted before its use in humans. ${ }^{207}$
In another study, the authors elaborated gold surfaces functionalized to anidulafungin (ANF) or thymol (THY) with HP- $\beta-C D$ and randomly methylated $\beta-C D$ (RAMEB) complexes. Both antifungal complexes displayed similar anti-biofilm action. The results indicated that CDs improved the solubility of ANF, and together, the complexes inhibited the adhesion of $C$. albicans biofilm. In addition, THY-CD complex could potentially eliminate the biofilm synthesized by $C$. albicans. However, a considerable difference exists between THY and ANF molecules; ANF is more than seven times larger than THY and cannot be completely incorporated into the cavity of CD, while THY is a small molecule. Thus, the THY molecule loaded into RAMEB could interact efficiently with the cells and prevent the growth of C. albicans. ${ }^{177}$

Table 3 summarizes the results of several studies related to the application of CDs most used for control of microbial biofilms.

\section{Solid lipid nanoparticles}

SLNs are colloidal drug delivery systems in which the matrix is formed by solid lipids and usually consists of physiologically well-tolerated substances; thus, the system offers low cytotoxicity. The structure of SLNs is very similar to nanoemulsions, but their core is formed by lipids that are solid at room temperature. This structural rigidity provides less mobility to the incorporated drug, which is manifested in terms of a better control during the release of drugs. The production of SLNs can be easily scaled to the level of pharmaceutical industry. ${ }^{140}$ SLNs comprise one or more solid lipids, and their structure is stabilized by the presence of surfactants.

SLNs show the properties of different colloidal carriers. For instance, these are physiologically acceptable compounds like emulsions and LIPs and capable of yielding a controlled release of drugs from lipid matrices such as PNs. The mentioned advantages include the incorporation of lipophilic and hydrophilic drugs, physical stability, controlled drug release, biocompatibility, potential for site-specific drug delivery, improved drug stability, better formulation stability, ability to freeze-dry and reconstitute, high drug payload, controllable particle size, avoidance of carrier toxicity, low production cost, and easy scale-up and manufacturing. ${ }^{208}$ Figure 6 schematizes the SLNs structure for drug delivery.

However, certain limitations are also associated with the SLN system. These include limitation of drug load due to the solubility of the drug in the solid lipid, drug expulsion phenomenon when lipid crystallizes to the stable $\beta$-form, 
Table 3 CDs for control of microbial biofilms

\begin{tabular}{|c|c|c|c|c|c|}
\hline Formulation & $\begin{array}{l}\text { Active } \\
\text { ingredients }\end{array}$ & $\begin{array}{l}\text { Applications of nanostructured } \\
\text { formulations }\end{array}$ & Composition & Pathogen & Ref \\
\hline $\mathrm{BzCl}-\mathrm{HP}-\beta-\mathrm{CD}$ & $\begin{array}{l}\text { Benzalkonium } \\
\text { chloride }\end{array}$ & $\begin{array}{l}\text { The ability to take up antiseptics and sustain } \\
\text { their delivery for several hours }\end{array}$ & $\mathrm{HP}-\beta-\mathrm{CD}$ & $\begin{array}{l}\text { Staphylococcus epidermidis and } \\
\text { Escherichia coli }\end{array}$ & 197 \\
\hline UA-CD & Usnic acid & $\begin{array}{l}\text { Improve the release of a drug into the } \\
\text { bacterial cells }\end{array}$ & $\gamma$-cyclodextrin & Staphylococcus aureus & 198 \\
\hline VAN-HP- $\beta-C D$ & Vancomycin & Anti-biofilm activity of HP- $\beta-C D$ complex & $\mathrm{HP}-\beta-\mathrm{CD}$ & $\begin{array}{l}\text { Pseudomonas aeruginosa and } \\
\text { S. aureus }\end{array}$ & 199 \\
\hline HAM-HP- $\beta-C D$ & Hamamelitannin & Anti-biofilm activity of HP- $\beta-C D$ complex & $H P-\beta-C D$ & P. aeruginosa and S. aureus & 199 \\
\hline TCS-HP- $\beta-C D$ & Triclosan & Influence on its antibacterial and anti-QS activity & $H P-\beta-C D$ & E. coli and S. aureus & 200 \\
\hline TCS-CM- $\beta-C D$ & Triclosan & Influence on its antibacterial and anti-QS activity & $C M-\beta-C D$ & E. coli and S. aureus & 200 \\
\hline $\mathrm{HP}-\beta-\mathrm{CD}$ & NA & $\begin{array}{l}\text { Removed the biofilm-forming complex with the } \\
\text { extracellular polymeric substances }\end{array}$ & $\mathrm{HP}-\beta-\mathrm{CD}$ & P. aeruginosa & 201 \\
\hline RFB- $\beta-C D$ & Rifabutin & $\begin{array}{l}\text { Improvement of solubility and antimicrobial } \\
\text { activity of rifabutin }\end{array}$ & $\beta-C D$ & $\begin{array}{l}\text { Enterococcus faecalis, S. aureus, } \\
\text { Proteus vulgaris, and P. aeruginosa }\end{array}$ & 202 \\
\hline AgNPs- $\beta-C D$ & AgNPs & Inhibit the formation of biofilm & $\beta-C D$ & S. epidermidis & 204 \\
\hline $\mathrm{ZnO}-\mathrm{CD}-\mathrm{Cfp}$ & $\begin{array}{l}\mathrm{ZnO}-\mathrm{NPs} \text { and } \\
\text { cefepime }\end{array}$ & $\begin{array}{l}\text { Lead to an improvement in the anti-biofilm } \\
\text { activity }\end{array}$ & $\beta-C D$ & E. coli & 205 \\
\hline MICO-HP- $\beta-C D$ & Miconazole & Improve water solubility & $H P-\beta-C D$ & Candida albicans & 206 \\
\hline MICO- $\beta-C D$ & Miconazole & Improve water solubility & $\beta-C D$ & C. albicans & 206 \\
\hline$A m B-\gamma-C D$ & Amphotericin & Formulate a topical amphotericin preparation & $\gamma-C D$ & $\begin{array}{l}\text { C. albicans, Candida dubliniensis, } \\
\text { Candida glabrata, Candida } \\
\text { guilliermondii, Candida } \\
\text { parapsilosis, and Candida krusei }\end{array}$ & 207 \\
\hline ANF-HP- $\beta-C D$ & Anidulafungin & Improve the solubility of ANF & $H P-\beta-C D$ & C. albicans & 177 \\
\hline THY-HP- $\beta-C D$ & Thymol & Improve the solubility of THY & $H P-\beta-C D$ & C. albicans & 177 \\
\hline ANF- $\beta-C D$ & Anidulafungin & Improve the solubility of ANF & $\beta-C D$ & C. albicans & 177 \\
\hline THY- $\beta-C D$ & Thymol & Improve the solubility of THY & $\beta-C D$ & C. albicans & 177 \\
\hline
\end{tabular}

Abbreviations: CDs, cyclodextrins; $\mathrm{BzCl}$, benzalkonium chloride; HP- $\beta-C D$, 2-hydroxypropyl- $\beta-C D$; UA, usnic acid; VAN, vancomycin; HAM, hamamelitannin; TCS, triclosan; QS, quorum sensing; CM- $\beta-C D$, O-carboxymethyl- $\beta-C D$; RFB, rifabutin; AgNPs, silver nanoparticles; Cfp, cefepime; ZnO-NPs, zinc oxide nanoparticles; MICO, miconazole; AmB, amphotericin B; ANF, anidulafungin; THY, thymol; Ref, reference; NA, not applicable.

and particle concentration in the aqueous dispersions ranging from about $1 \%$ to a maximum of only $30 \% .{ }^{209}$

Singh et al, ${ }^{210}$ with an aim to increase antimicrobial activity against $S$. aureus biofilms, developed SLNs containing cefuroxime axetil (CA). The authors used stearic acid (SA) as a single lipid and SA and tristearin (TRI) as a binary lipid;

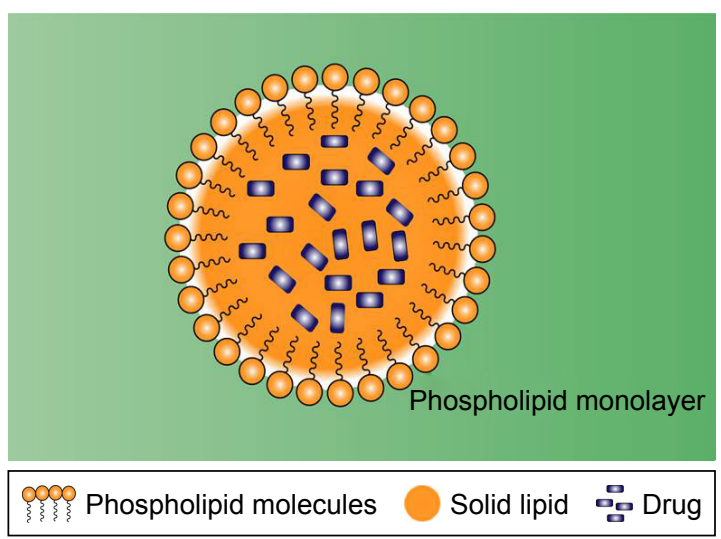

Figure 6 Solid lipid nanoparticles structure. the emulsification-evaporation method was used for the formation of SLNs. The nanosystem displayed a low efficiency of encapsulation. To improve this parameter, an SLN formulation (CA-SLN) was developed using binary lipid that exhibited an encapsulation efficiency of $70.62 \% \pm 0.82 \%$. The high efficiency of SLNs consisting of binary lipids was attributed to the large deformation of the crystal structure of SA in the presence of TRI, leading to the formation of cavities in its structure and efficient accommodation of drug molecules. The size of the formed nanoparticles was in the range of $279.2 \pm 28.5 \mathrm{~nm}$, and the zeta potential (ZP) was -23.58 to $-25.95 \mathrm{mV}$. The in vitro analysis of the release of free CA displayed a $99.68 \%$ release in just $2 \mathrm{~h}$, whereas CA-SLN exhibited a $53.68 \%$ release in $2 \mathrm{~h}$ and $95.58 \%$ within $12 \mathrm{~h}$, indicating that nanoparticles provide an additional feature of prolonged drug release owing to the diffusion of the drug through the lipid matrix of the nanoparticles. The in vitro anti-biofilm studies exhibited an inhibition zone of $9 \mathrm{~mm}$ for the free drug, whereas the treatment with CASLN created an inhibition zone of $13 \mathrm{~mm}$. According to the 
authors, the above-mentioned observation was attributed to the enhanced diffusion and accumulation of CA-SLN in the polysaccharide matrix of the biofilm/microbial cells. The CA-SLN exhibited an MIC of $4 \mu \mathrm{g} / \mathrm{mL}$, whereas free drug solution displayed an MIC of $10 \mathrm{mg} / \mathrm{mL}$. Therefore, the authors believe that the bilipid SLNs consisting of SA and TRI meet the requirements for use as carriers of cefuroxime to inhibit $S$. aureus biofilm.

Nafee et $\mathrm{al}^{211}$ developed SLNs with an aim to optimize the delivery of QSIs in lung tissue of patients with CF. SLNs were synthesized by hot-melt homogenization with glyceryl palmitostearate, glyceryl behenate, and TRI. The lipophilic nature of QSI facilitated its incorporation into SLNs demonstrating an encapsulation efficiency of $68 \%-95 \%$. The release of QSI from different SLNs was studied in phosphate-buffered saline (PBS) buffer and simulated lung fluid (SLF). A controlled release of QSI in PBS buffer was observed with 60\%-95\% of drug release over $8 \mathrm{~h}$. Therefore, SLF was considered to be a more relevant and a better medium for in vivo conditions; the release of QSI was prolonged in SLF showing greater than $20 \%$ burst in all SLNs. Mucus interaction assay demonstrated that the SLN could not alter physicochemical characteristics even when in contact with the highly characteristic thick mucus in patients with CF. Further, no significant aggregation was observed in maintaining its potential for carrying QSIs. The cytotoxic property of plain and loaded SLNs was checked on Calu-3 cells (human airway cell line) representing the bronchial area. The experiment demonstrated 80\%-100\% of cells to be viable after incubation with SLNs. Pyocyanin, the virulence factor, produced by $P$. aeruginosa is required for complete virulence in animal models. It promotes virulence by interfering with numerous cellular processes involved in the inhibition of pyocyanin. The inhibition of pyocyanin demonstrated that the formulation not only maintained the activity of the free QSI but was superior at all the tested concentrations. The QSI-loaded SLNs were superior to the free QSI in inhibiting pyocyanin. The authors reported an inhibition of the growth of $P$. aeruginosa upon treatment with SLN. According to the authors, SLNs, efficiently loaded with the novel QSIs, could be formulated with a release of the payload over more than $8 \mathrm{~h}$. The hydrophilic surface of SLNs allowed the QSIs to efficiently penetrate the mucus, thereby acting as an efficient drug carrier for an effective therapy for CF. Thus, the use of SLNs reflects a new perspective in the nano-based delivery of novel anti-infectives.

Taylor et al, ${ }^{212}$ with the aim of preventing and treating nosocomial infections in surgical implants, synthesized SLNs composed of SA, lauric acid (LA), and oleic acid (OA).
The strategy was based on the use of SLNs to destabilize bacterial adhesion in tissues and surfaces, thus preventing the formation of biofilms. Furthermore, the antibacterial action of LA and OA stimulated the disruption of bacterial cell membrane. All SLN formulations depicted a hydrodynamic radius below $200 \mathrm{~nm}$ and a negative surface charge; the SLN solutions were coated with silicone polyvinyl chloride (PVC) to produce coatings with antimicrobial potential. Confocal microscopy was used to analyze the bacterial adhesion that revealed the ability of bacteria to adhere to the coating surfaces in the absence of SLN; however, after coating the surface, no bacteria could adhere to the endotracheal tube surface coated with SLN. The observation was reflected in the adhesion rate, which was $96.93 \%$ lower than in the uncoated surfaces. In the case of uncoated surfaces, the presence of bacteria and integral membrane morphologies was observed, whereas amorphous fragments and free bacterial DNA were observed on the coated surfaces, indicating a disruption of the cell wall and bacterial killing. According to the authors, potential adhesion was drastically reduced due to the presence of roughness on the surface, a decrease in the contact area, and weakening of the bacterial adhesion mechanism. Moreover, the small percentage of bacteria that achieved adhesion displayed destabilized walls due to the presence of fatty acids in the SLN with bactericidal effect. The authors postulated that it is essential to search for new alternatives, such as SLNs, which are not dependent on the antimicrobial drug action due to the multidrug resistance of microbes to antibiotics. Such SLNs may be applied as coatings of surgical implants to exert an anti-biofilm activity.

Table 4 summarizes the results of several studies related to the application of SLNs most used for control of microbial biofilms.

\section{Polymeric nanoparticles}

PNs may be defined as solid colloidal particles with a size less than $1 \mu \mathrm{m}$ and carrying bioactive molecules or substances. These can be synthesized using different methods with a feature size of $100-500 \mathrm{~nm} .^{213}$

The early 1970s witnessed the introduction of methods for the preparation of nanoparticles. According to their composition and structural organization, nanoparticles can be classified as nanospheres and nanocapsules. The nanospheres do not contain oil in their composition and comprise a polymeric matrix with the active substance retained or adsorbed in the matrix. Nanocapsules consist of a polymeric shell disposed around an oily core, where the active substance can be dissolved in the core and/or adsorbed onto the polymer wall. ${ }^{214}$ 
Table 4 SLNs for control of microbial biofilms

\begin{tabular}{|c|c|c|c|c|c|}
\hline Formulation & $\begin{array}{l}\text { Active } \\
\text { ingredients }\end{array}$ & $\begin{array}{l}\text { Applications of nanostructured } \\
\text { formulations }\end{array}$ & Composition & Pathogen & Ref \\
\hline CA-SLN & $\begin{array}{l}\text { Cefuroxime } \\
\text { axetil }\end{array}$ & $\begin{array}{l}\text { Improve inhibitory activity against } \\
\text { Staphylococcus aureus biofilm }\end{array}$ & Stearic acid and tristearin & S. aureus & 210 \\
\hline QSI-SLN & $\begin{array}{l}\text { Quorum sensing } \\
\text { inhibitor }\end{array}$ & $\begin{array}{l}\text { Improve the pulmonary delivery of } \\
\text { novel quorum sensing inhibitors }\end{array}$ & $\begin{array}{l}\text { Glyceryl palmitostearate, } \\
\text { glyceryl behenate, and tristearin }\end{array}$ & $\begin{array}{l}\text { Pseudomonas } \\
\text { aeruginosa }\end{array}$ & 211 \\
\hline FA-SLN & Fatty acids & $\begin{array}{l}\text { Coatings with nontoxic chemistries } \\
\text { that act against bacteria by multiple } \\
\text { mechanisms at the nanoscale }\end{array}$ & $\begin{array}{l}\text { Stearic acid, lauric acid, and } \\
\text { oleic acid }\end{array}$ & P. aeruginosa & 212 \\
\hline
\end{tabular}

Abbreviations: SLN, solid lipid nanoparticle; CA, cefuroxime axetil; QSI, quorum sensing inhibitor; FA, fatty acid; Ref, reference.

PNs have some advantages over other nanoparticulate systems. These include high stability in the body, long storage stability, and increased biocompatibility and biodegradability. These features allow the development of nanosystems with different degradation times and controlled drug release. The main polymers include polycaprolactone, poly lactic-coglycolic acid (PLGA), polylactic acid, and chitosan (CS), a polysaccharide of natural origin that has been widely used due to its biodegradability and mucoadhesive capacity. ${ }^{215,216}$ The disadvantages of nanoparticles in relation to PNs could be attributed to the possible toxicity of the biodegradation products and a higher cost compared to other nanostructured systems, depending on the material and process used for the development of the nanosystem. ${ }^{217}$ Figure 7 schematizes the PNs structure for drug delivery.

Numerous reports in the literature cite the utilization of PNs for controlled drug release and as a vector for a wide range of diseases; however, with the advent of bacterial resistance to antibiotics and the recent reports on the biofilm production, the data involving the use of PNs against biofilms are still scarce.

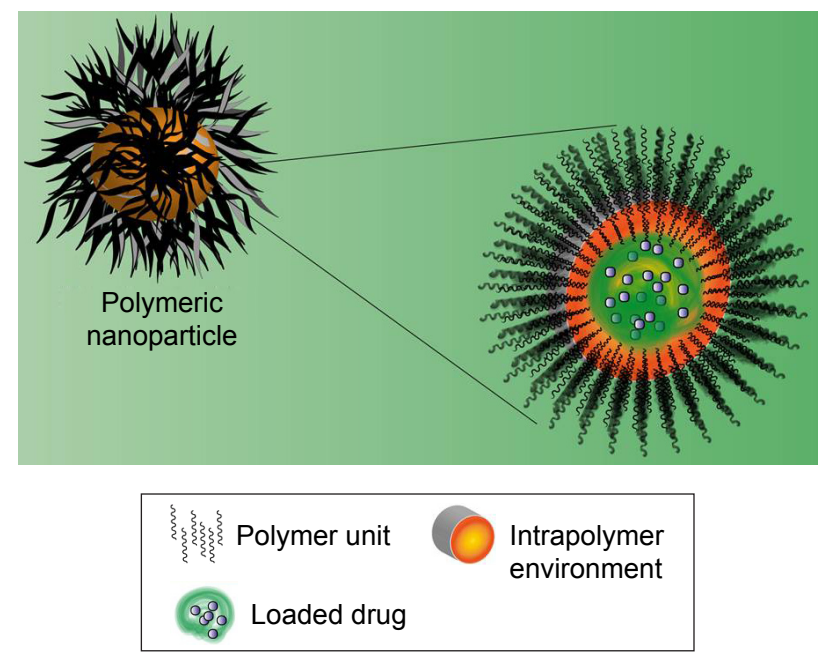

Figure 7 Polymeric nanoparticles structure for drug delivery.
Da Silva et $\mathrm{a}^{218}$ evaluated the biofilm formation in the sealant-dentin interface when treated with phosphorylated chitosan (PHCS) and chitosan connected to Rose Bengal (CSRB), which is a photo sensitizer. A combination of PHCS and CSRB (RBPH), and CS nanoparticles was incorporated into the sealant (zinc oxide-eugenol) used to explore the benefits of applying CS in endodontics. The roots of bovine teeth were used because they are physiologically and histologically very similar to human teeth and facilitate the application of the treatments due to their size. Biofilm formation was induced by applying E. faecalis and subsequent subjection to PHCS, CSRB, RBPH, and CS nanoparticles embedded in the sealant. The group submitted to CS nanoparticles incorporated into the sealant displayed a lower tendency of biofilm formation, demonstrating antimicrobial action; this action was probably due to the electrostatic interaction between the bacterial components and CS that resulted in the destabilization of the bacterial wall. However, CS nanoparticles have a positive surface charge that influences their interaction with the negatively charged dentin; this interaction hinders the adhesion of bacteria onto the tooth tissue, thereby preventing biofilm formation. Biofilm growth was also inhibited within the sealer-dentin interface when treated with PHCS, but there was a moderate inhibition when treated with CSBH followed by photodynamic therapy.

Abdelghany et $\mathrm{al}^{219}$ developed a strategy to increase GEN retention in PLGA nanoparticles to verify the effectiveness of these nanoparticles in controlled drug release in vitro and in vivo against infection by $P$. aeruginosa. Two methodologies were employed to obtain the PNs: water-inoil-in-water method (w/o/w) and solid-in-oil-in-water method $(\mathrm{s} / \mathrm{o} / \mathrm{w})$. Nanoparticles generated by the w/o/w method had a size up to $251 \mathrm{~nm}$, encapsulating $6.4 \mu \mathrm{g}$ of GEN per milligram of PLGA. The authors reported that an alteration of the $\mathrm{pH}$ of the aqueous phase from 5.0 to 7.4 resulted in an increase of about three times in the drug-entrapping rate of PLGA nanoparticles, without significantly changing the 
particles diameter. An increased entrapment rate was also observed for the particles generated by s/o/w method when changing the aqueous phase $\mathrm{pH}$ from 5.0 to 7.4 , yielding particles of $359 \mathrm{~nm}$ size. The release profile was similar for nanparticles obtained by both methodologies at $\mathrm{pH} 7.4$ with a $50 \%$ release in $24 \mathrm{~h}$ and a slower and continuous release for 16 days. For the nanoparticles obtained at $\mathrm{pH} 5.0$, an initial release of only $25 \%$ was observed after 24 h; however, after 7 days of release, the released drug concentration was similar to the nanoparticles prepared at $\mathrm{pH}$ 7.4. These differences in the release profiles resulted from the differences in the drug distribution in the polymeric network and core of the nanoparticles. With respect to bacterial growth in planktonic form, an MIC of 1.5 and $3.0 \mathrm{mg} / \mathrm{mL}$ for free and nanocoated GEN was observed, respectively, although free GEN in the planktonic form led to a more efficient inhibition of bacterial growth as compared to the nanocoated drug (on observing the GEN activity on preformed biofilm of $P$. aeruginosa). This offered an improved, efficient, and greater inhibition compared to the free drug, probably due to the slow and controlled release. In the in vivo studies, $96 \mathrm{~h}$ after the infection, the animals treated with nanoparticles exhibited a significant reduction in bacterial CFU compared to the untreated controls. Further, a significant decrease was also observed in interleukin-6 (an inflammatory mediator), indicating the severity of the injury in animals treated with polymeric PLGA nanoparticles. According to the authors, nanoparticles and microparticles harbor the potential to be utilized in aerosol delivery and may increase the therapeutic efficacy of GEN and other aminoglycosides for the treatment of lung infections.

Cai et $\mathrm{al}^{220}$ developed lipid polymer nanoparticles (LPNs) in order to carry amoxicillin (AMOXIL) to enhance antimicrobial efficacy against planktonic and biofilm forms of H. pylori. According to the authors, the outer lipid bilayer of the PNs can merge easily into the polysaccharide matrix (main component of the biofilm) and then destroy this protective layer of bacterial microenvironment, leading AMOXIL directly through the free bacterial cells. The core of the PNs consists of pectin sulfate (PEC) and mixed lipids including rhamnolipids and phospholipids. The PEC inhibited $H$. pylori by competing with target cells, and the presence of rhamnolipids and phospholipids contributed to a second antibacterial activity due to their anti-adhesive properties, making the biofilm formation difficult. All LPNs displayed a size range from 147 to $243 \mathrm{~nm}$, and AMOXILl encapsulation efficiency rate was $93.6 \%-96.7 \%$. In the antibacterial activity tests, approximately $53 \%$ of live bacteria were observed in planktonic form, with no significant difference between the two treatments; however, in the assays involving biofilm, $90.2 \%$ of live bacteria were observed when treated with free AMOXIL, and when treated with LPNs, the bacterial viability dropped to a range of $18.6 \%-32.6 \%$, indicating that the LPNs have a superior effect to the conventional antibiotic treatment. Fluorescence tests indicated that bacteria treated with LPNs were not able to invade AGS cells, whereas approximately $100 \%$ of AGS cells were invaded and lysed in the presence of free AMOXIL, showing that LPNs may be a promising strategy for tissue protection against $H$. pylori and a tool against the formation of bacterial biofilms.

Takahashi et $\mathrm{al}^{221}$ developed and evaluated the antimicrobial potential of PLGA-PNs and chitosan-associated PLGA (CS-PLGA)-PNs carrying CAM in biofilms of $S$. epidermidis using the field emission-scanning electron microscopy (FE-SEM) technique. The PNs were prepared by emulsification-solvent diffusion method with a diameter of 252-416.5 $\mathrm{nm}$ and a ZP between $-15.2 \pm 0.6$ and $19.9 \pm 1.7 \mathrm{mV}$. The ZP of PLGA-PNs remained negative due to dissociation of the carboxyl group of PLGA in water, whereas the ZP of CS-PLGA-PNs remained positive due to the protonation of the amino group of CS. In trials conducted to evaluate the antimicrobial potential of nanoparticles on biofilms, the highest antimicrobial potential was exhibited by the PLGA-PNs carrying CAM with $62 \%$ of dead bacteria. Confocal laser scanning microscopy (CLSM) demonstrated that biofilms treated with PLGA-PNs carrying CAM displayed pores, showing an antimicrobial activity on their polysaccharide matrix. The images obtained by FE-SEM depicted that biofilms treated with CS-PLGA-PNs consisted of small pores in the polysaccharide matrix with no bacterial killing. However, the images of biofilms treated with PLGA-PNs carrying CAM exhibited a highly eroded and disturbed matrix with large pores. In addition, a decrease in the thickness of the biofilms was observed, indicating the bacterial death. The authors concluded that PNs made of PLGA may serve as effective carriers of CAM in anti-biofilm treatment. They suggested that FE-SEM could be a useful technique to obtain important information, thereby allowing the development and improvement of strategies in the medical area.

Table 5 summarizes the results of several studies related to the application of PNs most used for control of microbial biofilms.

\section{Metallic nanoparticles}

MNPs are metallic particles with one or more dimensions (length, width, and thickness) in the range of 1-100 nm. Faraday ${ }^{222}$ recognized for the first time the presence of MNPs in solution, and Gustav Mie in 1908 gave a quantitative 
Table 5 PNs for control of microbial biofilms

\begin{tabular}{|c|c|c|c|c|c|}
\hline Formulation & $\begin{array}{l}\text { Active } \\
\text { ingredients }\end{array}$ & $\begin{array}{l}\text { Applications of } \\
\text { nanostructured formulations }\end{array}$ & Composition & Pathogen & Ref \\
\hline CS-PNs & $\begin{array}{l}\text { Zinc oxide- } \\
\text { eugenol }\end{array}$ & $\begin{array}{l}\text { Explore the benefits of applying } \\
\text { chitosan in endodontics }\end{array}$ & Chitosan & $\begin{array}{l}\text { Enterococcus } \\
\text { faecalis }\end{array}$ & 218 \\
\hline PLGA-PNs & Gentamicin & Increase the half-life of the drug & Poly lactic-co-glycolic acid & $\begin{array}{l}\text { Pseudomonas } \\
\text { aeruginosa }\end{array}$ & 219 \\
\hline PEC-LPNs & Amoxicillin & $\begin{array}{l}\text { Enhance the antimicrobial } \\
\text { efficacy against planktonic and } \\
\text { biofilm forms }\end{array}$ & $\begin{array}{l}\text { Pectin sulfate and mixed } \\
\text { lipids containing rhamnolipids } \\
\text { and phospholipids }\end{array}$ & $\begin{array}{l}\text { Helicobacter } \\
\text { pylori }\end{array}$ & 220 \\
\hline PLGA-PNs & NA & $\begin{array}{l}\text { Determine the antibacterial } \\
\text { activity of NPs on the biofilm }\end{array}$ & Poly(DL-lactide-co-glycolide) & $\begin{array}{l}\text { Staphylococcus } \\
\text { epidermidis }\end{array}$ & 221 \\
\hline CS-PLGA-PNs & NA & $\begin{array}{l}\text { Determine the antibacterial } \\
\text { activity of NPs on the biofilm }\end{array}$ & $\begin{array}{l}\text { Poly(DL-lactide-co-glycolide) } \\
\text { and chitosan }\end{array}$ & S. epidermidis & 221 \\
\hline CAM-PLGA-PNs & Clarithromycin & $\begin{array}{l}\text { Determine the antibacterial } \\
\text { activity of NPs on the biofilm }\end{array}$ & Poly(DL-lactide-co-glycolide) & S. epidermidis & 221 \\
\hline
\end{tabular}

Abbreviations: PN, polymeric nanoparticle; CS, chitosan; PLGA, poly lactic-co-glycolic acid; PEC, pectin sulfate; LPN, lipid polymer nanoparticle; NP, nanoparticle; CAM, clarithromycin; Ref, reference; NA, not applicable.

explanation of their color. ${ }^{223}$ The principal characteristics of MNPs are large surface area-to-volume ratio as compared to their bulk equivalents, large surface energies, the transition between molecular and metallic states providing specific electronic structure (local density of states), plasmon excitation, quantum confinement, short range ordering, increased number of kinks, a large number of low-coordination sites such as corners and edges, a large number of "dangling bonds" and consequently specific chemical properties, and the ability to store excess electrons. ${ }^{224}$

The major bottleneck during experimental synthesis of MNPs is obtaining stable colloidal suspensions, as MNPs have a high surface energy, favoring thermodynamically the aggregation of those ready to form metal-metal bonds. ${ }^{225}$ In order to prevent the aggregation of nanoparticles, the preparation of colloidal systems is generally performed in the presence of agents known as stabilizers that are adsorbed onto the surfaces of the nanoparticles, forming a self-assembled layer, which prevents coalescence. Some of the most effective stabilizers are polymeric, for example, polyvinylpyrrolidone, ${ }^{225}$ polyvinyl alcohol, ${ }^{226}$ and polyacrylic acid, ${ }^{227}$ which possess basic sites of Lewis with high affinity for nanoparticles, and sufficiently long organic chains that create a steric hindrance to prevent interactions among them.

The MNPs have immense potential for several technological applications and are being tremendously investigated for their antimicrobial and antifungal perspective. Zinc, titanium, silver, and gold are some of the most widely studied nanoparticles among several others.

\section{Zinc}

Khan et $\mathrm{al}^{228}$ studied the effect of zinc oxide nanoparticles (ZnO-NPs) on oral cavity bacteria (S. oralis ATCC 35037).
ZnO-NPs were prepared by sol-gel method and were characterized by X-ray diffraction (XRD) and transmission electron microscopy (TEM) that confirmed a polycrystalline wurtzite structure and crystalline polygonal shape, respectively. The particle showed a size distribution of $491 \mathrm{~nm}$ and a $\mathrm{ZP}$ of $16.4 \mathrm{mV}$, as determined by dynamic light scattering (DLS). The oral bacterial population was treated with $\mathrm{ZnO}-\mathrm{NPs}$, and a reduction in total bacterial counts was observed. The authors applied a concentration of $10 \mathrm{mg} / \mathrm{mL}$ of $\mathrm{ZnO}-\mathrm{NPs}$, and the CFU was reduced to be $66 \%$ and $59 \%$ on NA and MRS agar plates, respectively. At $50 \mathrm{mg} / \mathrm{mL}$ concentration, up to $92 \%$ reduction in the bacterial survival was recorded as compared to the untreated controls. However, at $100 \mathrm{mg} / \mathrm{mL}$ level, the ZnO-NPs inhibited the biofilm formation on polystyrene and glass surfaces and acrylic denture.

In another study, Khan et al $^{229}$ also studied the antimicrobial and anti-biofilm potential of ZnO-NPs against the oral bacterial isolates of Rothia dentocariosa (Ora-7) and Rothia mucilaginosa (Ora-16). They used the sol-gel method for obtaining the ZnO-NPs and characterized them by TEM and XRD. The ZnO-NPs showed a smooth-surface polygonal shape with an average size of $35.23 \mathrm{~nm}$. The growthinhibitory activity of ZnO-NPs against $R$. dentocariosa and $R$. mucilaginosa was determined by $\mathrm{IC}_{50}$ to be 53 and $76 \mu \mathrm{g} / \mathrm{mL}$, respectively. The authors coated the artificial teeth and dental prostheses with $R$. dentocariosa and $R$. mucilaginous and conducted a study on the effect of nanoparticles on biofilm formation, and the results showed that $\mathrm{ZnO}$-NPs inhibited the bacterial biofilm formation on the surfaces; the NPs were more effective against Ora-7 at all concentrations tested, while the clove oil was active at a concentration of $10 \mathrm{mg} / \mathrm{mL}$. 
Sangani et $\mathrm{al}^{230}$ synthesized ZnO-NPs by a sol-gel procedure and characterized them by TEM. This method yielded particles with an average size of $20 \mathrm{~nm}$. The study aimed to assess the biofilm formation by 15 clinical isolates and one reference (ATCC 9027) strain of $P$. aeruginosa and the antibacterial activity of ZnO-NPs. The $\mathrm{ZnO}-\mathrm{NPs}$ were tested at different concentrations in the range of $0-400 \mu \mathrm{g} / \mathrm{mL}$, MIC was determined by broth dilution method, and minimum bactericidal concentration (MBC) was also determined. The average MIC and MBC of ZnO-NPs for the 15 isolates were 158 and $325 \mu \mathrm{g} /$ $\mathrm{mL}$, respectively, while those for the reference strain were 150 and $325 \mu \mathrm{g} / \mathrm{mL}$, respectively. The $\mathrm{MIC}_{50}$ and $\mathrm{MIC}_{90}$ of the $\mathrm{ZnO}$ NPs were 150 and $175 \mu \mathrm{g} / \mathrm{mL}$, respectively. The biofilms were formed in 96-well flat-bottom tissue culture plates (TCPs), and the $\mathrm{ZnO}-\mathrm{NPs}$ levels were tested in the range of $50-350 \mu \mathrm{g} / \mathrm{mL}$. The results showed about $75 \%$ and $94 \%$ reduction in the optical densities (ODs) at 250 and $350 \mu \mathrm{g} / \mathrm{mL}$ level, respectively, and the $\mathrm{ZnO}-\mathrm{NPs}$ were able to eliminate preformed biofilm.

Dwivedi et $\mathrm{al}^{231}$ employed a soft chemical/solution process to obtain $\mathrm{ZnO}-\mathrm{NPs}$ and characterized them by TEM, atomic force microscopy, and XRD. The ZnO-NPs showed a smooth surface, spherical shape, and wurtzite phase, and the size was in the range of $10-15 \mathrm{~nm}$. The disk diffusion assay was chosen to evaluate the antibacterial activity against $P$. aeruginosa which showed the best zone inhibition of $16 \mathrm{~mm}$ at $100 \mathrm{mg} / \mathrm{mL}$ of ZnO-NPs. The inhibition of the biofilm formation was also evaluated in this study, and the ZnO-NPs were able to inhibit biofilm formation at the concentrations of 50 and $100 \mu \mathrm{g} / \mathrm{mL}$. The interaction of ZnO-NPs with bacterial solution produces reactive oxygen species (ROS) that is an important factor in the inhibition of biofilm. An increased production of ROS was directly proportional to the increase in antibacterial activity of $\mathrm{ZnO}-\mathrm{NPs}$; therefore, it can be presumed that the mechanism of action is related to the higher production of ROS. This study advocates the potential of ZnO-NPs usage as future nano-antibiotics.

Bacteria can stay in biomaterials such as polymers and consequently form antibiotic-resistant bacterial biofilms. Seil and Webster ${ }^{232}$ studied the effect of incorporation of $\mathrm{ZnO}$ nanoparticles into PVC. The ZnO-NPs of about $60 \mathrm{~nm}$ diameters were procured from Nanophase Technologies and were incorporated into PVC by sonication to facilitate the homogenization. The presence of ZnO-NPs on the PVC surface was confirmed via SEM. In order to evaluate the antimicrobial activity of ZnO-NPs against biofilms of $S$. aureus (ATCC 25923), they treated a PVC membrane with different concentrations of ZnO-NPs ( $0 \%$, 2\%, 10\%, 25\%, and $50 \%, \mathrm{w} / \mathrm{v}$ ) to superimpose coverslips and inoculated
$3 \times 10^{6} \mathrm{CFU}$ on each coverslip. The ODs were recorded after 24 and $72 \mathrm{~h}$ of the inoculation and analyzed by crystal violet staining. The polymer composites containing ZnO-NPs clearly showed a reduction in the number of total bacterial count as compared to those without ZnO-NPs (control). A reduction of $24 \%$ and $28 \%$ in the biofilm formation by the composite containing ZnO-NPs at $25 \%$ and $50 \%$ (w/v) concentration was observed, respectively, over the control. The crystal violet staining analysis showed about $55 \%$ reduction in the biofilm formation on the surface of the composites containing different concentrations of ZnO-NPs against the control. The difference in the reduction in biofilm formation at the different concentrations of polymer ZnO-NPs composites was not significant $(P<0.05)$.

Lee et $\mathrm{al}^{233}$ studied the anti-biofilm activity of $\mathrm{Zn}^{2+}$ and/or ZnO-NPs against $P$. aeruginosa PAO1, E. coli O157:H7 (ATCC 43895), and a methicillin-sensitive S. aureus (MSSA; ATCC 6538) and a methicillin-resistant S. aureus (MRSA; ATCC BA-1707) strain. The test biofilm was formed on polystyrene plates in accordance with Pratt and Kolter. ${ }^{234}$ The formation of $P$. aeruginosa biofilm on polystyrene surfaces was inhibited by $\mathrm{ZnCl}_{2}$ and $\mathrm{Zn}\left(\mathrm{NO}_{3}\right)_{2}$ in a dose-dependent manner, while $\mathrm{ZnO}(1 \mathrm{mM}$; average diameter $50 \mathrm{~nm}$ ) reduced biofilm formation by $95 \%$. $\mathrm{ZnCl}_{2}$ and $\mathrm{ZnO}$ also actively inhibited the biofilm formation on a glass surface. $\mathrm{ZnO}$ at $5 \mathrm{mM}$ level was able to inhibit the biofilm formation of E. coli $\mathrm{O} 157: \mathrm{H} 7$, MSSA (ATCC 6538), and MRSA (ATCC BA-1707).

Table 6 summarizes the results of several studies related to the application of ZnO-NPs most used for control of microbial biofilms.

Table 6 Zinc and ZnO-NPs for control of microbial biofilms

\begin{tabular}{|c|c|c|c|c|}
\hline Formulation & $\begin{array}{l}\text { Active } \\
\text { ingredients }\end{array}$ & $\begin{array}{l}\text { Method of } \\
\text { preparation }\end{array}$ & Pathogen & Ref \\
\hline ZnO-NPs-So & Zinc oxide & Sol-gel & Streptococcus oralis & 228 \\
\hline ZnO-NPs-Rd & Zinc oxide & Sol-gel & $\begin{array}{l}\text { Rothia dentocariosa } \\
\text { and Rothia } \\
\text { mucilaginosa }\end{array}$ & 229 \\
\hline $\mathrm{ZnO}-\mathrm{NPs}-\mathrm{Pa}$ & Zinc oxide & Sol-gel & $\begin{array}{l}\text { Pseudomonas } \\
\text { aeruginosa }\end{array}$ & 230 \\
\hline ZnO-NPs-Pasc & Zinc oxide & $\begin{array}{l}\text { Soft chemical/ } \\
\text { solution process }\end{array}$ & P. aeruginosa & 231 \\
\hline $\mathrm{ZnO}-\mathrm{PVC}-\mathrm{NPs}$ & Zinc oxide & Nanophage & $\begin{array}{l}\text { Staphylococcus } \\
\text { aureus }\end{array}$ & 232 \\
\hline ZnO-NPs-Ec & Zinc oxide & NM & $\begin{array}{l}\text { P. aeruginosa, } \\
\text { Escherichia coli, } \\
\text { and S. aureus }\end{array}$ & 233 \\
\hline
\end{tabular}

Abbreviations: $\mathrm{ZnO}$, zinc oxide; NPs, nanoparticles; PVC, polyvinyl chloride; NM, not mentioned; Ref, reference; Sol-gel, chemical process used for the synthesis of a colloidal suspension; So, Streptococcus oralis; Rd, Rothia dentocariosa; Pa, Pseudomonas aeruginosa; Pasc, Pseudomonas aeruginosa-soft chemical; Ec, Escherichia coli. 


\section{Titanium}

Haghighi et $\mathrm{al}^{235}$ evaluated the application of titanium dioxide nanoparticles $\left(\mathrm{TiO}_{2}\right.$-NPs) and ethylene diamine tetra acetic acid (EDTA) as an antifungal agent against $C$. albicans biofilms. Titanium tetrachloride $\left(\mathrm{TiCl}_{4}\right)$ was used as a precursor in $\mathrm{TiO}_{2}-\mathrm{NPs}$ synthesis. The $\mathrm{TiO}_{2}$-NPs were further characterized for their shape and size using SEM and the type of crystalline structure using XRD. Fluconazole-sensitive (ATCC 10231) and fluconazole-resistant (ATCC 76615) reference strains of $C$. albicans were used to form biofilms. $\mathrm{TiO}_{2}$-NPs and EDTA were tested in the range of 4-8 and $6.5-15 \mu \mathrm{g} / \mathrm{mL}$, respectively, and fluconazole was used as a control. The antifungal activity of the samples was estimated via XTT reduction and ATP bioluminescence assays. The results obtained from both the methods showed that the biofilms of a fluconazole-sensitive strain of $C$. albicans were inhibited by $\mathrm{TiO}_{2}-\mathrm{NPs}(5.14 \mu \mathrm{g} / \mathrm{mL})$, EDTA $(8.09 \mu \mathrm{g} / \mathrm{mL})$, and fluconazole $(4 \mu \mathrm{g} / \mathrm{mL})$. The fluconazole-resistant strain required relatively higher concentrations of these agents, that is, 5.35, 11.33, and $8 \mu \mathrm{g} / \mathrm{mL}$, respectively $(P<0.05)$. The authors proposed that the antifungal activity of $\mathrm{TiO}_{2}-\mathrm{NPs}$ is probably associated with the intracellular ROS produced by them leading to cell death by altering normal respiratory activity. In order to explain the antifungal activity of EDTA, different theories such as the inhibition of filamentation process or chelation of some constituents essential to biofilm matrix have been proposed. These findings were further verified by both XTT and ATPase assays which showed the same outcomes, and these can also be a good choice to evaluate the anti-biofilm activity of $\mathrm{TiO}_{2}$-NPs.

Ibrahem et $\mathrm{al}^{236}$ carried out the biosynthesis of titanium nanoparticles (TiNPs) using vaginal Lactobacillus crispatus isolated from healthy Iraqi women. The nanoparticles were evaluated for their antibacterial and anti-adhesive properties against $E$. coli, $K$. pneumoniae, Morganella morganii, A. baumannii, and $S$. aureus isolated from urine samples of the Iraqi women exposed to recurrent urinary infection. The antibacterial activity was evaluated using microdilution method, and the sample concentration ranged from 4 to $128 \mathrm{mg} / \mathrm{mL}$. The effect of these nanoparticles on bacterial biofilm was tested using Congo Red agar and tube method, and the anti-adhesive property was tested by TCP method. The TiNPs exhibited anti-adhesive activity against all clinical isolates (except for E. coli), and the highest and lowest efficiency were recorded against M. morganii (48\%) and A. baumannii (6\%), respectively. Tube test method also showed similar results related to the inhibitory effect on biofilm formation, as TiNPs were effective against all strains except $E$. coli. The Congo Red agar method showed the presence of pink or pale gray colonies of $K$. pneumoniae, M. morganii, and $S$. aureus representing a reduced slime production by these strains; however, they typically formed black colonies in this specific medium. The black colonies formed by other strains indicated that the TiNP treatment did not alter the slime-producing property. The authors concluded that TiNPs can be considered as a promising antibacterial agent in the treatment of UTIs as they are cost effective, nontoxic, and ecofriendly.

Maurer-Jones et $\mathrm{al}^{237}$ evaluated several types of $\mathrm{TiO}_{2}-$ NPs including acid-catalyzed $\mathrm{TiO}_{2}$-NPs synthesized in house, and Evonik Aeroxide Degussa P25 and Eusolex T-Eco (both commercially available) for their competence to inhibit Shewanella oneidensis biofilm using quartz crystal microbalance and riboflavin secretion by high-performance liquid chromatography. When compared to the controls, no differences were observed in the strain viability after an exposure to various concentrations of the three types of $\mathrm{TiO}_{2}$, but when exposed to all samples of $\mathrm{TiO}_{2}$ some sort of dose-dependent decline in the growth of strain could be observed. The changes were observed in the mass added to the crystal in order to form biofilm and viscoelastic properties irrespective of $\mathrm{TiO}_{2}-\mathrm{NP}$ exposure to the strains, although this alteration did not confer any resistance property. When the strain was exposed to high concentrations of $\mathrm{TiO}_{2}$ (all samples), an unexpected increase in riboflavin secretion was recorded. Riboflavin is a direct way to measure the bacterial growth, as it results from the molecule flavin mononucleotide, normally secreted by $S$. oneidensis. The authors suggested that these changes could not be considered a consequence of oxidative stress, but the altered gene expression in the bacteria due to $\mathrm{TiO}_{2}-\mathrm{NPs}$ exposure may lead to subtle changes in the bacterial function.

Table 7 summarizes the results of several studies related to the application of TiNPs and $\mathrm{TiO}_{2}-\mathrm{NPs}$ most used for control of microbial biofilms.

\section{Silver}

Namasivayam et al ${ }^{238}$ analyzed the anti-biofilm property of catheters coated with AgNPs against clinical isolates of S. aureus. AgNPs synthesized by Azadirachta indica leaf extract were applied to a catheter and were characterized by SEM, which showed the complete dispersion of the uniform spherical nanoparticles of 50-60 nm size on the surface of the catheter fiber. A differential effect on biofilm inhibition was observed in the catheter coated with nanoparticles, and the highest inhibition was observed after $72 \mathrm{~h}$ of incubation. 
Table 7 TiNPs and $\mathrm{TiO}_{2}-\mathrm{NPs}$ for control of microbial biofilms

\begin{tabular}{|c|c|c|c|c|}
\hline Formulation & Active ingredients & Method of preparation & Pathogen & Ref \\
\hline $\mathrm{TiO}_{2}-\mathrm{NPs}-\mathrm{Ca}$ & Titanium dioxide & $\begin{array}{l}\text { Hydrolysis of titanium } \\
\text { tetrachloride precursor }\end{array}$ & Candida albicans & 235 \\
\hline TiNPs & Titanium & $\begin{array}{l}\text { Biosynthesis of titanium } \\
\text { nanoparticles using vaginal } \\
\text { Lactobacillus crispatus }\end{array}$ & $\begin{array}{l}\text { L. crispatus, Escherichia coli, Klebsiella } \\
\text { pneumoniae, Morganella morganii, Acinetobacter } \\
\text { baumannii, and Staphylococcus aureus }\end{array}$ & 236 \\
\hline $\mathrm{TiO}_{2}-\mathrm{NPs}$ as-syn & Titanium dioxide & Acid-catalyzed & Shewanella oneidensis & 237 \\
\hline $\mathrm{TiO}_{2}-\mathrm{NPs} \mathrm{P} 25$ & Titanium dioxide & Acid-catalyzed & S. oneidensis & 237 \\
\hline $\mathrm{TiO}_{2}-\mathrm{NPs} \mathrm{T}-\mathrm{EcO}$ & Titanium dioxide & Acid-catalyzed & S. oneidensis & 237 \\
\hline
\end{tabular}

Abbreviations: TiNPs, titanium nanoparticles; $\mathrm{TiO}_{2}-\mathrm{NPs}$, titanium dioxide nanoparticles; $\mathrm{TiO}_{2}-\mathrm{NPs}_{-}-\mathrm{Ca}$, titanium dioxide nanoparticles against $\mathrm{Candida}$ albicans; $\mathrm{TiO}{ }_{2}-\mathrm{NPs}_{3}$ assyn, acid-catalyzed titanium dioxide nanoparticles synthesized in house; $\mathrm{TiO}_{2}-\mathrm{NPs}$ P25, acid-catalyzed titanium dioxide nanoparticles synthesized in Evonik Aeroxide Degussa $\mathrm{P} 25 ; \mathrm{TiO}_{2}-\mathrm{NPs} \mathrm{T}-\mathrm{Eco}$, acid-catalyzed titanium dioxide nanoparticles synthesized in Eusolex T-Eco; Ref, reference.

In the biochemical composition, the total number of carbohydrates and the biofilm matrix proteins were greatly reduced. This study could be insightful toward the development of medical devices coated with antimicrobials against pathogenic microorganisms.

Park et $\mathrm{al}^{239}$ analyzed the antimicrobial activity of AgNPs against PA01 planktonic bacteria and biofilm of $P$. aeruginosa, and the activity was compared with that of silver ions. The inactivation of biofilms by AgNPs was very sensitive to stirring, which caused a high AgNP bio-absorption. Although AgNPs activity against planktonic cells was approximately $10 \%$ of the activity of the silver ions, their activity against biofilm cells was comparable to that of the silver ions at the same concentration, after 90 min of agitation (about $3.5 \mathrm{log}$ inactivation of biofilm cells). This study pointed out that AgNPs inactivate biofilms by bio-absorption; however, the same did not occur with the ionic silver as such.

Martinez-Gutierrez et $\mathrm{al}^{240}$ explained how biofilms protect pathogenic organisms from adverse environmental conditions and can be reservoirs and sources of disease outbreaks, especially in medical equipment. The major objective of their study was to evaluate the anti-biofilm activity of AgNPs against various microorganisms of clinical interest. The antimicrobial activity of AgNPs was tested in biofilms obtained under static conditions and high fluid shear conditions in a bioreactor. After exposure to $100 \mathrm{mg} / \mathrm{mL}$ AgNPs, a $4 \mathrm{log}$ reduction was recorded in the CFU of $P$. aeruginosa under turbulent fluid conditions in a biofilm reactor. The antibacterial activity of AgNPs against various microbial strains grown in polycarbonate membranes was well documented. It was concluded that AgNPs effectively prevent the formation of biofilms and also kill the bacteria in established biofilms, suggesting the potential role of AgNPs in the prevention and treatment of biofilm-related infections. The AgNPs at $250 \mathrm{mg} / \mathrm{mL}$ or a higher concentration were able to inhibit bacterial growth without using any antibiotics; this indicates the behavior of AgNPs as an antimicrobial agent and as a potential modifier of the bacterial cell wall. However, further research is still required to utilize AgNPs for preventive and therapeutic strategies.

The work of Gurunathan et $\mathrm{al}^{241}$ focused on the application of AgNPs as antibacterial, antifungal, antiviral, antiinflammatory, and anti-angiogenic agents due to their unique biological, physical, and chemical properties. The study aimed to investigate the antibacterial and anti-biofilm activity of isolated AgNPs alone or in combination with conventional antibiotics against various human pathogenic bacteria. The authors showed a reliable, simple, cost-efficient, and natural synthesis of AgNPs by treating silver ions with Allophylus cobbe leaf extract. The AgNPs synthesis was characterized by UV-Vis absorption spectroscopy, XRD, Fourier transform infrared spectroscopy (FTIR), X-ray photoelectron spectroscopy (XPS), DLS, and TEM. Further, the antibiotic, antibacterial, and anti-biofilm activity of AgNPs or AgNPs combined with an antibiotic was evaluated using a series of tests such as in vitro, disk diffusion, biofilm inhibition, and generation of ROS against $P$. aeruginosa, Shigella flexneri, S. aureus, and Streptococcus pneumoniae. A significant antimicrobial and anti-biofilm activity was observed with antibiotics in combination, with the lowest dose of AgNPs using the plant extract of $A$. cobbe, and in other cases sublethal doses of antibiotics. A significant synergistic effect was observed for ampicillin and vancomycin against Gram-negative and Gram-positive bacteria, respectively. The study proposed that the biogenic AgNPs in combination with antibiotics can be used for the treatment of infectious bacterial diseases. This study also showed evidence of antibacterial and antibiofilm properties of AgNPs facilitated by A. cobbe and their resilience against various human pathogenic bacteria, which advocate the use of AgNPs as coadjutants for the treatment of infectious diseases.

Kalishwaralal et $\mathrm{al}^{242}$ proposed that biofilms are formed by the bacteria that attach to the surface and aggregate to form a hydrated polymeric matrix. The formation of these sessile 
colonies and their inbuilt resistance to antimicrobial agents are a cause of many important and chronic bacterial infections. Such biofilms play a key role in the development of infectious eye disease in humans such as microbial keratitis. Various approaches have been attempted to avert infections related to biofilms in health institutes. These methods have their own limitations such as chemical barriers, emerging antibiotics-resistant strains, and so on. AgNPs are well known for their antimicrobial activity; therefore, in this study, biologically synthesized AgNPs showed an anti-biofilm activity, which was tested in vitro on biofilms formed by $P$. aeruginosa and $S$. epidermidis after $24 \mathrm{~h}$ of treatment. The treatment resulted in more than $95 \%$ inhibition of biofilm formation, and it was uniform in the test species. This study recommends the future application of AgNPs in the treatment of microbial keratitis owing to their anti-biofilm potential.

Monteiro et $\mathrm{al}^{243}$ investigated the effect of AgNPs on the susceptibility of biofilm development in C. albicans and $C$. glabrata during middle and maturation stages. The AgNP suspensions ( $5 \mathrm{~nm}$ ) were synthesized by reducing silver nitrate with sodium citrate solution and were used to treat biofilms of Candida developed after 5, 12 (intermediary phase), and $48 \mathrm{~h}$ (maturation phase) of growth on acrylic surfaces. Their efficacy was determined by measuring total biomass (using crystal violet staining) and the number of CFU. The AgNPs caused a significant decline in the total biomass and the number of CFU of Candida biofilms, ranging from $23 \%$ to $51.5 \%$ and 0.63 to $1.59 \log _{10}\left(\mathrm{CFU} / \mathrm{cm}^{2}\right)$, respectively. Thereafter, no significant differences were recorded in the total biomass of biofilm on exposure to AgNPs at different developmental stages ( 24 or 48 h). However, the number of CFU after 24 and $48 \mathrm{~h}$ of exposure of the biofilm to AgNPs was significantly different only in C. albicans strain 324LA/94. Generally, the developmental phases (transitional as well as maturation) do not affect the susceptibility of biofilms of $C$. albicans and C. glabrata to AgNPs. These findings are fundamental to the adoption of new therapies to prevent denture stomatitis. In the future, these nanoparticles can be incorporated into denture base resins in a safer way or may be used as a dental decontamination solution for the elderly people, especially in developing countries.

Qin et $\mathrm{al}^{244}$ examined the prevention of periprosthetic infection via biofilm inhibition by AgNPs $(20 \mathrm{~nm})$ produced in situ and fixed on a titanium surface by silver plasma immersion ion implantation. The surface was characterized by FE-SEM and XPS. Spherical nanoparticles were homogeneously distributed on the titanium surface, and an increase in the immersion time led to an increase in the average diameter and distribution of the metallic AgNPs. The AgNPs immobilized on the titanium surface did not show any cytotoxicity against MC3T3-E1 cell line. The immobilized metallic silver particles were tested against biofilms of S. epidermidis (ATCC 35984) on the surface and analyzed by crystal violet staining, spread plate method, CLSM, and SEM, and the results showed an in vitro decrease in biofilm formation via inhibition of bacterial adhesion.

Table 8 summarizes the results of several studies related to the application of AgNPs most used for control of microbial biofilms.

\section{Gold}

Khan et $\mathrm{al}^{245}$ explored gold nanoparticles (AuNPs) to enhance the efficacy of photodynamic therapy by methylene blue against resistant $C$. albicans and biofilm formation. The AuNPs and AuNP-methylene blue conjugates were characterized by physicochemical methods such as XRD, UV-Vis absorption spectrophotometry, cross-correlation of photons, FTIR, fluorescence spectroscopy, and electron microscopy.

Table 8 AgNPs for control of microbial biofilms

\begin{tabular}{|c|c|c|c|c|}
\hline Formulation & $\begin{array}{l}\text { Active } \\
\text { ingredients }\end{array}$ & Method of preparation & Pathogen & Ref \\
\hline $\mathrm{AgNPs}$ & Silver & Synthesized by Azadirachta indica leaf extract & Staphylococcus aureus & 238 \\
\hline AgNPs-PA & Silver & $\begin{array}{l}\text { Purchased from ABC Nanotech Co. } \\
\text { (STU2060I I; Daejeon, South Korea) }\end{array}$ & $\begin{array}{l}\text { PA0I planktonic bacteria and Pseudomonas } \\
\text { aeruginosa }\end{array}$ & 239 \\
\hline$A g N P s-A b$ & Silver & Reduction of silver nitrate & $\begin{array}{l}\text { Acinetobacter baumannii, P. aeruginosa, S. aureus, } \\
\text { Streptococcus mutans, and Candida albicans }\end{array}$ & 240 \\
\hline AgNPs-SP & Silver & $\begin{array}{l}\text { Bioreduction of silver nitrate with Allophylus } \\
\text { cobbe leaves }\end{array}$ & $\begin{array}{l}\text { P. aeruginosa, Shigella flexneri, S. aureus, and } \\
\text { Streptococcus pneumoniae }\end{array}$ & 241 \\
\hline $\mathrm{AgNPs}-\mathrm{Se}$ & Silver & $\begin{array}{l}\text { Reduction of silver nitrate with Bacillus } \\
\text { licheniformis biomass }\end{array}$ & P. aeruginosa and Staphylococcus epidermidis & 242 \\
\hline $\mathrm{AgNPs}-\mathrm{Ca}$ & Silver & Reduction of silver nitrate with sodium citrate & C. albicans and Candida glabrata & 243 \\
\hline AgNPs-Ti & Silver & NM & S. epidermidis & 244 \\
\hline
\end{tabular}

Abbreviations: AgNPs, silver nanoparticles; AgNPs-PA, AgNPs to Pseudomonas aeruginosa; AgNPs-Ab, AgNPs to Acinetobacter baumannii; AgNPs-SP, AgNPs to Streptococcus pneumonia; AgNPs-Se, AgNPs to Staphylococcus epidermidis; AgNPs-Ca, AgNPs to Candida albicans; AgNPs-Ti, AgNPs immobilized on titanium; NM, not mentioned; Ref, reference. 
The properties of the conjugates were elucidated by several methods such as anti-biofilm testing, laser scanning, confocal, and electron microscopy. The microscopic analysis showed a significant reduction in biofilm formation as well as the activity of $C$. albicans in the presence of conjugates. Fluoro-spectroscopic analyses confirmed type I phototoxicity against the biofilms. These findings indicate that the conjugated AuNPs generated by photodynamic treatment of methylene blue can be used for the control of acquired nosocomial infection and inhibit the formation of biofilm by $C$. albicans.

AuNPs $(10 \mathrm{~nm})$ were prepared to store and release nitric oxide (NO) by the activation of their surfaces with functional polymers modified with NO donor molecules. ${ }^{246}$ Initially, the copolymer chains consisting of poly (methyl methacrylate oligo-ethylene glycol ether) and poly (benzyl vinyl chloride) were synthesized via reversible addition fragmentation chain transfer polymerization. The chlorine functional groups reacted with cyclohexylamine to introduce secondary amine groups in the copolymer chains. The surface of AuNPs was coated with the copolymers by exploiting the affinity of the terminal group for gold to reach a thickness of $0.6 \mathrm{~nm}$. The secondary amine functional groups were converted to $\mathrm{N}$-diazenium diolate, NO donor molecules, at high pressure (5 atm). The AuNPs carrying NO were further characterized by TEM, DLS, thermal gravimetric analysis, and XPS. The nanoparticles showed the slow release of NO in biological media. TEM showed an enhancement in the stability of nanoparticles, while DLS confirmed an improved particle size and hydrodynamics. The results concluded that NO can be released slowly at $\mathrm{pH}$ 6.8, which can be explored for various applications such as dispersal of $P$. aeruginosa biofilm and destruction of cancer cells.

Boda et $\mathrm{al}^{247}$ addressed the issue of bacterial resistance to drugs, particularly in relation to staphylococci biofilm. The ultrasmall AuNPs were tested for antibacterial activity against two Gram-positive bacteria, $S$. aureus and $S$. epidermidis, and two Gram-negative bacteria, E. coli and $P$. aeruginosa. The AuNPs, with core diameters of $0.8-1.4 \mathrm{~nm}$, showed MIC and $\mathrm{MBC}$ of $25 \times 10^{-6} \mathrm{~m}$ [AU]. The agar disk diffusion test demonstrated higher bactericidal activity of AuNPs and Au. The zone of inhibition showed that $S$. epidermidis was less susceptible to AuNPs than S. aureus, whereas the reverse was true in the case of kanamycin. However, thiol-stabilized AuNPs having a diameter of $1.9 \mathrm{~nm}$ (AuroVist) did not cause significant toxicity in any bacterial strain. The ultrasmall AuNPs caused about $5 \log _{10}$ reductions in bacterial growth in the first $5 \mathrm{~h}$ of exposure and inadequate recovery after $21 \mathrm{~h}$. The biofilm treated with ultrasmall AuNPs showed bubbles and lysis in the bacterial membrane. After $24 \mathrm{~h}$ of the treatment of mature biofilms with $50 \times 10^{-6} \mathrm{~m}$ [AU] of ultrasmall AuNPs, a decrease of $80 \%-90 \%$ was recorded in bacterial cell viability. A study to understand the mechanism of antimicrobial action of ultrasmall AuNPs against Gram-positive bacteria is underway. This study demonstrated the potential activity of ultrasmall AuNPs as an effective therapeutic option against staphylococcal infections.

Sathyanarayanan et $\mathrm{al}^{248}$ explained about the challenges in eliminating the microbial biofilms in implant biomaterials or devices by antibiotics. They observed that exopolymeric substances protect the microorganisms from most of the antibiotics and make the cell immune. The applications of MNPs have now been widely considered to control bacterial infections. Gold and iron oxide nanoparticles are extensively used in various medical applications; however, their potential to eradicate biofilms from biomaterial implants is still under investigation. In a recent study, the growth of $S$. aureus and $P$. aeruginosa biofilm was significantly inhibited at higher concentrations of AuNPs and iron oxide compared to the control.

Table 9 summarizes the results of several studies related to the application of AuNPs most used for control of microbial biofilms.

\section{Final considerations}

The exploration of novel approaches toward the improvement of human life is everlasting, and it is evident that the search for alternatives for the treatment and control of microbial

Table 9 AuNPs for control of microbial biofilms

\begin{tabular}{lllll}
\hline Formulation & Active ingredients & Method of preparation & Pathogen & Ref \\
\hline $\begin{array}{l}\text { AuNP-methylene } \\
\text { AuNP-NO }\end{array}$ & Methylene blue & $\begin{array}{l}\text { Turkevich-Frens method } \\
\text { Reduction of } \mathrm{HAuCl}_{4} \\
\text { with trisodium citrate }\end{array}$ & $\begin{array}{l}\text { Candida albicans } \\
\text { Pseudomonas aeruginosa }\end{array}$ \\
Ultrasmall AuNPs & Gold & NM & Staphylococcus aureus, Staphylococcus \\
epidermidis, Escherichia coli, and P. aeruginosa & 245 \\
AuNPs & Gold & $\begin{array}{l}\text { Reduction of } \mathrm{HAuCl}_{4} \\
\text { with trisodium citrate }\end{array}$ & S. aureus and P. aeruginosa & \\
\hline
\end{tabular}

Abbreviations: AuNPs, gold nanoparticles; NM, not mentioned; Ref, reference. 
diseases associated with biofilms is a complex path. According to the scientific reports presented in this review article, it may be concluded that the application of nanotechnology in drug delivery systems has enormous potential and can be considered as an effective alternative for the treatment of microbial biofilms in the near future. The ability of the nanoparticles to synergize the active molecules for the inhibition of biofilms is a promising characteristic as it allows the use of drugs available in clinical practice in a more efficient manner that guarantees overcoming of the constraints related to the bioavailability of the antimicrobials.

\section{Acknowledgments}

We thank São Paulo Research Foundation - FAPESP (grant \#2014/24626-9 and \#2016/08559-5) and the Scientific Support and Development Program of School of Pharmaceutical Sciences (UNESP). We also thank Reinier Bron for their support with the figures.

\section{Disclosure}

The authors report no conflicts of interest in this work.

\section{References}

1. Leventhal GE, Hill AL, Nowak MA, Bonhoeffer S. Evolution and emergence of infectious diseases in theoretical and real-world networks. Nat Commun. 2015;6:6101.

2. Jones KE, Patel NG, Levy MA, et al. Global trends in emerging infectious diseases. Nature. 2008;451(7181):990-993.

3. Fux CA, Costerton JW, Stewart PS, Stoodley P. Survival strategies of infectious biofilms. Trends Microbiol. 2005;13(1):34-40.

4. Aparna MS, Yadav S. Biofilms: microbes and disease. Braz J Infect Dis. 2008;12(6):526-530.

5. Bjarnsholt $\mathrm{T}$. The role of bacterial biofilms in chronic infections. APMIS. 2013;121(136):1-58

6. Burmølle M, Ren D, Bjarnsholt T, Sørensen SJ. Interactions in multispecies biofilms: do they actually matter? Trends Microbiol. 2014; 22(2):84-91.

7. Costerton JW, Lewandowski Z, Caldwell DE, Korber DR, LappinScott HM. Microbial biofilms. Annu Rev Microbiol. 1995;49:711-745.

8. Flemming HC, Wingender J. The biofilm matrix. Nat Rev Microbiol. 2010;8(9):623-633.

9. Xavier JB, Picioreanu C, Almeida JS, van Loosdrecht MCM. Monitorização e modelação da estrutura de biofilmes [Monitoring and modeling of biofilm structure]. Bol Biotecnol. 2003;76(1):2-13. Portuguese [with English abstract].

10. D’Acunto B, Frunzo L, Klapper I, Mattei MR. Modeling multispecies biofilms including new bacterial species invasion. Math Biosci. 2015; 259:20-26

11. Almeida MAN, De França FP. Biofilm formation on brass coupons exposed to a cooling system of an oil refinery. $J$ Ind Microbiol Biotechnol. 1998;20(1):39-44.

12. Percival SL, Knapp JS, Edyvean RGJ, Wales DS. Biofilms, mains water and stainless steel. Water Res. 1998;32(7):2187-2201.

13. Percival SL. Importance of biofilm formation in surgical infection. Br J Surg. 2017;104(2):e85-e94.

14. Myszka K, Czaczyk K. Bacterial biofilms on food contact surfaces a review. Pol J Food Nutr Sci. 2011;61(3):173-180.

15. Wilkins M, Hall-Stoodley L, Allan RN, Faust SN. New approaches to the treatment of biofilm-related infections. J Infect. 2014;69 (Suppl 1): S47-S52.
16. O’Toole G, Kaplan HB, Kolter R. Biofilm formation as microbial development. Аппи Rev Microbiol. 2000;54(1):49-79.

17. Castro-Rosas J, Escartín EF. Increased tolerance of Vibrio cholerae O1 to temperature, $\mathrm{pH}$, or drying associated with colonization of shrimp carapaces. Int J Food Microbiol. 2005;102(2):195-201.

18. Simões M. Antimicrobial strategies effective against infectious bacterial biofilms. Curr Med Chem. 2011;18(14):2129-2145.

19. Blackledge MS, Worthington RJ, Melander C. Biologically inspired strategies for combating bacterial biofilms. Curr Opin Pharmacol. 2013;13(5):699-706.

20. Davies D. Understanding biofilm resistance to antibacterial agents. Nat Rev Drug Discov. 2003;2(2):114-122.

21. Dunne WM Jr. Bacterial adhesion: seen any good biofilms lately? Clin Microbiol Rev. 2002;15(2):155-166.

22. Friedlander RS, Vlamakis H, Kim P, Khan M, Kolter R, Aizenberg J. Bacterial flagella explore microscale hummocks and hollows to increase adhesion. Proc Natl Acad Sci U S A. 2013;110(14):5624-5629.

23. Hall-Stoodley L, Costerton JW, Stoodley P. Bacterial biofilms: from the natural environment to infectious diseases. Nat Rev Microbiol. 2004; 2(2):95-108.

24. Harshey RM. Bacterial motility on a surface: many ways to a common goal. Аппи Rev Microbiol. 2003;57(1):249-273.

25. Hölscher T, Bartels B, Lin YC, et al. Motility, chemotaxis and aerotaxis contribute to competitiveness during bacterial pellicle biofilm development. J Mol Biol. 2015;427(23):3695-3708.

26. Pavithra D, Doble M. Biofilm formation, bacterial adhesion and host response on polymeric implants - issues and prevention. Biomed Mater. 2008;3(3):034003

27. Burrows LL. Pseudomonas aeruginosa twitching motility: type IV pili in action. Annu Rev Microbiol. 2012;66(1):493-520.

28. Persat A, Nadell CD, Kim MK, et al. The mechanical world of bacteria. Cell. 2015;161(5):988-997.

29. Rochford ET, Richards RG, Moriarty TF. Influence of material on the development of device-associated infections. Clin Microbiol Infect. 2012;18(12):1162-1167.

30. Hodgkinson AJ, Carpenter EA, Smith CS, Molan PC, Prosser CG. Adhesion molecule expression in the bovine mammary gland. Vet Immunol Immunopathol. 2007;115(3-4):205-215.

31. Trentin DDS, Giordani RB, Macedo AJ. Biofilmes bacterianos patogênicos: aspectos gerais, importância clínica e estratégias de combate [Pathogenic bacterial biofilms: general aspects, clinical importance, and combat strategies]. Rev Lib. 2013;14(22):113-238. Portuguese [with English abstract].

32. Lynch AS, Robertson GT. Bacterial and fungal biofilm infections. Annu Rev Med. 2008;59(1):415-428.

33. Rendueles $\mathrm{O}$, Ghigo JM. Multi-species biofilms: how to avoid unfriendly neighbors. FEMS Microbiol Rev. 2012;36(5):972-989.

34. Dickschat JS. Quorum sensing and bacterial biofilms. Nat Prod Rep. 2010;27(3):343-369.

35. Wonnenberg B, Tschernig T, Voss M, et al. Probenecid reduces infection and inflammation in acute Pseudomonas aeruginosa pneumonia. Int J Med Microbiol. 2014;304(5-6):725-729.

36. Ulett GC, Totsika M, Schaale K, Carey AJ, Sweet MJ, Schembri MA. Uropathogenic Escherichia coli virulence and innate immune responses during urinary tract infection. Curr Opin Microbiol. 2013;16(1): $100-107$.

37. Ojha AK, Hatfull GF. Biofilms of Mycobacterium tuberculosis: new perspectives of an old pathogen. In: Pere-Joan Cardona, editor. Understanding Tuberculosis - Deciphering the Secret Life of the Bacilli. InTech; 2012:182-192.

38. Chen L, Wen YM. The role of bacterial biofilm in persistent infections and control strategies. Int J Oral Sci. 2011;3(2):66-73.

39. Marrie TJ, Nelligan J, Costerton JW. A scanning and transmission electron microscopic study of an infected endocardial pacemaker lead. Circulation. 1982;66(6):1339-1341.

40. Rybtke M, Hultqvist LD, Givskov M, Tolker-Nielsen T. Pseudomonas aeruginosa biofilm infections: community structure, antimicrobial tolerance and immune response. J Mol Biol. 2015;427(23):3628-3645. 
41. Hirsh DS, Bloom HL. Clinical use of antibacterial mesh envelopes in cardiovascular electronic device implantations. Med Devices (Auckl). 2015;8:71-78.

42. Baddour LM, Epstein AE, Erickson CC, et al; American Heart Association Rheumatic Fever, Endocarditis, and Kawasaki Disease Committee; Council on Cardiovascular Disease in Young; Council on Cardiovascular Surgery and Anesthesia; Council on Cardiovascular Nursing; Council on Clinical Cardiology; Interdisciplinary Council on Quality of Care; American Heart Association. Update on cardiovascular implantable electronic device infections and their management: a scientific statement from the American Heart Association. Circulation. 2010;121(3):458-477.

43. Madhavan M, Sohail MR, Friedman PA, et al; Mayo Cardiovascular Infections Study Group. Outcomes in patients with cardiovascular implantable electronic devices and bacteremia caused by Gram-positive cocci other than Staphylococcus aureus. Circ Arrhythm Electrophysiol. 2010;3(6):639-645.

44. Bruun NE, Habib G, Thuny F, Sogaard P. Cardiac imaging in infectious endocarditis. Eur Heart J. 2014;35(10):624-632.

45. Lin TI, Huang YF, Liu PY, et al. Pseudomonas aeruginosa infective endocarditis in patients who do not use intravenous drugs: analysis of risk factors and treatment outcomes. J Microbiol Immunol Infect. 2016;49(4):516-522.

46. Yoon SS, Hennigan RF, Hilliard GM, et al. Pseudomonas aeruginosa anaerobic respiration in biofilms: relationships to cystic fibrosis pathogenesis. Dev Cell. 2002;3(4):593-603.

47. Cohen TS, Prince A. Cystic fibrosis: a mucosal immunodeficiency syndrome. Nat Med. 2012;18(4):509-519.

48. Gjødsbøl K, Christensen JJ, Karlsmark T, Jørgensen B, Klein BM, Krogfelt KA. Multiple bacterial species reside in chronic wounds: a longitudinal study. Int Wound J. 2006;3(3):225-231.

49. Fazli M, Bjarnsholt T, Kirketerp-Møller K, et al. Quantitative analysis of the cellular inflammatory response against biofilm bacteria in chronic wounds. Wound Repair Regen. 2011;19(3):387-391.

50. da Silva PB, Ramos MA, Bonifácio BV, et al. Nanotechnological strategies for vaginal administration of drugs-a review. J Biomed Nanotechnol. 2014;10(9):2218-2243.

51. Gaydos CA, Barnes M, Aumakhan B, et al. Chlamydia trachomatis age-specific prevalence in women who used an internet-based selfscreening program compared to women who were screened in family planning clinics. Sex Transm Dis. 2011;38(2):74-78.

52. Wessman M, Bjarnsholt T, Eickhardt-Sørensen SR, Johansen HK, Homøe P. Mucosal biofilm detection in chronic otitis media: a study of middle ear biopsies from Greenlandic patients. Eur Arch Otorhinolaryngol. 2015;272(5):1079-1085.

53. Ng CG, Loke MF, Goh KL, Vadivelu J, Ho B. Biofilm formation enhances Helicobacter pylori survivability in vegetables. Food Microbiol. 2017; 62:68-76.

54. Sgouras DN, Trang TTH, Yamaoka Y. Pathogenesis of Helicobacter pylori infection. Helicobacter. 2015;20:8-16.

55. Monno R, Fumarola L, Capolongo C, et al. Susceptibility of Helicobacter pylori to antibiotics including tigecycline. J Med Microbiol Diagn. 2015;S5:005.

56. Yoon BI, Kim S, Han DS, et al. Acute bacterial prostatitis: how to prevent and manage chronic infection? J Infect Chemother. 2012;18(4): 444-450.

57. Wagenlehner FM, Pilatz A, Bschleipfer T, et al. Bacterial prostatitis. World J Urol. 2013;31(4):711-716.

58. Zumstein V, Betschart P, Albrich WC, et al. Biofilm formation on ureteral stents - incidence, clinical impact and prevention. Swiss Med Wkly. 2017;147:w14408.

59. Singh R, Shivaprakash MR, Chakrabarti A. Biofilm formation by zygomycetes: quantification, structure and matrix composition. Microbiology. 2011;157(Pt 9):2611-2618.

60. Rizzello L, Cingolani R, Pompa PP. Nanotechnology tools for antibacterial materials. Nanomedicine (Lond). 2013;8(5):807-821.
61. Cheng L, Zhang K, Weir MD, Melo MA, Zhou X, Xu HH. Nanotechnology strategies for antibacterial and remineralizing composites and adhesives to tackle dental caries. Nanomedicine (Lond). 2015;10(4): 627-641.

62. Habimana O, Semião AJC, Casey E. The role of cell-surface interactions in bacterial initial adhesion and consequent biofilm formation of nanofiltration/reverse osmosis membranes. J Membr Sci. 2014; 454:82-96.

63. Garrett TR, Bhakoo M, Zhang Z. Bacterial adhesion and biofilms on surfaces. Prog Nat Sci. 2008;18(9):1049-1056.

64. Antas PR, Brito MM, Peixoto É, Ponte CG, Borba CM. Neglected and emerging fungal infections: review of hyalohyphomycosis by Paecilomyces lilacinus focusing in disease burden, in vitro antifungal susceptibility and management. Microbes Infect. 2012;14(1):1-8.

65. Mayer FL, Wilson D, Hube B. Candida albicans pathogenicity mechanisms. Virulence. 2013;4(2):119-128.

66. Nett JE, Andes DR. Fungal biofilms: in vivo models for discovery of antibiofilm drugs. In: Ghannoum M, Parsek M, Whiteley M, Mukherjee P, editors. Microbial Biofilms. 2nd ed. Vol 3. Washington, DC: ASM Press; 2015:33-49.

67. Yanagisawa N, Li DQ, Ljungh A. Protein adsorption on ex vivo catheters and polymers exposed to peritoneal dialysis effluent. Perit Dial Int. 2004;24(3):264-273.

68. Herwald SE, Kumamoto CA. Candida albicans niche specialization: features that distinguish biofilm cells from commensal cells. Curr Fungal Infect Rep. 2014;8(2):179-184.

69. Douglas LJ. Candida biofilms and their role in infection. Trends Microbiol. 2003;11(1):30-36.

70. Kojic EM, Darouiche RO. Candida infections of medical devices. Clin Microbiol Rev. 2004;17(2):255-267.

71. Desai JV, Mitchell AP, Andes DR. Fungal biofilms, drug resistance, and recurrent infection. Cold Spring Harb Perspect Med. 2014;4(10): a019729.

72. Chandra J, Mukherjee PK, Ghannoum MA. Candida biofilms associated with CVC and medical devices. Mycoses. 2012;55 (Suppl 1):46-57.

73. Ramage G, Mowat E, Jones B, Williams C, Lopez-Ribot J. Our current understanding of fungal biofilms. Crit Rev Microbiol. 2009;35(4): 340-355.

74. Velegraki A, Cafarchia C, Gaitanis G, Iatta R, Boekhout T. Malassezia infections in humans and animals: pathophysiology, detection, and treatment. PLoS Pathog. 2015;11(1):e1004523.

75. Cushion MT, Collins MS, Linke MJ. Biofilm formation by Pneumocystis spp. Eukaryot Cell. 2009;8(2):197-206.

76. Carreto-Binaghi LE, Damasceno LS, Pitangui Nde S, et al. Could Histoplasma capsulatum be related to healthcare-associated infections? Biomed Res Int. 2015;2015:982429.

77. Martinez LR, Casadevall A. Biofilm formation by Cryptococcus neoformans. In: Ghannoum MA, Parsek M, Whiteley M, Mukherjee PK, editors. Microbial Biofilms. 2nd ed. Washington, DC: ASM Press; 2015:135-147.

78. Gibson JF, Johnston SA. Immunity to Cryptococcus neoformans and C. gattii during cryptococcosis. Fungal Genet Biol. 2015;78:76-86.

79. Ramage G, Rajendran R, Sherry L, Williams C. Fungal biofilm resistance. Int J Microbiol. 2012;2012:528521.

80. Miceli MH, Díaz JA, Lee SA. Emerging opportunistic yeast infections. Lancet Infect Dis. 2011;11(2):142-151.

81. Mitchell KF, Zarnowski R, Sanchez H, et al. Community participation in biofilm matrix assembly and function. Proc Natl Acad Sci US A. 2015; 112(13):4092-4097.

82. Tsang PW, Bandara HM, Fong WP. Purpurin suppresses Candida albicans biofilm formation and hyphal development. PLoS One. 2012;7(11):e50866.

83. Silva S, Negri M, Henriques M, Oliveira R, Williams DW, Azeredo J. Candida glabrata, Candida parapsilosis and Candida tropicalis: biology, epidemiology, pathogenicity and antifungal resistance. FEMS Microbiol Rev. 2012;36(2):288-305 
84. Vylkova S, Lorenz MC. Modulation of Phagosomal $\mathrm{pH}$ by Candida albicans promotes hyphal morphogenesis and requires Stp2p, a regulator of amino acid transport. PLoS Pathog. 2014;10(3):e1003995.

85. Harding MW, Marques LL, Howard RJ, Olson ME. Can filamentous fungi form biofilms? Trends Microbiol. 2009;17(11):475-480.

86. Enjalbert B, Whiteway M. Release from quorum-sensing molecules triggers hyphal formation during Candida albicans resumption of growth. Eukaryot Cell. 2005;4(7):1203-1210.

87. Hornby JM, Jensen EC, Lisec AD, et al. Quorum sensing in the dimorphic fungus Candida albicans is mediated by farnesol. Appl Environ Microbiol. 2001;67(7):2982-2992.

88. Semighini CP, Hornby JM, Dumitru R, Nickerson KW, Harris SD. Farnesol-induced apoptosis in Aspergillus nidulans reveals a possible mechanism for antagonistic interactions between fungi. Mol Microbiol. 2006;59(3):753-764.

89. Scheper MA, Shirtliff ME, Meiller TF, Peters BM, Jabra-Rizk MA. Farnesol, a fungal quorum-sensing molecule triggers apoptosis in human oral squamous carcinoma cells. Neoplasia. 2008;10(9): 954-963.

90. Dichtl K, Ebel F, Dirr F, Routier FH, Heesemann J, Wagener J. Farnesol misplaces tip-localized Rho proteins and inhibits cell wall integrity signalling in Aspergillus fumigatus. Mol Microbiol. 2010; 76(5):1191-1204

91. Sharma M, Prasad R. The quorum-sensing molecule farnesol is a modulator of drug efflux mediated by $\mathrm{ABC}$ multidrug transporters and synergizes with drugs in Candida albicans. Antimicrob Agents Chemother. 2011;55(10):4834-4843.

92. Leonhardt I, Spielberg S, Weber M, et al. The fungal quorum-sensing molecule farnesol activates innate immune cells but suppresses cellular adaptive immunity. MBio. 2015;6(2):e00143.

93. Chen H, Fujita M, Feng Q, Clardy J, Fink GR. Tyrosol is a quorumsensing molecule in Candida albicans. Proc Natl Acad Sci US A. 2004; 101(14):5048-5052.

94. Harriott MM, Lilly EA, Rodriguez TE, Fidel PL, Noverr MC. Candida albicans forms biofilms on the vaginal mucosa. Microbiology. 2010; 156(Pt 12):3635-3644

95. Nobile CJ, Johnson AD. Candida albicans biofilms and human disease. Annu Rev Microbiol. 2015;69(1):71-92.

96. Pappas PG. Invasive candidiasis. Infect Dis Clin North Am. 2006; 20(3):485-506.

97. Campion EW, Kullberg BJ, Arendrup MC. Invasive candidiasis. N Engl J Med. 2015;373(15):1445-1456.

98. Sardi Jde C, Pitangui Nde S, Rodríguez-Arellanes G, Taylor ML, Fusco-Almeida AM, Mendes-Giannini MJ. Highlights in pathogenic fungal biofilms. Rev Iberoam Micol. 2014;31(1):22-29.

99. Caggiano G, Coretti C, Bartolomeo N, Lovero G, De Giglio O, Montagna MT. Candida bloodstream infections in Italy: changing epidemiology during 16 years of surveillance. Biomed Res Int. 2015; 2015:256580.

100. Rongpharpi SR, Gur R, Duggal S, et al. Candida krusei fungemia in 7 neonates: clonality tracked to an infusate. Am J Infect Control. 2014; 42(11):1247-1248.

101. Spanakis EK, Aperis G, Mylonakis E. New agents for the treatment of fungal infections: clinical efficacy and gaps in coverage. Clin Infect Dis. 2006;43(8):1060-1068.

102. Sobel JD. Recurrent vulvovaginal candidiasis. Am J Obstet Gynecol. 2016;214(1):15-21.

103. Gemmill JA, Stratton P, Cleary SD, Ballweg ML, Sinaii N. Cancers, infections, and endocrine diseases in women with endometriosis. Fertil Steril. 2010;94(5):1627-1631.

104. Auler ME, Morreira D, Rodrigues FF, et al. Biofilm formation on intrauterine devices in patients with recurrent vulvovaginal candidiasis. Med Mycol. 2010;48(1):211-216.

105. Ader F. Invasive pulmonary aspergillosis in patients with chronic obstructive pulmonary disease: an emerging fungal disease. Curr Infect Dis Rep. 2010;12(6):409-416.
106. Dimopoulos G, Frantzeskaki F, Poulakou G, Armaganidis A. Invasive aspergillosis in the intensive care unit. Ann N Y Acad Sci. 2012; 1272(1):31-39.

107. Bakare N, Rickerts V, Bargon J, Just-Nübling G. Prevalence of Aspergillus fumigatus and other fungal species in the sputum of adult patients with cystic fibrosis. Mycoses. 2003;46(1-2):19-23.

108. Bohse ML, Woods JP. RNA interference-mediated silencing of the YPS3 gene of Histoplasma capsulatum reveals virulence defects. Infect Immun. 2007;75(6):2811-2817.

109. Suárez-Alvarez RO, Pérez-Torres A, Taylor ML. Adherence patterns of Histoplasma capsulatum yeasts to bat tissue sections. Mycopathologia. 2010;170(2):79-87.

110. Pitangui NS, Sardi JC, Silva JF, et al. Adhesion of Histoplasma capsulatum to pneumocytes and biofilm formation on an abiotic surface. Biofouling. 2012;28(7):711-718.

111. Martin-Garrido I, Carmona EM, Specks U, Limper AH. Pneumocystis pneumonia in patients treated with rituximab. Chest. 2013;144(1): 258-265.

112. Huang L, Cattamanchi A, Davis JL, et al; International HIV-associated Opportunistic Pneumonias (IHOP) Study; Lung HIV Study. HIVassociated Pneumocystis pneumonia. Proc Am Thorac Soc. 2011;8(3): 294-300

113. Chayakulkeeree M, Perfect JR. Cryptococcosis. Infect Dis Clin North Am. 2006;20(3):507-544, v-vi.

114. Hernández YU, Monzón JF, Delgado-Hernández R, SotoHernández JL, Cárdenas G. Cryptococcoma of the brain in an immunocompetent man. Natl Med J India. 2013;26(4):216-217.

115. Liao Y, Lu X, Yang S, Luo Y, Chen Q, Yang R. Epidemiology and outcome of Trichosporon fungemia: a review of 185 reported cases from 1975 to 2014. Open Forum Infect Dis. 2015;2(4):Epub Sep 25.

116. Iturrieta-González IA, Padovan AC, Bizerra FC, Hahn RC, Colombo AL Multiple species of Trichosporon produce biofilms highly resistant to triazoles and amphotericin B. PLoS One. 2014;9(10):e109553.

117. de Pavia Fagundes Júnior AA, de Carvalho RT, Focaccia R, et al. Emergência de infecção por Trichosporon Asahii em pacientes portadores de insuficiência cardíaca em unidade de terapia intensiva cardiológica: relato de caso e revisão da literatura [Trichosporon asahii an emerging etiologic agent of fungal infection and colonization in heart failure patients in intensive care unit: case report and literature review]. Rev Bras Ter Intensiva. 2008;20(1):106-109. Portuguese [with English abstract].

118. Mattede MGS, Piras C, Mattede KDS, Ferrari AT, Baldotto LS, Assbu MSZ. Urinary tract infections due to Trichosporon spp. in severely ill patients in an intensive care unit. Rev Bras Ter Intensiva. 2015;27(3):247-251.

119. Römling U, Balsalobre C. Biofilm infections, their resilience to therapy and innovative treatment strategies. J Intern Med. 2012;272(6):541-561.

120. Römling U, Kjelleberg S, Normark S, Nyman L, Uhlin BE, Åkerlund B. Microbial biofilm formation: a need to act. J Intern Med. 2014; 276(2):98-110.

121. Dicicco M, Neethirajan S, Singh A, Weese JS. Efficacy of clarithromycin on biofilm formation of methicillin-resistant Staphylococcus pseudintermedius. BMC Vet Res. 2012;8:225.

122. De Oliveira MMM, Brugnera DF, Picolli RH. Biofilmes microbianos na indústria de alimentos: uma revisão [Microbial biofilms in the food industry: a review]. Rev Inst Adolfo Lutz. 2010;69(3):277-284. Portuguese [with English abstract].

123. Gilbert P, Allison DG, McBain AJ. Biofilms in vitro and in vivo: do singular mechanisms imply cross-resistance? J Appl Microbiol. 2002;92 Suppl:98S-110S.

124. Romaní AM, Fund K, Artigas J, Schwartz T, Sabater S, Obst U Relevance of polymeric matrix enzymes during biofilm formation. Microb Ecol. 2008;56(3):427-436.

125. Yang YL, Chen M, Gu JL, et al. Cryptococcosis in kidney transplant recipients in a Chinese university hospital and a review of published cases. Int J Infect Dis. 2014;26:154-161 
126. Høiby N, Ciofu O, Johansen HK, et al. The clinical impact of bacterial biofilms. Int J Oral Sci. 2011;3(2):55-65.

127. Smith AW. Biofilms and antibiotic therapy: is there a role for combating bacterial resistance by the use of novel drug delivery systems? Adv Drug Deliv Rev. 2005;57(10):1539-1550.

128. Soto SM. Role of efflux pumps in the antibiotic resistance of bacteria embedded in a biofilm. Virulence. 2013;4(3):223-229.

129. Mah TF. Biofilm-specific antibiotic resistance. Future Microbiol. 2012;7(9):1061-1072.

130. Podnecky NL, Rhodes KA, Schweizer HP. Efflux pump-mediated drug resistance in Burkholderia. Front Microbiol. 2015;6:305.

131. Schlisselberg DB, Kler E, Kisluk G, Shachar D, Yaron S. Biofilm formation ability of Salmonella enterica serovar Typhimurium acrAB mutants. Int J Antimicrob Agents. 2015;46(4):456-459.

132. Gillis RJ, White KG, Choi K-H, Wagner VE, Schweizer HP, Iglewski BH. Molecular basis of azithromycin-resistant Pseudomonas aeruginosa biofilms. Antimicrob Agents Chemother. 2005;49(9): 3858-3867.

133. Van Acker H, Van Dijck P, Coenye T. Molecular mechanisms of antimicrobial tolerance and resistance in bacterial and fungal biofilms. Trends Microbiol. 2014;22(6):326-333.

134. Prasad R, Goffeau A. Yeast ATP-binding cassette transporters conferring multidrug resistance. Annu Rev Microbiol. 2012;66(1):39-63.

135. Mateus C, Crow SA Jr, Ahearn DG. Adherence of Candida albicans to silicone induces immediate enhanced tolerance to fluconazole. Antimicrob Agents Chemother. 2004;48(9):3358-3366.

136. Tan A, Chawla R, G N, et al. Nanotechnology and regenerative therapeutics in plastic surgery: the next frontier. J Plast Reconstr Aesthet Surg. 2016;69(1):1-13.

137. Lin TC, Hung KH, Peng CH, et al. Nanotechnology-based drug delivery treatments and specific targeting therapy for age-related macular degeneration. J Chin Med Assoc. 2015;78(11):635-641.

138. Barkalina N, Charalambous C, Jones C, Coward K. Nanotechnology in reproductive medicine: emerging applications of nanomaterials. Nanomedicine. 2014;10(5):921-938.

139. Bharali DJ, Siddiqui IA, Adhami VM, et al. Nanoparticle delivery of natural products in the prevention and treatment of cancers: current status and future prospects. Cancers (Basel). 2011;3(4): 4024-4045.

140. Pelgrift RY, Friedman AJ. Nanotechnology as a therapeutic tool to combat microbial resistance. Adv Drug Deliv Rev. 2013;65(13-14): 1803-1815.

141. Martin C, Low WL, Gupta A, et al. Strategies for antimicrobial drug delivery to biofilm. Curr Pharm Des. 2015;21(1):43-66.

142. Forier K, Raemdonck K, De Smedt SC, Demeester J, Coenye T, Braeckmans K. Lipid and polymer nanoparticles for drug delivery to bacterial biofilms. J Control Release. 2014;190:607-623.

143. Singh R, Nadhe S, Wadhwani S, Shedbalkar U, Chopade BA. Nanoparticles for control of biofilms of Acinetobacter species. Materials (Basel). 2016;9(5):E383.

144. Al-Jamal WT, Kostarelos K. Liposomes: from a clinically established drug delivery system to a nanoparticle platform for theranostic nanomedicine. Acc Chem Res. 2011;44(10):1094-1104.

145. Akbarzadeh A, Rezaei-Sadabady R, Davaran S, et al. Liposome: classification, preparation, and applications. Nanoscale Res Lett. 2013; $8(1): 102$.

146. Ahmed K, Muiruri PW, Jones GH, Scott MJ, Jones MN. The effect of grafted poly(ethylene glycol) on the electrophoretic properties of phospholipid liposomes and their adsorption to bacterial biofilms. Colloids Surf A Physicochem Eng Asp. 2001;194(1-3):287-296.

147. Robinson AM, Bannister M, Creeth JE, Jones MN. The interaction of phospholipid liposomes with mixed bacterial biofilms and their use in the delivery of bactericide. Colloids Surf A Physicochem Eng Asp. 2001;186(1-2):43-53.

148. Catuogno C, Jones MN. The antibacterial properties of solid supported liposomes on Streptococcus oralis biofilms. Int J Pharm. 2003; 257(1-2):125-140.
149. Drulis-Kawa Z, Dorotkiewicz-Jach A, Gubernator J, Gula G, Bocer T, Doroszkiewicz W. The interaction between Pseudomonas aeruginosa cells and cationic PC:Chol:DOTAP liposomal vesicles versus outermembrane structure and envelope properties of bacterial cell. Int J Pharm. 2009;367(1-2):211-219.

150. Gubernator J, Drulis-Kawa Z, Dorotkiewicz-Jach A, Doroskiewiecz W, Kozubek A. In vitro antimicrobial activity of liposomes containing ciprofloxacin, meropenem and gentamicin against gram-negative clinical bacterial strains. Lett Drug Des Discov. 2007;4(4):297-304.

151. Omri A, Suntres ZE, Shek PN. Enhanced activity of liposomal polymyxin B against Pseudomonas aeruginosa in a rat model of lung infection. Biochem Pharmacol. 2002;64(9):1407-1413.

152. Rukholm G, Mugabe C, Azghani AO, Omri A. Antibacterial activity of liposomal gentamicin against Pseudomonas aeruginosa: a time-kill study. Int J Antimicrob Agents. 2006;27(3):247-252.

153. Mugabe C, Azghani AO, Omri A. Liposome-mediated gentamicin delivery: development and activity against resistant strains of Pseudomonas aeruginosa isolated from cystic fibrosis patients. J Antimicrob Chemother. 2005;55(2):269-271.

154. Alipour M, Suntres ZE, Omri A. Importance of DNase and alginate lyase for enhancing free and liposome encapsulated aminoglycoside activity against Pseudomonas aeruginosa. J Antimicrob Chemother. 2009;64(2):317-325.

155. Alhajlan M, Alhariri M, Omri A. Efficacy and safety of liposomal clarithromycin and its effect on Pseudomonas aeruginosa virulence factors. Antimicrob Agents Chemother. 2013;57(6):2694-2704.

156. Alipour M, Halwani M, Omri A, Suntres ZE. Antimicrobial effectiveness of liposomal polymyxin B against resistant Gram-negative bacterial strains. Int J Pharm. 2008;355(1-2):293-298.

157. Alipour M, Suntres ZE, Lafrenie RM, Omri A. Attenuation of Pseudomonas aeruginosa virulence factors and biofilms by coencapsulation of bismuth-ethanedithiol with tobramycin in liposomes. J Antimicrob Chemother. 2010;65(4):684-693.

158. Bonifácio BV, Silva PB, Ramos MA, Negri KM, Bauab TM, Chorilli M. Nanotechnology-based drug delivery systems and herbal medicines: a review. Int J Nanomedicine. 2013;9(1):1-15.

159. Ryan R, Altria K, McEvoy E, Donegan S, Power J. A review of developments in the methodology and application of microemulsion electrokinetic chromatography. Electrophoresis. 2013;34(1):159-177.

160. Lawrence MJ, Rees GD. Microemulsion-based media as novel drug delivery systems. Adv Drug Deliv Rev. 2000;45(1):89-121.

161. Muzaffar F, Singh UK, Chauhan L. Review on microemulsion as futuristic drug delivery. Int J Pharm Pharm Sci. 2013;5(3):39-53.

162. Al-Adham IS, Ashour H, Al-Kaissi E, Khalil E, Kierans M, Collier PJ. Studies on the kinetics of killing and the proposed mechanism of action of microemulsions against fungi. Int J Pharm. 2013;454(1): 226-232.

163. Singh PK, Kashif Iqubal M, Shukla VK, Shuaib M. Microemulsions: current trends in novel drug delivery systems. J Pharm Chem Biol Sci. 2014;1(1):39-51.

164. Mishra A, Panola R, Rana AC. Microemulsions: as drug delivery system. J Sci Innov Res. 2014;3(4):467-474.

165. Hung CF, Fang CL, Liao MH, Fang JY. The effect of oil components on the physicochemical properties and drug delivery of emulsions: tocol emulsion versus lipid emulsion. Int J Pharm. 2007;335(1-2): 193-202.

166. Anton N, Vandamme TF. Nano-emulsions and micro-emulsions: clarifications of the critical differences. Pharm Res. 2011;28(5):978-985.

167. Bruxel F, Laux M, Wild LB, Fraga M, Koester LS, Texeira HF. Nanoemulsão como sistemas de liberação parenteral de fármacos [Nanoemulsions as parenteral drug delivery systems]. Quim Nova. 2012;35(9):1827-1840. Portuguese [with English asbtract].

168. Ramalingam K, Amaechi BT, Ralph RH, Lee VA. Antimicrobial activity of nanoemulsion on cariogenic planktonic and biofilm organisms. Arch Oral Biol. 2012;57(1):15-22.

169. Ramalingam K, Frohlich NC, Lee VA. Effect of nanoemulsion on dental unit waterline biofilm. J Dent Sci. 2013;8(3):333-336. 
170. Teixeira PC, Leite GM, Domingues RJ, Silva J, Gibbs PA, Ferreira JP. Antimicrobial effects of a microemulsion and a nanoemulsion on enteric and other pathogens and biofilms. Int J Food Microbiol. 2007; 118(1):15-19.

171. Liu CH, Huang HY. Antimicrobial activity of curcumin-loaded myristic acid microemulsions against Staphylococcus epidermidis. Chem Pharm Bull (Tokyo). 2012;60(9):1118-1124.

172. Al-Adham IS, Al-Hmoud ND, Khalil E, Kierans M, Collier PJ. Microemulsions are highly effective anti-biofilm agents. Lett Appl Microbiol. 2003;36(2):97-100.

173. Villiers A. Sur la fermentation de la fécule par l'action du ferment butyrique [The fermentation of starch by the action of butyric]. Compt Rend Acad Sci. 1891;112:536-538. French [with English abstract].

174. Zhang J, Ma PX. Cyclodextrin-based supramolecular systems for drug delivery: recent progress and future perspective. Adv Drug Deliv Rev. 2013;65(9):1215-1233.

175. Morin-Crini N, Crini G. Environmental applications of water-insoluble $\beta$-cyclodextrin-epichlorohydrin polymers. Prog Polym Sci. 2013; 38(2):344-368.

176. Martins MRFM, Veiga F. Promotores de permeação para a liberação transdérmica de fármacos: uma nova aplicação para as ciclodextrinas [Permeation promoters for transdermal drug delivery: a new application for cyclodextrins]. Rev Bras Ciênc Farm. 2002;38(1):33-54. Portuguese [with English abstract].

177. Gharbi A, Humblot V, Turpin F, Pradier CM, Imbert C, Berjeaud JM Elaboration of antibiofilm surfaces functionalized with antifungalcyclodextrin inclusion complexes. FEMS Immunol Med Microbiol. 2012;65(2):257-269.

178. Szente L, Szemán J, Sohajda T. Analytical characterization of cyclodextrins: history, official methods and recommended new techniques. J Pharm Biomed Anal. 2016;130:347-365.

179. Acuña-Rougier C, Olea-Azar C. Thermodynamic and geometric study of diasteroisomeric complexes formed by racemic flavanones and three cyclodextrins through NMR. J Incl Phenom Macrocycl Chem. 2013;75(1-2):119-136.

180. Folch-Cano C, Yazdani-Pedram M, Olea-Azar C. Inclusion and functionalization of polymers with cyclodextrins: current applications and future prospects. Molecules. 2014;19(9):14066-14079.

181. Otero-Espinar FJ, Torres-Labandeira JJ, Alvarez-Lorenzo C, Blanco-Méndez J. Cyclodextrins in drug delivery systems. J Drug Deliv Sci Technol. 2010;20(4):289-301.

182. Lakkakula JR, Maçedo Krause RW. A vision for cyclodextrin nanoparticles in drug delivery systems and pharmaceutical applications. Nanomedicine (Lond). 2014;9(6):877-894.

183. Loftsson T, Duchene D. Cyclodextrins and their pharmaceutical applications. Int J Pharm. 2007;329(1-2):1-11.

184. Matsuda H, Arima H. Cyclodextrins in transdermal and rectal delivery. Adv Drug Deliv Rev. 1999;36(1):81-99.

185. Pinho E, Grootveld M, Soares G, Henriques M. Cyclodextrins as encapsulation agents for plant bioactive compounds. Carbohydr Polym. 2014;101:121-135.

186. Lula I, Denadai ÂL, Resende JM, et al. Study of angiotensin-(1-7) vasoactive peptide and its $\beta$-cyclodextrin inclusion complexes: complete sequence-specific NMR assignments and structural studies. Peptides. 2007;28(11):2199-2210.

187. Cortés ME, Bonilla JC, Sinisterra RD. Biofilm formation, control and novel strategies for eradication. In: Mendez-Vilas A, editor. Science Against Microbial Pathogens: Communicating Current Research and Technological Advances. Badajoz: Formatex Research Center; 2011:896-905.

188. Healing G, Sulemann T, Cotton P, et al. Safety data on 19 vehicles for use in 1 month oral rodent pre-clinical studies: administration of hydroxypropyl- $\beta$-cyclodextrin causes renal toxicity. $J$ Appl Toxicol. 2016;36(1):140-150.

189. Suvarna V, Gujar P, Murahari M. Complexation of phytochemicals with cyclodextrin derivatives - an insight. Biomed Pharmacother. 2017;88:1122-1144.
190. Gharib R, Greige-Gerges H, Fourmentin S, Charcosset C, Auezova L. Liposomes incorporating cyclodextrin-drug inclusion complexes: current state of knowledge. Carbohydr Polym. 2015;129:175-186.

191. Holm R, Olesen NE, Hartvig RA, Jørgensen EB, Larsen DB, Westh P. Effect of cyclodextrin concentration on the oral bioavailability of danazol and cinnarizine in rats. Eur J Pharm Biopharm. 2016;101:9-14.

192. Trotta F, Dianzani C, Caldera F, Mognetti B, Cavalli R. The application of nanosponges to cancer drug delivery. Expert Opin Drug Deliv. 2014;11(6):931-941.

193. Freires IDA, Murata RM, Furletti VF, et al. Coriandrum sativum L. (Coriander) essential oil: antifungal activity and mode of action on Candida spp., and molecular targets affected in human whole-genome expression. PLoS One. 2014;9(6):e99086.

194. Husain FM, Ahmad I, Khan MS, et al. Sub-MICs of Mentha piperita essential oil and menthol inhibits AHL mediated quorum sensing and biofilm of Gram-negative bacteria. Front Microbiol. 2015;6:420.

195. Azzimonti B, Cochis A, Beyrouthy ME, et al. Essential oil from berries of lebanese Juniperus excelsa M. Bieb displays similar antibacterial activity to chlorhexidine but higher cytocompatibility with human oral primary cells. Molecules. 2015;20(5):9344-9357.

196. dos Santos JF, Torres-Labandeira JJ, Matthijs N, Coenye T, Concheiro A, Alvarez-Lorenzo C. Functionalization of acrylic hydrogels with $\alpha$-, $\beta$ - or $\gamma$-cyclodextrin modulates protein adsorption and antifungal delivery. Acta Biomater. 2010;6(10):3919-3926.

197. Garcia-Fernandez MJ, Brackman G, Coenye T, Concheiro A, AlvarezLorenzo C. Antiseptic cyclodextrin-functionalized hydrogels and gauzes for loading and delivery of benzalkonium chloride. Biofouling. 2013;29(3):261-271.

198. Iordache F, Grumezescu V, Grumezescu AM, et al. Gammacyclodextrin/usnic acid thin film fabricated by MAPLE for improving the resistance of medical surfaces to Staphylococcus aureus colonization. Appl Surf Sci. 2015;336:407-412.

199. Brackman G, Garcia-Fernandez MJ, Lenoir J, et al. Dressings loaded with cyclodextrin-hamamelitannin complexes increase Staphylococcus aureus susceptibility toward antibiotics both in single as well as in mixed biofilm communities. Macromol Biosci. 2016;16(6):859-869.

200. Fidaleo M, Zuorro A, Lavecchia R. Enhanced antibacterial and antiquorum sensing activities of triclosan by complexation with modified $\beta$-cyclodextrins. World J Microbiol Biotechnol. 2013;29(9):1731-1736.

201. Alayande AB, Kim LH, Kim IS. Cleaning efficacy of hydroxypropylbeta-cyclodextrin for biofouling reduction on reverse osmosis membranes. Biofouling. 2016;32(4):359-370.

202. Shanmuga Priya A, Sivakamavalli J, Vaseeharan B, Stalin T. Improvement on dissolution rate of inclusion complex of Rifabutin drug with $\beta$-cyclodextrin. Int J Biol Macromol. 2013;62:472-480.

203. Loftsson T, Brewster ME. Cyclodextrins as functional excipients: methods to enhance complexation efficiency. J Pharm Sci. 2012;101(9): 3019-3032.

204. Jaiswal S, Bhattacharya K, McHale P, Duffy B. Dual effects of $\beta$-cyclodextrin-stabilised silver nanoparticles: enhanced biofilm inhibition and reduced cytotoxicity. J Mater Sci Mater Med. 2015; 26(1):5367.

205. Oprea AE, Pandel LM, Dumitrescu AM, et al. Bioactive $\mathrm{ZnO}$ coatings deposited by MAPLE-an appropriate strategy to produce efficient anti-biofilm surfaces. Molecules. 2016;21(2):220.

206. Nava-Ortiz CAB, Burillo G, Concheiro A, et al. Cyclodextrinfunctionalized biomaterials loaded with miconazole prevent Candida albicans biofilm formation in vitro. Acta Biomater. 2010;6(4): 1398-1404.

207. Ruiz HK, Serrano DR, Dea-Ayuela MA, et al. New amphotericin B-gamma cyclodextrin formulation for topical use with synergistic activity against diverse fungal species and Leishmania spp. Int J Pharm. 2014;473(1-2):148-157.

208. Ekambaram P, Sathali AAH, Priyanka K. Solid lipid nanoparticles: a review. Sci Rev Chem Commun. 2012;2(1):80-102.

209. Singh B, Bandyopadhyay S, Kapil R, Katare OP. Novel nanostructured lipidic drug delivery systems. Pharma Rev. 2009;7(42):118-122. 
210. Singh B, Vuddanda PR, M R V, Kumar V, Saxena PS, Singh S. Cefuroxime axetil loaded solid lipid nanoparticles for enhanced activity against S. aureus biofilm. Colloids Surf B Biointerfaces. 2014;121:92-98.

211. Nafee N, Husari A, Maurer CK, et al. Antibiotic-free nanotherapeutics: ultra-small, mucus-penetrating solid lipid nanoparticles enhance the pulmonary delivery and anti-virulence efficacy of novel quorum sensing inhibitors. J Control Release. 2014;192:131-140.

212. Taylor EN, Kummer KM, Dyondi D, Webster TJ, Banerjee R. Multiscale strategy to eradicate Pseudomonas aeruginosa on surfaces using solid lipid nanoparticles loaded with free fatty acids. Nanoscale. 2014;6(2):825-832.

213. Quintanar-Guerrero D, Allémann E, Doelker E, Fessi H. Preparation and characterization of nanocapsules from preformed polymers by a new process based on emulsification-diffusion technique. Pharm Res. 1998;15(7):1056-1062.

214. Schaffazick SR, Guterres SS. Caracterização e estabilidade físicoquímica de sistemas poliméricos nanoparticulados para administração de fármacos [Characterization and physico-chemical stability of nanoparticulate polymer systems for administration of drugs]. Quim Nova. 2006;26(5):726-737. Portuguese [with English abstract].

215. Plapied L, Duhem N, des Rieux A, Préat V. Fate of polymeric nanocarriers for oral drug delivery. Curr Opin Colloid Interface Sci. 2011;16(3):228-237.

216. Reis CP, Neufeld RJ, Ribeiro AJ, Veiga F. Nanoencapsulation I. Methods for preparation of drug-loaded polymeric nanoparticles. Nanomedicine. 2006;2(1):8-21.

217. Shaffer C. Nanomedicine transforms drug delivery. Drug Discov Today. 2005;10(23-24):1581-1582.

218. Da Silva L, Finer Y, Friedman S, Basrani B, Kishen A. Biofilm formation within the interface of bovine root dentin treated with conjugated chitosan and sealer containing chitosan nanoparticles. J Endod. 2013;39(2):249-253.

219. Abdelghany SM, Quinn DJ, Ingram RJ, et al. Gentamicin-loaded nanoparticles show improved antimicrobial effects towards Pseudomonas aeruginosa infection. Int J Nanomedicine. 2012;7:4053-4063.

220. Cai J, Huang H, Song W, et al. Preparation and evaluation of lipid polymer nanoparticles for eradicating $\mathrm{H}$. pylori biofilm and impairing antibacterial resistance in vitro. Int J Pharm. 2015;495(2):728-737.

221. Takahashi C, Ogawa N, Kawashima Y, Yamamoto H. Observation of antibacterial effect of biodegradable polymeric nanoparticles on Staphylococcus epidermidis biofilm using FE-SEM with an ionic liquid. Microscopy (Oxf). 2015;64(3):169-180.

222. Faraday M. The Bakerian lecture: experimental relations of gold (and other metals) to light. Philos Trans R Soc Lond. 1857;147:145-181.

223. Horvath H. Gustav Mie and the scattering and absorption of light by particles: historic developments and basics. J Quant Spectrosc Radiat Transf. 2009;110(11):787-799.

224. Melo MA Jr, Santos LSS, Gonçalves M do C, Nogueira AF. Preparação de nanopartículas de prata e ouro: um método simples para a introdução da nanociência em laboratório de ensino [Preparation of silver and gold nanoparticles: a simple method to introduce nanotechnology into teaching laboratories]. Quím Nova. 2012;35(9):1872-1878. Portuguese [with English abstract].

225. Klabunde KJ. Frontmatter and index. Nanoscale Materials in Chemistry. New York: John Wiley \& Sons, Inc.; 2001:i-xi.

226. Kumar M, Varshney L, Francis S. Radiolytic formation of Ag clusters in aqueous polyvinyl alcohol solution and hydrogel matrix. Radiat Phys Chem. 2005;73(1):21-27.

227. Xu XL, Yin YD, Ge XW, Wu HK, Zhang ZH. $\gamma$-Radiation synthesis of poly(acrylic acid)-metal nanocomposites. Mater Lett. 1998;37: 354-358.

228. Khan ST, Ahamed M, Al-Khedhairy A, Musarrat J. Biocidal effect of copper and zinc oxide nanoparticles on human oral microbiome and biofilm formation. Mater Lett. 2013;97:67-70.

229. Khan ST, Ahamed M, Musarrat J, Al-Khedhairy AA. Anti-biofilm and antibacterial activities of zinc oxide nanoparticles against the oral opportunistic pathogens Rothia dentocariosa and Rothia mucilaginosa. Eur J Oral Sci. 2014;122(6):397-403.
230. Sangani MH, Moghaddam MN, Forghanifard MM. Inhibitory effect of zinc oxide nanoparticles on pseudomonas aeruginosa biofilm formation. Nanomedicine J. 2015;2(2):121-128.

231. Dwivedi S, WahabR, Khan F, Mishra YK, Musarrat J, Al-Khedhairy AA. Reactive oxygen species mediated bacterial biofilm inhibition via zinc oxide nanoparticles and their statistical determination. PLoS One. 2014;9(11):e111289.

232. Seil JT, Webster TJ. Reduced Staphylococcus aureus proliferation and biofilm formation on zinc oxide nanoparticle PVC composite surfaces. Acta Biomater. 2011;7(6):2579-2584.

233. Lee JH, Kim YG, Cho MH, Lee J. ZnO nanoparticles inhibit Pseudomonas aeruginosa biofilm formation and virulence factor production. Microbiol Res. 2014;169(12):888-896.

234. Pratt LA, Kolter R. Genetic analysis of Escherichia coli biofilm formation: roles of flagella, motility, chemotaxis and type I pili. Mol Microbiol. 1998;30(2):285-293.

235. Haghighi F, Mohammadi SR, Mohammadi P, Hosseinkhani S. Antifungal activity of $\mathrm{TiO}_{2}$ nanoparticles and EDTA on Candida albicans Biofilms. Infect Epidemiol Med. 2013;1(1):33-38.

236. Ibrahem KH, Salman JAS, Ali FA. Effect of titanium nanoparticles biosynthesis by Lactobacillus crispatus on urease, hemolysin \& biofilm forming by some bacteria causing recurrent UTI in Iraqi women. Eur Sci J. 2014;10(9):324-338.

237. Maurer-Jones MA, Gunsolus IL, Meyer BM, Christenson CJ, Haynes CL. Impact of $\mathrm{TiO}_{2}$ nanoparticles on growth, biofilm formation, and flavin secretion in Shewanella oneidensis. Anal Chem. 2013;85(12): $5810-5818$.

238. Namasivayam SKR, Christo BB, Arasu SMK, Kumar KAM, Deepak K. Anti biofilm effect of biogenic silver nanoparticles coated medical devices against biofilm of clinical isolate of Staphylococcus aureus. Glob J Med Res. 2013;13(3):Epub June 24.

239. Park H, Park S, Roh J, et al. Biofilm-inactivating activity of silver nanoparticles: a comparison with silver ions. J Ind Eng Chem. 2013; 19(2):614-619.

240. Martinez-Gutierrez F, Boegli L, Agostinho A, et al. Anti-biofilm activity of silver nanoparticles against different microorganisms. Biofouling. 2013;29(6):651-660.

241. Gurunathan S, Han JW, Kwon DN, Kim JH. Enhanced antibacterial and anti-biofilm activities of silver nanoparticles against Gramnegative and Gram-positive bacteria. Nanoscale Res Lett. 2014; 9(1):373.

242. Kalishwaralal K, BarathManiKanth S, Pandian SR, Deepak V, Gurunathan S. Silver nanoparticles impede the biofilm formation by Pseudomonas aeruginosa and Staphylococcus epidermidis. Colloids Surf B Biointerfaces. 2010;79(2):340-344.

243. Monteiro DR, Takamiya AS, Feresin LP, et al. Susceptibility of Candida albicans and Candida glabrata biofilms to silver nanoparticles in intermediate and mature development phases. $J$ Prosthodont Res. 2015;59(1):42-48.

244. Qin H, Cao H, Zhao Y, et al. In vitro and in vivo anti-biofilm effects of silver nanoparticles immobilized on titanium. Biomaterials. 2014; 35(33):9114-9125.

245. Khan S, Alam F, Azam A, Khan AU. Gold nanoparticles enhance methylene blue-induced photodynamic therapy: a novel therapeutic approach to inhibit Candida albicans biofilm. Int J Nanomedicine. 2012;7:3245-3257.

246. Duong HTT, Adnan NNM, Barraud N, et al. Functional gold nanoparticles for the storage and controlled release of nitric oxide: applications in biofilm dispersal and intracellular delivery. J Mater Chem B. 2014;2(31):5003-5011.

247. Boda SK, Broda J, Schiefer F, et al. Cytotoxicity of ultrasmall gold nanoparticles on planktonic and biofilm encapsulated gram-positive staphylococci. Small. 2015;11(26):3183-3193.

248. Sathyanarayanan MB, Balachandranath R, Genji Srinivasulu Y, Kannaiyan SK, Subbiahdoss G. The effect of gold and iron-oxide nanoparticles on biofilm-forming pathogens. ISRN Microbiol. 2013; 2013:272086. 
International Journal of Nanomedicine

Dovepress

\section{Publish your work in this journal}

The International Journal of Nanomedicine is an international, peerreviewed journal focusing on the application of nanotechnology in diagnostics, therapeutics, and drug delivery systems throughou the biomedical field. This journal is indexed on PubMed Central, MedLine, CAS, SciSearch ${ }^{\circledR}$, Current Contents ${ }^{\circledR} /$ Clinical Medicine,
Journal Citation Reports/Science Edition, EMBase, Scopus and the Elsevier Bibliographic databases. The manuscript management system is completely online and includes a very quick and fair peer-review system, which is all easy to use. Visit http://www.dovepress.com/ testimonials.php to read real quotes from published authors.

Submit your manuscript here: http://www.dovepress.com/international-journal-of-nanomedicine-journal 